University of Louisville

ThinkIR: The University of Louisville's Institutional Repository

Electronic Theses and Dissertations

$5-2021$

\title{
Ecological, evolutionary, and molecular mechanisms driving pyocin diversity in pseudomonas aeruginosa.
}

Aubrey A. Mojesky

University of Louisville

Follow this and additional works at: https://ir.library.louisville.edu/etd

Part of the Microbiology Commons

\section{Recommended Citation}

Mojesky, Aubrey A., "Ecological, evolutionary, and molecular mechanisms driving pyocin diversity in pseudomonas aeruginosa." (2021). Electronic Theses and Dissertations. Paper 3598.

https://doi.org/10.18297/etd/3598

This Doctoral Dissertation is brought to you for free and open access by ThinkIR: The University of Louisville's Institutional Repository. It has been accepted for inclusion in Electronic Theses and Dissertations by an authorized administrator of ThinkIR: The University of Louisville's Institutional Repository. This title appears here courtesy of the author, who has retained all other copyrights. For more information, please contact thinkir@louisville.edu. 
ECOLOGICAL, EVOLUTIONARY, AND MOLECULAR MECHANISMS DRIVING PYOCIN DIVERSITY IN PSEUDOMONAS AERUGINOSA

By

Aubrey A. Mojesky

Centre College, 2014

\author{
A Dissertation \\ Submitted to the Faculty of the \\ College of Arts and Sciences of the University of Louisville \\ In Partial Fulfillment of the Requirements \\ For the Degree of \\ Doctor of Philosophy \\ In Biology \\ Department of Biology \\ University of Louisville \\ Louisville, Kentucky
}

May 2021 

ECOLOGICAL, EVOLUTIONARY, AND MOLECULAR MECHANISMS DRIVING PYOCIN DIVERSITY IN PSEUDOMONAS AERUGINOSA By

Aubrey A. Mojesky

Centre College, 2014

A Dissertation Approved on

April 12, 2021

By the following Dissertation Committee:

$\overline{\text { Dr. Deborah Yoder-Himes }}$

Dr. Sarah Emery

Dr. Linda Fuselier

Dr. Farrah Bashey-Visser 


\section{ACKNOWLEDGEMENTS}

I would like to thank Dr. Deborah Yoder-Himes as well as Dr. Susanna Remold for their guidance over the past five years. I would also like to thank my committee members Dr. Sarah Emery, Dr. Linda Fuselier, and Dr. Farrah Bashey-Visser for their support, assistance, and helpful input throughout this process.

I would like to thank Dr. Rachel Whitaker and her group at the University of Illinois Urbana-Champaign for providing whole genome sequence data for the isolates in our collection. I would also like to thank TJ Brandt and Rhiannon Cecil for welcoming me into their lab group. Lastly, I would like to express my gratitude to my family for their unconditional support and encouragement over the past five years. 


\section{ABSTRACT \\ ECOLOGICAL, EVOLUTIONARY, AND MOLECULAR MECHANISMS DRIVING PYOCIN DIVERSITY IN PSEUDOMONAS AERUGINOSA}

Aubrey A. Mojesky

April 12, 2021

Bacteriocins are narrow-spectrum antibiotics produced in nearly all lineages of bacteria, meaning that these antimicrobials target closely related individuals. The bacteriocins of Pseudomonas aeruginosa, called pyocins, are highly prevalent and diverse in populations of this species. Laboratory studies have shown that pyocins can function to mediate the outcome of interactions, often allowing for the coexistence of multiple strains, as no one pyocin genotype is competitively superior. Although this has been demonstrated under laboratory conditions, the function of pyocins in natural settings and the ecological, evolutionary, and genetic mechanisms underlying pyocin diversity remains unclear. As such, for my dissertation, I conducted research that investigated the driving forces underlying diversity in pyocin phenotype and genotype in free-living isolates of $P$. aeruginosa.

In Chapter II, I collected $P$. aeruginosa isolates from spatially structured household bathroom and kitchen sink drains to examine relationships among pyocin phenotype with spatial structure, environment of isolation, resource competition, and phylogenetic distance. I found isolates from different houses 
and different drain types to vary in pyocin-mediated inhibition, suggesting that dispersal limitations and environmental conditions help shape pyocin diversity. I also found that pyocin-mediated inhibition was most likely to occur between isolates that were intermediately phylogenetically related, but inhibition was not driven by resource competition.

In Chapter III, I searched genome sequences of the isolates in my collection for pyocin genes to investigate the relationships between pyocin genotype and spatial structure, environment of isolation, and pyocin phenotype. I found isolates collected from bathroom sink drains to encode more pyocin genes than those collected from kitchen sink isolates, and isolates from different houses varied primarily with respect to pyocin immunity genes. These findings indicate that environment of isolation and, to a lesser extent, spatial structure contribute to differences in pyocin gene content. I found that while immunity genes and particular killing genes partially contribute to the outcome of inhibitory interactions, pyocin-mediated inhibition is a complex process likely driven by differing levels of expression, alternative mechanisms of resistance, and receptor specificity. 


\section{TABLE OF CONTENTS}

PAGE

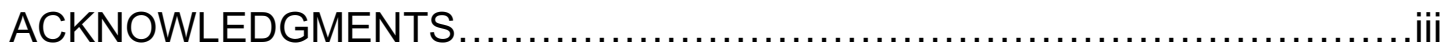

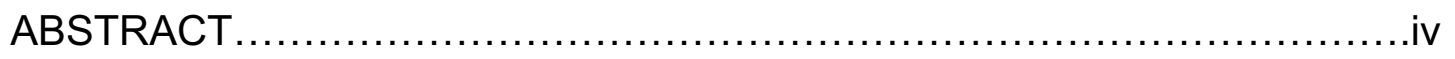

LIST OF TABLES ..................................................................

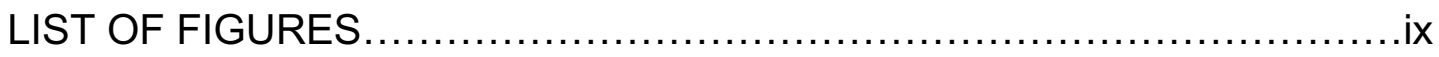

CHAPTER

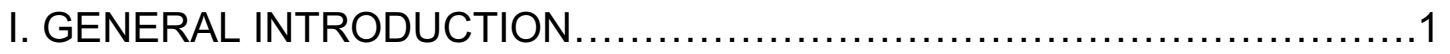

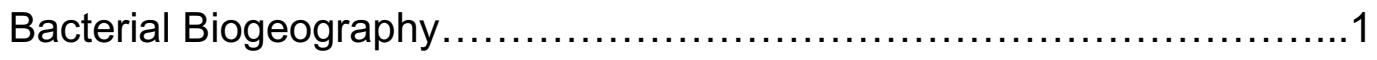

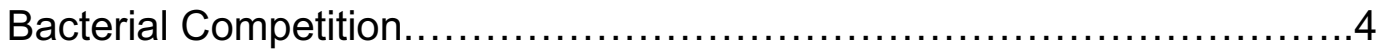

Hamilton's Theory of Inclusive Fitness ..................................

Bacteriocins - Spiteful, Narrow-spectrum Antibiotics.....................10

Pseudomonas aeruginosa - a Versatile, Opportunistic Pathogen..........13

Pyocins - the Bacteriocins of $P$. aeruginosa.............................16

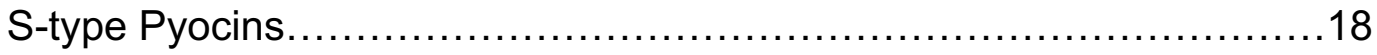

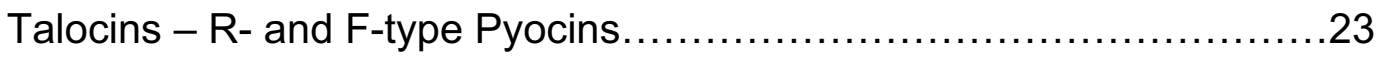

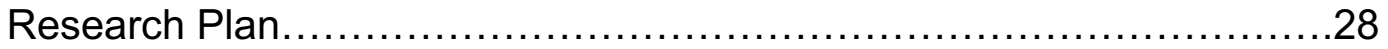

II. SPATIAL STRUCTURE MAINTAINS PYOCIN DIVERSITY

IN HOUSEHOLD PSEUDMONAS AERUGINOSA...........................30

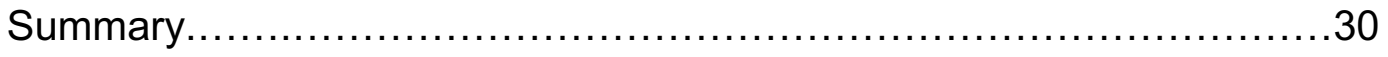

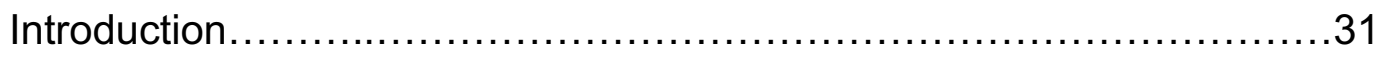




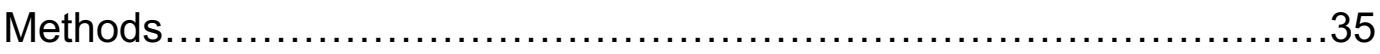

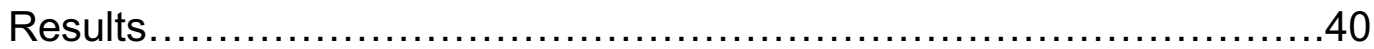

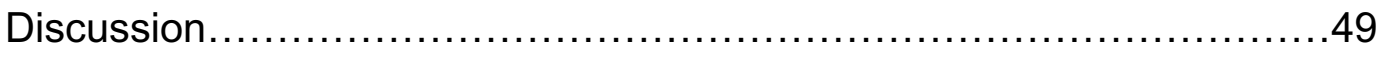

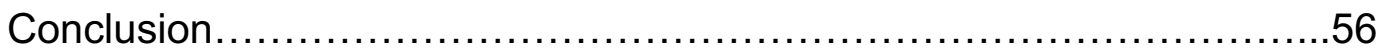

III. GENETIC PATTERNS OF PYOCIN DIVERSITY IN HOUSEHOLD PSEUDOMONAS AERUGINOSA ........................................57

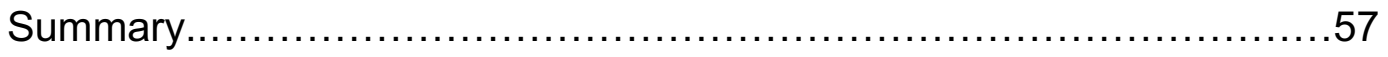

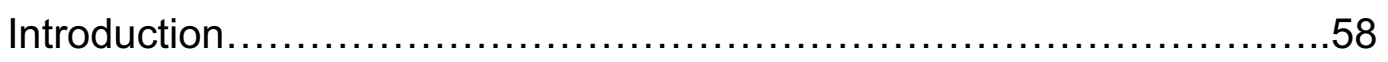

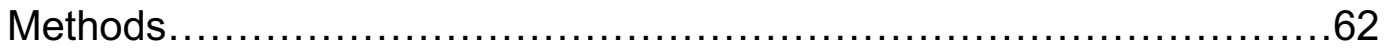

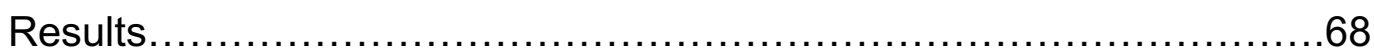

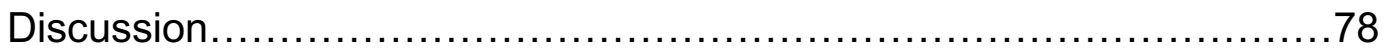

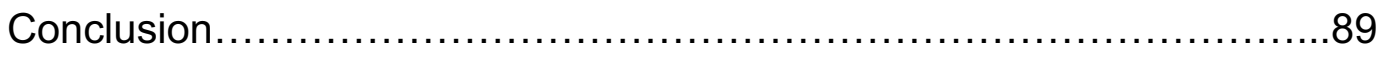

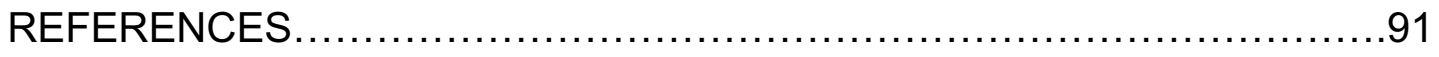

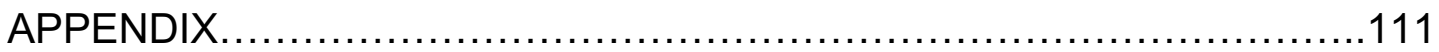

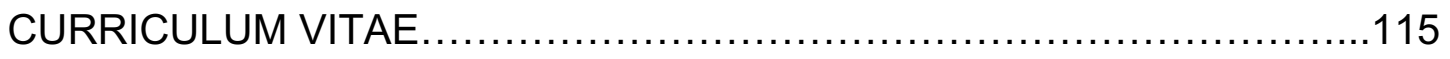




\section{LIST OF TABLES}

\section{TABLE}

PAGE

1. Mean percentage of inhibition across scale ...............................44

2. Generalized linear mixed model for metabolic dissimilarity

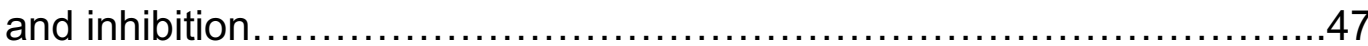

3. Generalized linear mixed model for genetic distance and

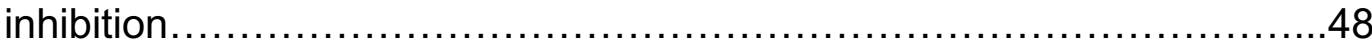

4. S-type pyocin genes screened in all genomes.........................111

5. R- and F-type pyocin genes screened in all genomes...................112 


\section{LIST OF FIGURES}

FIGURE

PAGE

1. Regulation of pyocin gene expression ..................................18

2. Genetic structure of a colicin and an S-type pyocin.......................20

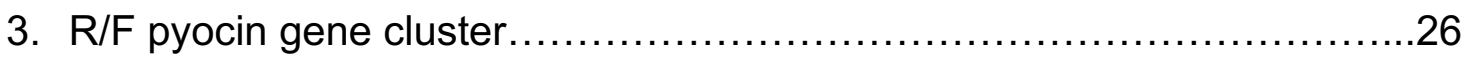

4. Pairwise inhibition assay outcomes.....................................43

5. Inhibition when isolates are collected at different spatial scales.............44

6. Inhibition when isolates are collected from different drain types.............46

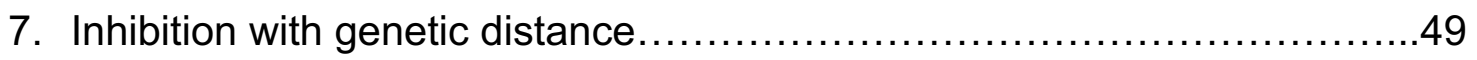

8. Presence/absence of all genes in the R/F pyocin gene cluster for each

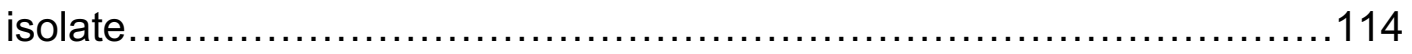

9. Diversity in pyocin gene and genotype ................................... 70

10. Mean number of pyocin genes per isolate across houses..................72

11. Mean number of pyocin genes per isolate across drain types..............74

12. Inhibition in S-, R-, and F-type pyocins..................................

13. Inhibition among different combinations of killing genes....................77

14. Inhibition when an immunity gene is present or absent....................78 


\section{CHAPTER I}

\section{GENERAL INTRODUCTION}

\section{Bacterial Biogeography}

Biogeography is a discipline that seeks to characterize the patterns of biodiversity over space and time as well as gain an understanding of the processes underlying these observed patterns. Biogeography has long been studied in macro-organisms, such as plants and animals, and it has been welldocumented that these systems exhibit particular biogeographic patterns [1, 2]. Conversely, the patterns that might arise in bacterial biogeography have historically been unexplored. However, advancements in sequencing technologies now allow for deeper investigations into bacterial diversity, and this has increased the capability to investigate biogeographic patterns in these organisms [3, 4].

Martiny et al. [5] defined four hypotheses that seek to understand the processes influencing bacterial biogeographic patterns. The first, a null hypothesis, is that these organisms do not exhibit biogeographic patterns, meaning they are randomly distributed in space. The second hypothesis is often referred to as the Baas-Becking Hypothesis: "Everything is everywhere - the environment selects" [6], suggesting that the distribution of bacteria reflects only current abiotic and biotic conditions in the environment. A third hypothesis proposes that bacterial patterns are influenced by historical 
conditions such as dispersal limitations and past environmental conditions. The last hypothesis combines the second and third hypotheses by arguing that patterns of diversity in bacteria reflect both current conditions and past events [5].

Empirical studies have widely demonstrated that free-living bacterial species display non-random biogeographic patterns in nature [7-10], which allows us to reject the null hypothesis. Overall, it appears that both current environmental conditions and historical processes affect bacterial composition, suggesting that the last hypothesis proposed by Martiney et al. [5] may most accurately reflect the biological underpinnings of bacterial biogeography. Studies in bacterial populations have examined relationships between diversity and geographic distance, which provides insight into the historical processes underlying observed patterns of diversity, such as dispersal limitations as well as previous selection and drift. Large-scale intercontinental studies in Synechococcus [11] and Sulfolobus [7] assemblages have revealed strong effects of geographic distance on bacterial and archaeal composition, respectively. Furthermore, studies done at smaller spatial scales in Pseudomonas fluorescens [12] and among species in the Xenorhabdus genus [13] have revealed genotypic and phenotypic differences among geographically isolated bacteria. Some studies, however, have not identified this pattern [14], suggesting that the detection of such a relationship varies among studies, taxa, methodology, and perhaps, to an extent, the scale of the study.

Additionally, studies in bacterioplankton, microbial communities in aquatic 
environments, and soil bacterial communities in rhizospheres have found that contemporary environmental conditions play a significant role in influencing bacterial composition [15, 16], which supports the Baas-Becking Hypothesis. While less common, some studies examine the effects of both geographic distance and environmental conditions on bacterial composition and have found evidence signifying that both factors play an important role in shaping patterns of distribution in these organisms $[8,10,17]$. Taken together, these findings indicate that historical events and current conditions can contribute to patterns of bacterial diversity, but the degree of this influence may be dependent upon the scale of the study as well as the study system.

Notably, at least some dispersal limitation is required to detect a relationship between geographic distance and diversity because differentiation due to past events would be countered by homogenizing selection imposed under high rates of dispersal [18]. The detection of such a relationship with geographic distance can also be impacted by a bacterial taxon's ability to colonize a new location [5]. For example, some taxa are more tolerant to stressful conditions and, therefore, may be able to more easily colonize new locations than other taxa that are more fastidious. A study done using species in the Bacillus genus showed that this spore-forming organism has high rates of migration, which minimizes the influence of geographic distance on these populations [19]. Additional factors that may play an important role in the colonization rate of a bacterium are interactions with residents of a new location, including competitive and synergistic interactions, and population density, as a 
higher population density would allow for colonization more easily. The type of environment will also play a role in a bacterium's dispersal capabilities; certain habitats, such as those in aquatic settings, will allow for higher rates of dispersal than those in terrestrial environments [5].

Due to the small number of studies addressing the effects of both geographic distance and current environmental conditions, more research is needed across different taxa to identify the specific mechanisms underlying bacterial biogeography. In this dissertation, by using strains of Pseudomonas aeruginosa collected from spatially structured kitchen and bathroom sink drains across different houses, I explored the extent to which these previously mentioned underlying mechanisms contributed to patterns of diversity observed in my strain collection.

\section{Bacterial Competition}

The effects of biotic factors, such as the composition and abundance of other microorganisms, are often neglected in studies of bacterial biogeography. However, when examined, bacterial composition often correlates to measured biotic variables, suggesting that processes due to biotic variables may play a role in shaping patterns of bacterial biogeography [20].

One biotic variable contributing to patterns of bacterial diversity is competition over shared resources. Like macro-organisms, bacteria compete over shared, limiting resources such as carbon, nitrogen, and metals [21]. Resource competition can be placed into two categories: scramble (passive) and 
interference (contest) competition [22]. Scramble competition among microorganisms occurs when organisms compete indirectly through rapid growth or through the secretion of extracellular molecules used to obtain nutrients [20]. For example, the bacterial species Escherichia coli can shift its metabolism in the presence of oxygen, which allows it to grow more quickly and take up nutrients faster than its competitors [23].

Another form of scramble competition is mediated through the production and release of extracellular molecules such as siderophores, which are ironscavenging compounds that can obtain free iron in the environment for use by the producing cell. While siderophores could help to mediate competitive interactions due to differences in iron-binding affinities of different siderophore molecules [24], production of these iron-binding molecules may also be considered a cooperative behavior because, when they are produced, the bound iron is considered a "public good" and can be taken up by other bacterial cells in some cases [25]. Consequently, this can sometimes lead to "cheating," a phenomenon in which cells can exploit a resource produced by a competitor without expending the energy to manufacture the product themselves. In other words, cells may lose the ability to produce and release siderophores but retain the ability to take up the iron bound to them [26-29]. Another example of cooperation and consequential cheating in $P$. aeruginosa occurs during a process called quorum sensing (QS) that allows bacterial cells to communicate through the release of signal molecules. The observance of "cheaters" in this process has been identified when cells benefit from this process but do not 
produce the QS molecules themselves [30, 31].

Interference competition occurs when organisms compete by directly damaging one another. One such type of interference competition in bacteria is contact-dependent and mediated through the Type VI secretion system (T6SS), in which a needle-like apparatus is used to inject toxins directly into a target cell [32]. Another mechanism of interference competition is the secretion of antimicrobial compounds, which is widespread in all lineages of bacteria $[5,20]$ Some researchers have proposed that, instead of modulating competitive interactions, sub-inhibitory levels of antimicrobials could function as signaling molecules for cell-to-cell communication purposes [33]; however, numerous empirical studies in laboratory settings have shown that the production of these molecules does, in fact, play a significant role in mediating the outcomes of competitive interactions [34].

Furthermore, the killing range of a cell that is secreting antibiotics (the "producing cell") can often be correlated to its habitat and lifestyle, further providing evidence of these compounds' role in natural settings. As such, a generalist species that inhabits a diverse microbial habitat may benefit from the production of broad-spectrum antimicrobials that are effective against a wide range of microorganisms due to the variety of competitors it is likely to encounter. For example, species in the Streptomyces genus are commonly found in highly diverse environments such as in soils, and organisms in this bacterial genus carry genes for a wide array of antimicrobial compounds [35]. On the other hand, a specialist species with specific habitat requirements may be more likely to 
produce narrow-spectrum antibiotics that are effective against a smaller, more targeted group of microorganisms as it is not likely to encounter a diverse group of competitors [36]. Therefore, the production of antimicrobials plays an important role in mediating competition both within and between species.

The long-term evolutionary consequence of bacterial competition is a reduction in diversity at a local scale - the scale at which cells directly interact and impact one another. This is due to competitive exclusion, a phenomenon in which one organism outcompetes the other and drives it to extinction [37]. These interactions may also drive organisms to specialize on different resources and occupy new niches (niche partitioning) or, in the presence of spatial structure, microorganisms may have the capacity to coexist [36]. This dissertation explores the patterns of diversity in narrow-spectrum antibiotics, called bacteriocins, observed at different spatial scales and investigates the potential evolutionary remnants of competition mediated through these compounds' production.

\section{Hamilton's Theory of Inclusive Fitness}

Social behaviors such as altruism and spite are another mechanism underlying bacterial diversity. Darwin's theory of natural selection predicts that traits associated with greater reproductive success will be acted upon by selection and accumulate in natural populations [38]. Consequently, selection for social behaviors such as selfishness and mutualism are well supported by Darwin's ideas as these interactions will lead to an increase in reproductive success for the actor, who is the individual initiating the behavior, or both the 
actor and the recipient, who is the individual targeted by the behavior [39]. Less clear, however, are the reasons behind other social behaviors, such as altruism and spite, that may decrease the reproductive output of the individual initiating the behavior [40, 41]. The reasoning underlying these behaviors is difficult to understand as the actor will incur a fitness cost when performing altruistic or spiteful actions to provide a benefit, in the case of altruism, or to harm, in the case of spite, the individual on the receiving end of the behavior.

In the 1960s, Hamilton noted that behaviors such as altruism and spite could not be explained by Darwin's theories alone; however, they could be supported by the principle of inclusive fitness [40, 41]. Hamilton developed a theory that defined inclusive fitness as the sum of direct fitness, which is gained through producing offspring, and indirect fitness, which is obtained through interactions with close kin or individuals of common descent. He argued that although altruism and spite decrease an individual's direct fitness, these behaviors may increase indirect fitness, thereby maximizing inclusive fitness [ 40 , 41].

Altruism, the more studied and well understood of these social behaviors, is predicted to occur if the indirect fitness benefits are aimed toward individuals with high genetic relatedness to the actor; this action will increase the frequency of the genes shared by the individuals participating in this interaction [40, 41]. This behavior, mathematically modeled by Hamilton, will be favored by selection when $r b-c>0$, where $r$ is genetic relatedness between the actor and recipient, $b$ is the fitness benefit to the recipient, and $c$ is fitness cost to the actor [40, 41]. 
Altruism is clearly observed in highly eusocial insects, such as ants and bees, in which sterile workers give up the opportunity for independent reproduction to help individuals with high genetic relatedness, or their kin [42]. As a result, these interactions are often referred to as "kin selection" [43]. Another well-studied example of altruism exists in a group of social amoebae, often referred to as slime molds, particularly within the species Dictyostelium discoideum [44]. Under normal conditions, $D$. discoideum exists in a unicellular form; however, under conditions of low nutrients, these cells come together to form a multicellular slug. This slug transforms into a fruiting body through the differentiation of cells into a cluster of spores or into a long, rigid stalk, which supports the cluster of spores. The cells that make up the stalk are nonviable, and about $20 \%$ of these cells will die to support the reproduction of cells that have differentiated into spores in what appears to be a classic example of altruistic behavior [44].

\section{Spite - the Dark Side of Altruism}

Spite, the darker side of altruism, refers to behaviors that decrease the reproductive output of both the actor and the recipient [45]. Because spite is less understood and more rarely observed than altruism, it has been historically confused with selfishness, which harms a recipient but leads to a direct fitness increase for the actor. Selfish behaviors differ from spite, as truly spiteful behaviors must be costly in terms of fitness to both the actor and the recipient [39]. Spiteful behaviors can be explained by Hamilton's theory of inclusive fitness because, like altruism, spite maximizes inclusive fitness through a decrease in 
direct fitness with a subsequent increase in indirect fitness [40, 41]. Like altruism, spite will be favored when $r b-c>0$; with spiteful behaviors, however, $r$ is a negative genetic relatedness, meaning that the recipient is less related to the actor than the average member of the population. Furthermore, $b$ is a negative benefit, meaning that the action has a negative impact on the recipient, and $c$ is positive, meaning that the action is also costly to the actor. Therefore, a spiteful behavior will be favored if the negative genetic relatedness and negative impact on the recipient can outweigh the cost to the actor $[40,41,45]$. Contrasting with this theory is Wilsonian spite, which predicts that, in order for a spiteful behavior

to occur, the indirect beneficiary of the spiteful behavior must be more genetically related to the actor than the individual on the direct receiving end of the behavior $[46,47]$. Spite is rarely observed in nature as the particular population conditions that favor harming non-relatives to effectively help relatives are quite difficult to obtain [39, 45]; however, one clear example of a spiteful behavior is the bacterial production of anticompetitor toxins, such as bacteriocins [45].

\section{Bacteriocins - Spiteful, Narrow-spectrum Antibiotics}

Bacteriocins, a diverse family of antimicrobial toxins found in upwards of 99\% of Gram-negative and Gram-positive bacteria, are often cited as a classic example of spite, as these antibiotics result in a fitness cost to both the actor and the recipient $[45,48,49]$. As well as being costly to produce, bacteriocins are also typically released through lysis in Gram-negative bacteria, which kills the cell producing and releasing the bacteriocin [48]. Moreover, laboratory studies have 
demonstrated that, when grown alone, bacteriocin producers have a slower growth rate than non-producers, which shows the cost of carrying these toxins on reproductive fitness [48]. Unlike traditional antibiotics, bacteriocins are conventionally believed to have a relatively narrow killing spectrum, meaning that the capacity for killing by a bacteriocin producer is restricted to members of the same species or closely related species. This specificity results from the bacteriocin's requirement to bind to a particular receptor on the surface of a target cell in order for killing to occur [48]. However, recent research has shown that this general assumption does not hold for all bacteriocin-producing organisms [50-52]. For example, a study in enteric bacteria, such as E. coli and members of the Klebsiella genus, found that many of the strains used in this study exhibited a surprisingly high level of interspecific inhibition with many strains able to inhibit members of different taxa [52]. Additionally, the bacteriocins of Pseudomonas aeruginosa, called pyocins, have the potential to be effective against other species in the Pseudomonas genus and species in the Burkholderia genus $[50,51]$. However, these studies confirm that, to an extent, traditional assumptions of the narrow killing spectrum hold true as bacteriocinmediated inhibition has been found to occur more frequently within a species compared to interactions observed between different species.

Laboratory studies have demonstrated that, under certain conditions, the bacteriocins of $E$. coli, called colicins, have the ability to play important roles in maintaining intraspecies diversity through the creation of non-transitive networks, sometimes referred to as rock-paper-scissors networks, in which multiple strains 
can coexist due to different colicin genotypes and mechanisms of resistance [53]. For example, it is possible to have a strain capable of producing a bacteriocin, which may give it a competitive advantage over a strain that is sensitive to the bacteriocin. However, because these toxins are costly to carry and release, the producer is at a disadvantage because it has to pay this cost while the sensitive strain does not. Additionally, there could also exist a non-producing, resistant strain that cannot be killed by the producer but must pay the cost of resistance, usually through a mutation in the cell surface receptor, which is not paid by the sensitive strain. Therefore, a non-transitive rock-paper-scissors network can be maintained in which no one strain can outcompete the other [53]. However, the maintenance of such a network is dependent upon rates of dispersal and will be preserved only under conditions in which dispersal is limited, and therefore interactions occur locally, such as that of a static agar plate $[34,53,54]$. When rates of dispersal are high and interactions are occurring globally, such as within a shaking flask, the resistant strain can competitively exclude both the producer and sensitive strain as a result of homogenizing selection $[34,53]$.

Bacteriocin diversity in nature has been explored in previous studies [12, $14,51,55-58]$; however, it remains unclear if this diversity is a result of historical or contemporary processes, or if these antibiotics are playing an active, functional role in the maintenance of overall microbial diversity, thereby contributing to the structure of natural microbial assemblages. Furthermore, it is unclear if bacteriocin production is, in fact, a truly spiteful behavior and if the proposed genetic mechanisms driving such a behavior can be detected in natural 
microbial populations. This dissertation addresses the relationship between genetic relatedness and spiteful interactions mediated through the production of bacteriocins in $P$. aeruginosa. This was done by observing bacteriocin-mediated interactions among the $P$. aeruginosa isolates in my collection and measuring the phylogenetic distance between them. Specifically, this work seeks to elucidate the mechanisms underlying bacteriocin diversity by investigating patterns in genotype and phenotype among environmental isolates of $P$. aeruginosa.

\section{Pseudomonas aeruginosa - a Versatile, Opportunistic Pathogen}

Pseudomonas aeruginosa is a Gram-negative opportunistic pathogen perhaps most widely known and studied for causing chronic infections in individuals with Cystic Fibrosis (CF), an autosomal recessive disorder caused by a mutation in the cystic fibrosis transmembrane conductance regulator (CFTR) $[59,60]$. This mutation leads to a buildup of thick mucus in the lungs, which allows for sustained bacterial colonization. $P$. aeruginosa is one of the leading causes of morbidity and mortality in these individuals [60]; once this organism colonizes the lungs of an individual with CF, it is nearly impossible to eradicate [60]. This species is also responsible for a wide variety of infections including those in wounds, burns, and other nosocomial infections [61].

Pseudomonas aeruginosa PAO1, the most commonly studied and wellcharacterized laboratory strain of $P$. aeruginosa, has a relatively large genome size comprised of $\sim 6.3$ million base pairs with a GC content of $\sim 66.6 \%$ and 5,570 predicted open reading frames (ORFs) [62]. For comparison, E. coli has a 
genome size of 4.6 million base pairs with a GC content of $50.8 \%$ and 4,288 predicted open reading frames [63]. The large genome size of $P$. aeruginosa is thought to be due to increased genetic complexity and functional diversity. Compared to other well-studied bacterial species such as E. coli, Mycobacterium tuberculosis, and Bacillus subtilis, P. aeruginosa has more distinct paralogous groups of genes, or genes that have resulted from gene duplication but are functionally distinct from one another [62]. Furthermore, $P$. aeruginosa PAO1 was found to have a large number of transcriptional regulators and environmental sensors as well as diverse metabolic pathways and enzymes related to oxidative metabolism. Taken together, these components indicate that the genetic intricacy and regulatory flexibility, as well as variable metabolic capabilities, allow $P$. aeruginosa to persist in a wide variety of environmental conditions [62].

P. aeruginosa in the Built Environment

$P$. aeruginosa has historically been characterized as an organism with a broad fundamental niche, meaning that it has the ability to persist in a wide array of environmental conditions [62]. As such, this species has long been perceived as a global or ubiquitous organism. This has been an accepted hypothesis because $P$. aeruginosa is known for its wide metabolic capabilities and has also been isolated from a diverse array of environments including soils, water, and marine environments. Furthermore, as this is a particularly significant pathogen for individuals with CF, it has been of interest to determine the initial source of $P$. aeruginosa infection in these individuals. While patient-to-patient transmission of 
$P$. aeruginosa has been well documented [64-66], other potential sites harboring this species remain unclear. It is possible that certain environmental reservoirs of $P$. aeruginosa may also serve as a source of infection for these individuals.

To determine potential sources of initial infection, studies have examined $P$. aeruginosa distribution within the built environment, with a particular focus on hospital settings. In these environments, $P$. aeruginosa has been isolated from places such as sinks, drains, and water [67-70]. Additionally, previous studies have focused on identifying potential sources of $P$. aeruginosa within households, as this setting may also harbor $P$. aeruginosa [71-74]. Although $P$. aeruginosa is often referred to as ubiquitous, studies that have sampled the households of either individuals with CF or the households of individuals without $\mathrm{CF}$, have found that $P$. aeruginosa is not always recovered, which contrasts with the perception that this is a global organism with a broad fundamental niche. In fact, Remold et al. [74] found that $P$. aeruginosa was never recovered from indoor or outdoor soils and was rarely recovered from tap water samples, despite previous studies reporting isolating $P$. aeruginosa from these sources [75-77]. Another study, however, supports the findings of Remold et al. [74] through the observation that $P$. aeruginosa occurrence is rare in agricultural soil samples [77].

When $P$. aeruginosa is recovered from a household, it appears that this organism displays a high specificity in these environments, as it is most frequently recovered from the drains of kitchen sinks, bathroom sinks, showers, or toilets. Furthermore, some studies report that $P$. aeruginosa shows specificity 
to sub-categories of sampling locations such as types of drains. For example, Remold et al. [74] found $P$. aeruginosa to be isolated significantly more often from bathroom sink drains than kitchen sink drains. However, other studies, including another study done by Remold et al. [73] have not identified this pattern. In fact, Regnath et al. [71] recovered $P$. aeruginosa from $35 \%$ of kitchen sink drains and $34 \%$ of bathroom sink drains. The potential differences in recovery rates from bathroom and kitchen sink drains could be due to a variety of biotic and abiotic factors or from sampling bias. Regnath et al. [71] proposed that sinks used more frequently may be less likely to harbor $P$. aeruginosa because the increase in water flow may displace bacterial cells. These sampling studies indicate that, while $P$. aeruginosa is described as having the ability to persist in a wide array of environmental conditions, its realized niche, or the distribution that this organism actually exhibits in nature, appears to be much more constrained than its fundamental niche.

This dissertation continues the work in investigating the distribution of $P$. aeruginosa in households; however, we instead focus on sampling only bathroom and kitchen sink drains, as we know these are the locations most likely to harbor $P$. aeruginosa and this allowed us to investigate potential differences in recovery from different types of sink drains.

\section{Pyocins - the Bacteriocins of $P$. aeruginosa}

The bacteriocins of $P$. aeruginosa, called pyocins in this species, are one of the more well-characterized bacteriocin systems. Pyocins differ from 
bacteriocins produced in other species in that they are both highly abundant in $P$. aeruginosa populations as well as incredibly diverse. The pyocins of $P$. aeruginosa display variability in genetic structure, mode of action, and killing range. Furthermore, unlike the bacteriocins of other species, which are located on plasmids, pyocins are chromosomally encoded [78, 79]. Pyocins have been placed in three categories: S, R, and F. The S-type pyocins are soluble and share homology to the colicins of E. coli, while the R-and F-type pyocins are multiprotein molecules that are similar to bacteriophage [80]. There are multiple subtypes within each of these categories and strains have the ability to carry unique combinations of each type [80]. The $S, R$, and $F$ pyocins are discussed in more detail later in this chapter.

\section{Regulation of Pyocin Expression}

Due to the costly nature of pyocin production and release [80], pyocin and other associated genes are not constitutively expressed, meaning that these proteins are not always present in the cell. Instead, these genes are regulated through the SOS response, which occurs when bacteria respond to DNA damage [80-82]. While the SOS response in $P$. aeruginosa is more complex than that of other species like E. coli, the mechanism of pyocin expression as it relates to this response is similar in that it is also coordinated through the production of a protein called RecA (Fig. 1). Under conditions in which DNA damage occurs, a nucleoprotein called RecA will mediate the autocleavage of a protein called PrtR. Under normal conditions, PrtR acts as a repressor for prtN, a gene that encodes 
for an activator of pyocin expression. However, under stressful conditions, PrtR is cleaved, which derepresses prtN and allows for synthesis of its protein. PrtN binds to particular sequences called $\mathrm{P}$-boxes in the promotor regions of $\mathrm{S}, \mathrm{R}$, and F-type pyocins [81]. This process leads to the expression of all pyocin genes as well as a presumptive group of lysis genes that allow for the release of the pyocins from the cell [83]. Both prtN and prtR are conserved across strains of $P$. aeruginosa, which suggests that this regulatory system for pyocin expression is conserved throughout this species $[81,82]$. However, It is notable, that while Pboxes have been identified upstream of the majority of pyocins, an S-type pyocin called S5 does not have an identifiable P-box sequence, suggesting that this pyocin may have a different regulatory pathway than that of other pyocins [84].

A

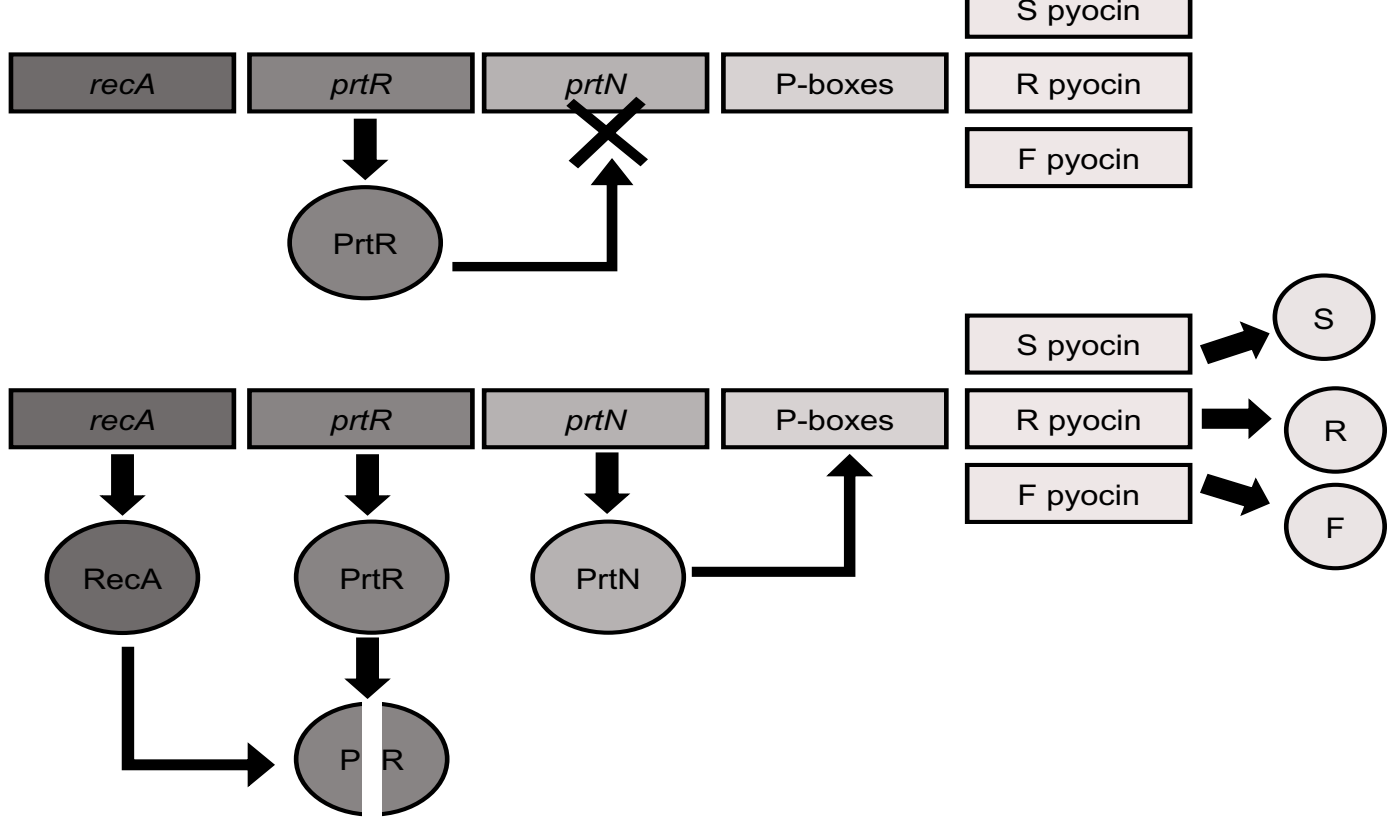

Figure 1. Regulation of pyocin gene expression under normal conditions $(A)$ and under conditions in which pyocin expression is induced (B) through stress or DNA damage. 


\section{S-type Pyocins}

The S-type pyocins contain many subtypes, S1-S6 as well as AP41, that have been empirically confirmed to demonstrate bactericidal activity [80]. Additionally, there are presumptive subtypes S7-S12, which have been predicted through $P$. aeruginosa genomic analysis [85]. The subtypes of S-type pyocins exhibit diversity in genetic structure, mode of action, and receptor specificity.

The genetic determinants of S-type pyocins share homology to the colicins of E. coli [80]. Colicin gene clusters have three components: a toxin gene responsible for killing activity, an immunity gene providing protection for the producer cell, and a lysis gene that enables a producing cell to release the toxin (Fig. 2) $[48,86]$. The immunity gene provides protection for the producer cell because when this protein is synthesized, it will bind to and inactivate the toxin protein [48]. While the majority of S-type pyocins share this genetic organization $[79,87]$, previous studies have shown that some strains will lack a toxin gene but carry the corresponding immunity gene, which, in these instances, is referred to as an "orphan" gene $[55,88]$. Additionally, S-type pyocins do not appear to have an identifiable lysis gene expressed alongside the toxin and immunity genes (Fig. 2) [80]. It has been proposed, however, by Nakayama et al. [83] that S-type pyocins may be released from a producer cell using a lysis cassette that is encoded in the R -and F-type pyocin gene cluster, which is discussed later in this chapter.

All identified S-type pyocin toxin and immunity genes are organized in 
operons composed of two open reading frames (ORFs), which code for both of these genes $[79,80,87]$. In studies on the molecular structures of S1 and S2 pyocins, the two ORFs for both pyocin types were found in close proximity; in fact, the stop codon of the ORF encoding the toxin gene is separated by the start codon for the ORF encoding the immunity gene by a single nucleotide and the presumptive ribosome binding site for the immunity gene is located within the region encoding the terminal portion of the toxin gene. This operon organization suggests that, in pyocins $\mathrm{S} 1$ and $\mathrm{S} 2$, the toxin and immunity genes are translated together because this structure allows for continuous contact of the ribosome with the mRNA during translation [79]. Despite this operon organization, however, one study has shown that immunity proteins may be expressed singly, particularly under non-stressful conditions, perhaps due to regulation through small non-coding RNAs [89].

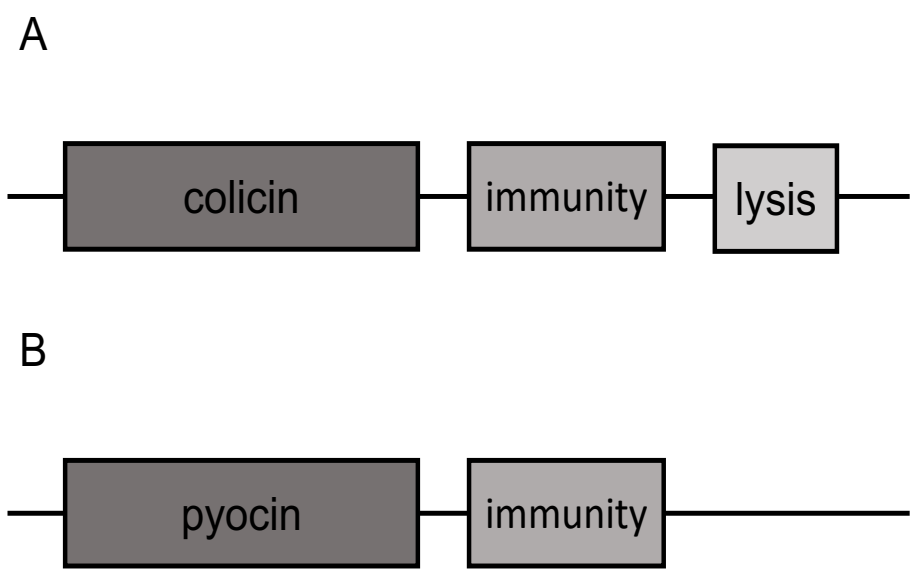

Figure 2. General genetic structure of a colicin in E. coli (A) and S-type pyocin in $P$. aeruginosa (B). 
S-type pyocins have a diverse array of modes of action to kill their sensitive competitors. Pyocins S1, S2, S3 and AP41 kill their sensitive competitors via DNase activity [79, $80,90,91]$. In addition to DNase activity, it has been proposed that pyocin S2 can target sensitive competitors through the inhibition of phospholipid synthesis, although the mechanism underlying this inhibition is not well understood [92]. Additionally, pyocin AP41 has been shown to induce expression of R- and F-type pyocins as well as bacteriophage in a sensitive target cell [87]. Pyocin S4 is presumed to kill via tRNase activity, S6 has rRNase activity, and the mode of action for S5 is pore formation, which leads to membrane damage and leakage of cellular contents [80, 93].

In order to kill a sensitive competitor, S-type pyocins must bind to specific cell surface receptors and subsequently be translocated into a target cell [80]. Subtypes vary in their receptor specificity, which, in addition to the presence of immunity genes, could also account for variability in killing spectra among different S-type pyocins. Pyocins S1, S2, S3 and S4 are taken into target cells via outer membrane ferripyoverdine receptors, which, under iron-limited conditions, are used in the uptake of siderophores. S2 and S4 [94] share the same receptor, siderophore ferripyoverdine receptor FvdAl, while S3 uses FvdAll [95] and S5 uses the FetA ferripyochelin receptor [93]. Consequently, these pyocins are better absorbed by sensitive cells under iron-limited conditions, due to an increase in the number of ferripyoverdine receptors on the surface of a sensitive target cell [96]. Researchers have been unable to find a specific receptor for pyocin S6, suggesting that perhaps this pyocin type does not target a 
particular type of ferripyoverdin receptor [89]. Similarly, the receptor for AP41 has not been definitively identified; it is believed to be a different receptor than those of pyocins S1-S4, but one in which iron is also involved [80, 95]. Once pyocins have bound to the appropriate receptors, they must be translocated into the sensitive target cell. While little is known about the mechanism of translocation for S-type pyocins, it has been proposed that because of the use of ferripyoverdine receptors in S1-S4, these pyocins may be moved into the target cell through a mechanism that is similar to that of the uptake of ferrisiderophore, which is the TonB system [97]. The mechanism by which AP41 is translocated has not yet been identified, but it is theorized that this pyocin may use the TolQRAB system, which is an uptake pathway involved in the translocation of the colicins of $E$. coli as well as certain types of bacteriophage $[80,98]$.

\section{Pyocin S3}

Pyocin S3 ws first identified in 1995 in a strain isolated in sputum from an individual with CF [99] and is distinguishable from other S-type pyocins [78, 80]. When compared to pyocins S1, S2, and AP41, S3 shares little homology with these subtypes regarding to the killing or immunity proteins $[78,80]$. Additionally, the GC contents of the killing and immunity genes in pyocin S3 were determined to be $56.6 \%$ and $42.7 \%$, respectively, which is lower than that of the $P$. aeruginosa genome (66.6\%) [90]. In addition to the RecA-mediated regulation that all pyocins share, pyocin S3 had additional transcriptional regulation factors at play. A small non-coding RNA, PesA, which is transcribed within the 
pathogenicity island PAPI-1, is commonly found in clinical isolates and was first identified in the common clinical laboratory strain PA14. PesA has been shown to exert positive control on $\mathrm{S} 3$ toxin and immunity protein expression in these clinical isolates, possibly by contributing to concurrent expression of these two proteins, though the specific mechanism underlying this process has yet to be elucidated [100].

\section{Pyocins AP41 and S8}

While many S-type pyocins share similarities in sequence composition, Stype pyocins AP41 and S8 have a distinctive genetic structure [80, 85, 87, 101]. AP41 genes are unique because they are located on a transposon, which has been appropriately named TnAP41. This transposon, which is composed of 3229 base pairs, is made up of two genes encoding the killing and immunity proteins for AP41. These two genes are located together on an operon and are flanked by inverted repeat sequences, which are typically found on transposons; however, this operon lacks the genes necessary for transposition, such as transposase [101]. It has also been noted that the GC content of TnAP41 is $54.1 \%$ [101] while the rest of the $P$. aeruginosa genome is $66.6 \%$ [62], which suggests that TnAP41 is a more recently acquired genetic element. In addition to TnAP41, another transposon has recently been identified in the $P$. aeruginosa genome as a carrier of a novel S-type pyocin, S8 [85]. This recently described transposon, Tn6350, also shares homology to the Tn3 family of transposons and is comprised of eight ORFs. These ORFs code for an ATPase, a transposase, a resolvase, pyocin S8, 
an immunity protein, and three hypothetical remaining proteins that have yet to be characterized [85].

\section{Talocins - R- and F-type pyocins}

In addition to the S-type pyocins, over $90 \%$ of $P$. aeruginosa strains produce at least one of two types of pyocins, the R-type pyocin or the F-type pyocin, with some strains carrying genes for both types of these pyocins [80, 102]. The R- and F-type pyocins, collectively referred to as talocins, are defective prophages that share many physiological similarities with bacteriophage as these pyocins can be induced by DNA damaging agents, display antimicrobial action, and require cell surface receptors in a recipient cell to function [80]. The R-type and F-type pyocins share homology with P2 and lambda phage, respectively, suggesting that these pyocins are likely ancestrally derived from these bacteriophages [83]. Both R- and F-type pyocins lack the genes responsible for head synthesis and consequently resemble headless bacteriophage tails that have, over time, specialized in bactericidal activity. Respectively, the R- and Ftype pyocin complexes are made up of 14 and 17 proteins, encoded in one or more operons in a distinct gene cluster on the P. aeruginosa chromosome (Fig. 3) [83].

It is thought that, like the colicins of E. coli, R and F-type pyocins are also released outside of the cell via lysis, but genes responsible for this process have not yet been well-characterized $[80,83]$; however, several ORFs that could potentially encode lytic genes for pyocin release have been identified. The gene 
encoded at the PA0629 locus shows some similarity to active domains of chitinases, a type of lytic enzyme, which indicates that a gene encoded in this ORF may be a lytic enzyme to facilitate the release of pyocins [83]. Additionally, the genes found at the PA0629, PA0630, and PA0631 loci in P. aeruginosa PAO1 share homologies to phage lytic genes and, more specifically, the genes at the PA0614 and PA0629 loci have been empirically shown to encode lytic enzymes in laboratory studies as cell lysis was observed when these loci were cloned into E. coli [83]. Consequently, it can be inferred that some, if not all of these ORFs, harbor lytic genes responsible for cell lysis and release of pyocins.

Like the S-type pyocins, the talocins have multiple subtypes (R1-R5 and F1-F3). The subtypes of both R- and F-type pyocins are similar structurally; however, there is variation among the tail fiber composition of the subtypes, which presumably allows for differential killing range as the tail fiber composition is thought to account for receptor specificity [80]. The receptors for talocins are lipopolysaccharides (LPS), which are large molecules found in the outer membrane of Gram-negative bacteria [103, 104]. Laboratory studies have demonstrated that R-type pyocins target the outer core component of LPS; however, the specific LPS target for the F-type pyocin is unknown [105]. Unlike the S-type pyocins, the talocins do not have immunity proteins, and instead, immunity is thought to be mediated through receptor incompatibility [80]. 

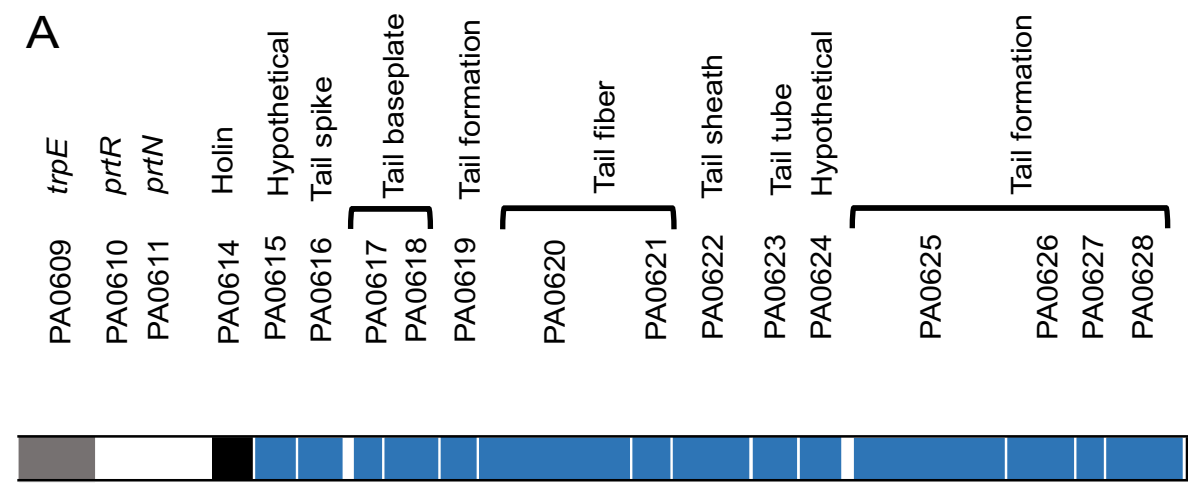

B
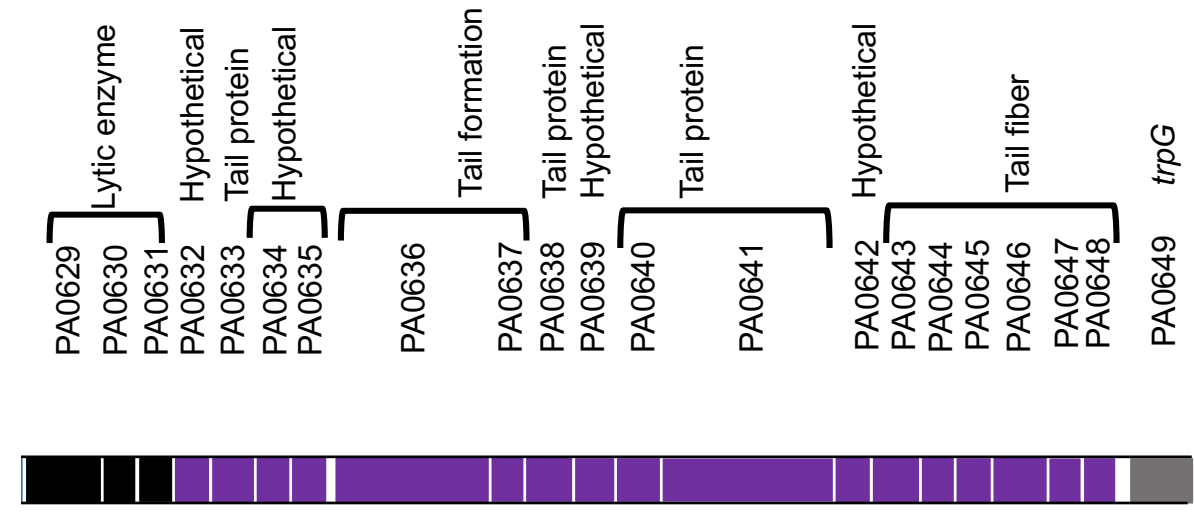

Figure 3. R/F pyocin gene cluster. Regulatory genes $p r t R$ and $p r t N$ appear in light grey while lysis-related genes appear in black. Genes encoding for structural components of R-type pyocins (A) are displayed in blue and genes encoding for structural components of F-type pyocins (B) are displayed in purple.

\section{R-type pyocins}

The R-type pyocins, which were first identified in 1964 [106-108], are 
inflexible and have been named for the rigidity of their structure [80]. R-type pyocins are composed of a hollow cylinder capable of contraction as well as a baseplate and six tail fibers, which are responsible for receptor binding and target specificity [109-111]. When the R-type pyocin binds to and makes firm contact with the LPS of a target cell, the pyocin complex will rapidly contract and penetrate the outer membrane $[103,112]$. Once this process occurs, there will be an arrest of macromolecule synthesis in the target cell and the intracellular contents will be released [113]. Cell death results from pore formation and subsequent membrane depolarization [80,114]. R-type pyocins are highly potent, and only one $\mathrm{R}$ pyocin molecule is required to kill a target cell [106]. There are five subtypes of this pyocin, R1-R5; these subtypes differ only in their killing range, which is mediated through differences in tail fiber composition [113]. The R-type genes are located between $\operatorname{trp} E$ and $\operatorname{trp} G$ on the $P$. aeruginosa chromosome. 13 ORFs (found at loci PA0616-PA0628 in P. aeruginosa PAO1) have been identified as being involved in R-type pyocin production. These genes encode for R-type pyocin protein subunits such as the baseplate, tail fibers, tail tube, and tail sheath $[81,83,115]$.

F-type pyocins

F-type pyocins were first identified in 1967 and are flexible non-contractile rod-like structures and resemble flexible phage tails $[116,117]$. There are three subtypes of F-type pyocins, F1-F3, and, like those of the R-type, these subtypes differ only in their tail fiber composition and the resulting killing range [117]. Little 
is known about the specifics of the killing mechanism of the F-type pyocin, but it is posited that this bacteriocin also kills target cells through pore formation. Unlike the R-type pyocins, which can kill a target cell with only one molecule, it has been reported that the $\mathrm{F} 1$ pyocins must be present as 280 molecules to kill a sensitive competitor [118]. The F-type pyocin gene cluster is located downstream of the R-type pyocin gene cluster. 17 ORFs in this region that have been identified as the genes potentially responsible for F-type pyocin production: PA0632-PA0648 in P. aeruginosa PAO1 [83].

Over time, the genetic determinants of pyocins have become more wellcharacterized; however, few studies have examined genetic diversity with respect to pyocins across different strains of $P$. aeruginosa, particularly in freeliving isolates. Furthermore, it is unclear if pyocin genotype can be directly linked to phenotype. Therefore, this dissertation addresses the pyocin genetic diversity in our environmental $P$. aeruginosa collection of isolates as well as the relationship between pyocin genetic determinants and patterns of inhibition observed in our laboratory study.

\section{Research plan}

While patterns of pyocin diversity have been studied in laboratory, clinical, and environmental isolates of $P$. aeruginosa to varying degrees, the ecological, evolutionary, and genetic mechanisms underlying this diversity in natural spatially isolated settings requires further investigation. This dissertation attempts to answer the following questions in regard to patterns of diversity in pyocin 
genotype and phenotype in household drain isolates of $P$. aeruginosa:

1. What is the relationship between spatial scale and pyocin inhibition/susceptibility? (Chapter 2)

2. What is the relationship between environment of isolation and pyocin inhibition/susceptibility? (Chapter 2)

3. What is the relationship between resource use and pyocin inhibition/susceptibility? (Chapter 2)

4. What is the relationship between phylogenetic distance and pyocin inhibition/susceptibility? (Chapter 2)

5. What are the overall patterns of diversity in pyocin genotype of our household strain collection? (Chapter 3)

6. What is the relationship between spatial isolation (house) and pyocin genotype? (Chapter 3)

7. What is the relationship between environment of isolation (drain type) and pyocin genotype? (Chapter 3)

8. What is the relationship between pyocin immunity genes and inhibition? (Chapter 3)

9. What is the relationship between the combination of pyocin killing genes and inhibition? (Chapter 3)

A central goal of biology is understanding the processes that generate and maintain diversity. This research works toward this goal as it elucidates the evolutionary, ecological, and genetic mechanisms underlying diversity in a 
system that is characterized by a profound amount of complexity. The ecological and evolutionary processes investigated in this work may provide insights into underpinnings of diversity in other systems of study. 


\section{CHAPTER II}

\section{SPATIAL STRUCTURE MAINTAINS DIVERSITY OF PYOCIN INHIBIITON IN HOUSEHOLD PSEUDOMONAS AERUGINOSA}

\section{Summary}

Nearly all bacteria produce narrow-spectrum antibiotics called

bacteriocins. Studies have shown that bacteriocins can mediate microbial interactions, but the mechanisms underlying patterns of inhibition are less well understood. We assembled a spatially structured collection of isolates of Pseudomonas aeruginosa from bathroom and kitchen sink drains in nine households. Growth inhibition of these $P$. aeruginosa by bacteriocins, known as pyocins in this species, was measured using pairwise inhibition assays. Carbon source usage of these isolates was measured, and genetic distance was estimated using multilocus sequencing. We found that as the distance between sites of isolation increased, there was a significantly higher probability of inhibition, and that pyocin inhibition and susceptibility vary greatly among isolates collected from different houses. We also detected support for other mechanisms influencing diversity: inhibition outcomes were influenced by the type of drain from which isolates were collected, and while we found no indication that carbon source utilization influences inhibition, inhibition was favored at an intermediate genetic distance. Overall, these results suggest that the combined effects of dispersal limitation among sites and competitive exclusion within them maintain 
diversity in pyocin inhibition and susceptibility phenotypes, and that additional processes such as local adaptation and effects of phylogenetic distance could further contribute to spatial variability.

\section{Introduction}

A central goal of evolutionary biology is understanding the underlying mechanisms that generate and maintain diversity. One factor thought to promote diversity in microorganisms is the production of bacteriocins, which are narrowspectrum antimicrobials produced by nearly all species of bacteria. These toxins differ from traditional antibiotics in that their targets are presumably restricted to members of the same species or closely related species, although there is some diversity among the phylogenetic killing range of these toxins $[51,52,119]$. The bacteriocins of Pseudomonas aeruginosa, called pyocins, are unique in both their highly abundant production and diversity. For example, $P$. aeruginosa has the ability to produce three different types of pyocins: S, R, and F. S-type pyocins are similar to the bacteriocins of E. coli, called colicins, and are typically composed of a toxin and immunity gene. On the other hand, $\mathrm{R}$ and $\mathrm{F}$ type pyocins resemble phage tails and resistance is thought to be mediated through receptor incompatibility [80]. Furthermore, each of these classes has multiple subtypes and isolates have the ability to produce unique combinations of each type [55, $78,80]$. We use inhibition assays to expose the potential pyocin-mediated interactions among environmental isolates of $P$. aeruginosa, that may or may not come into contact in the field. The observation of inhibition in these assays can 
be a result of the production of any type of pyocin ( $S, R$, and/or $F)$ and indicates that processes occurring in the environment contribute to the maintenance of diversity in pyocin inhibition and susceptibility.

One process believed to maintain diversity in bacteriocins is the presence of spatial structure in the environment, particularly when there is limited dispersal. We investigate the capacity to inhibit among $P$. aeruginosa isolates collected at varying levels of spatial separation: isolates from the same drain in a human house, from different drains from the same house, and from different houses in a metropolitan region. We predict a pattern of increased inhibition outcomes as the sites of isolation become more spatial distant, based on likely dispersal limitations among these drains and the large diversity of pyocins described among $P$. aeruginosa, including among household isolates $[51,55]$. We also expect little inhibition among isolates collected within the same drain, due to the elimination of susceptible phenotypes by pyocin producers or the evolution of resistance to pyocins encountered at the within-drain level. Furthermore, we predict variability in inhibition across different houses due to the stochastic nature of dispersal among sites, combined with the fact that there are no universal optimal pyocin gene contents [53].

Another factor that can promote diversity at a global scale is local adaptation to different environments [74]. This study focuses on isolates from household bathroom and kitchen sink drains, as previous sampling studies have revealed that this is where $P$. aeruginosa is most common in the house $[73,74]$. Previous sampling studies have shown conflicting results regarding the 
differences in $P$. aeruginosa recovery between bathroom and kitchen sink drains, with some studies showing $P$. aeruginosa to be more common in bathrooms [74] [72] while others show no differences in recovery between drains from these types of rooms $[71,73]$. This possible difference in recovery draws attention to the fact that environments may have differences such as the physical shape, frequency of use, and types of inputs associated with them. Such differences may result in differences in the relative contributions of competition versus selection by the environment. In the context of different types of household drains, this might result in differential exposure to one another and selection to inhibit one another, leading ultimately to differences among drain types in their inhabitants' inhibition profiles. We evaluated the relationship between drain type and recovery rate and inhibition patterns to investigate potential contributions of local adaptation to different habitat associated with bathroom versus kitchen sink drains.

Although there are indications that bacteriocin-mediated inhibition may not be directly predictive of competitive outcomes [55], there are two well studied hypotheses regarding the relationships between bacteria and whether or not bacteriocin-mediated inhibition should be favored [12, 14, 120]. First, if bacteriocins do contribute to the outcome of competitive interactions, it may be that bacteriocin-mediated inhibition will occur when two individuals have similar resource requirements, given that competition occurs over shared resources [12, $14,120,121]$. This is because while costly production of bacteriocins is not favored when niche overlap is minimal, it becomes more beneficial as niche 
overlap increases. As niche overlap becomes even stronger, the capacity to inhibit the competitor may decrease not because there is insufficient benefit to bacteriocin-mediated inhibition, but because the competitors may be similar in their bacteriocin genotypes as well as their metabolic profiles, causing them to lack the capacity to inhibit one another $[12,120]$. As such, we predict a "humpshaped" relationship between inhibition and metabolic dissimilarity in which inhibition is least favored among isolates with low and high resource overlap and is most likely to occur when interacting isolates share an intermediate number of resources. Previous studies have examined this relationship between resource competition and bacteriocin-mediated interactions but results vary in the degree to which they conform to this prediction $[12,14,120]$.

Second, a hump-shaped relationship such that bacteriocin-mediated inhibition is maximized when two individuals are genetically related at an intermediate level [120] is also predicted. This is because bacteriocin production targeting very closely related isolates will not be favored, because shared phylogenetic history will cause closely related isolates to carry the same bacteriocin immunity genes and therefore not be killed by their shared toxins. Bacteriocin-mediated competition should also be minimal when two individuals are genetically distant if, along with other traits, their resource use overlap declines over evolutionary time. The hump-shaped relationship has been found among laboratory and clinical isolates of $P$. aeruginosa by Schoustra et al. [120], but other studies of environmental microbes have found contrasting evidence for this relationship $[12,14,57]$. 
The goal of this study was to elucidate the underlying mechanisms that drive diversity in bacteriocin-mediated inhibition. Relationships among spatial scale, metabolic dissimilarity, genetic distance, and bacteriocin inhibition have been examined in different microbial systems with differing results. Furthermore, these patterns have not yet been studied in household isolates of $P$. aeruginosa, where the high production of pyocins $[51,55]$ suggests an important ecological role for these protein structures. We found the lowest probability of inhibition to be among isolates collected from the same drain and the highest probability of inhibition to be among isolates collected from different houses, and we identified additional substantial random variation among specific pairs of houses. No relationship was found between metabolic dissimilarity and inhibition; however, a significant hump-shaped relationship was found between genetic distance and inhibition, meaning that isolates of an intermediate genetic distance displayed the highest probability of inhibition.

\section{Methods}

\section{Bacterial Isolate Sampling}

70 houses in the Louisville, Kentucky metropolitan area were sampled from June 2016-May 2017. Bathroom and kitchen sink drains were sampled using a sterile cell scraper. Samples from all 70 houses were collected in sterile 1X PBS and stored at $4 \mathrm{C}$. Samples were plated onto cetrimide agar [122] and incubated at $37 \mathrm{C}$ for $24-48$ hours. If growth was observed on the plate, colonies were isolated and species-specific PCR primers were used to identify those 
colonies that were $P$. aeruginosa [123].

For the first 12 houses, up to 13 clonal picks were performed for each drain sample to maximize likelihood of recovery. Based on results of this sampling, a standardized protocol was used in sampling of houses 13-70. In these latter houses, the minimum of all colonies on a plate or up to seven colonies were isolated and $P$. aeruginosa was identified using a species-specific PCR reaction [123].

Across all 70 houses, nine houses yielded a total of 105 isolates. All $P$. aeruginosa isolated ( 105 isolates in all) were stored in $20 \%$ glycerol at $-80 \mathrm{C}$. Of these, three isolates were randomly chosen from each of the two drain types (bathroom sink drain and kitchen sink drain) in all nine houses to be used in pairwise inhibition assays. This resulted in a total of $54 P$. aeruginosa isolates for the pairwise inhibition assays.

\section{Pairwise Inhibition Assays}

The 54 (three isolates $x$ two drain types $x$ nine houses) isolates were tested for ability to inhibit and resist inhibition in all pairwise combinations according to the protocol described by Fyfe et al. [124]. Each pair was assayed three independent times, for a total of 2916 tests of inhibition. Briefly, individual clones of the 54 isolates were picked and used to inoculate $4 \mathrm{~mL}$ of LB broth. Each culture was grown for about 18 hours at $28 \mathrm{C}$ with shaking at $250 \mathrm{rpm}$. After the initial incubation period, $10 \mathrm{~L}$ of this overnight culture was used to inoculate two tubes of $4 \mathrm{~mL}$ LB broth. Cultures were incubated with shaking at 28 
C for 2-3 hours. Pyocin production was then induced in one culture (the "producer" culture) using mitomycin C, a DNA damaging agent that has been shown to induce bacteriocin expression [52, 83], to a final concentration of 2 g/uL. The second, uninduced ("indicator") culture was also incubated alongside the producer culture.

After $16-18$ hours incubation at $28 \mathrm{C}, 5 \mathrm{~L}$ of the producer cultures were spotted onto LB plates and incubated for 6 hours at 28 C. $1.5 \mathrm{~mL}$ of chloroform was added to each plate to kill the producer colonies and plates were allowed to dry for 30 minutes. Producer colonies were killed prior to soft agar overlay to avoid the observation of inhibition due to a mechanism other than pyocin production, such as contact-dependent or secretion-mediated killing. In each experimental block, the indicator cultures were standardized to the lowest observed O.D.595 reading among the set of 54 . Once standardized in this way, $100 \mathrm{~L}$ of each indicator culture was used to inoculate $6 \mathrm{~mL}$ of soft agar, which was vortexed gently and poured over the agar surface of plates that had been spotted with killed producer cultures. Plates were left to incubate for 16-18 hours at $28 \mathrm{C}$. Zones of inhibition of the indicator isolates were identified by visual inspection. Cases of inhibition presented as either a clear, defined zone of inhibition (indicating R or F-type pyocin) or diffuse zone of inhibition (indicating Stype pyocin inhibition); both inhibition phenotypes were considered cases of inhibition for the purposes of data collection. 


\section{Genetic Distance}

Genomic DNA was extracted from isolates using $1 \mathrm{~mL}$ of overnight culture and Wizard Genomic DNA purification kit (Promega, Madison, WI, USA). Genetic distances were estimated using Illumina whole genome sequencing and ARIBA, [125] which was used to extract seven housekeeping genes (ascA, aroE, guaA, $\operatorname{trp} E$, mutL, nuoD, $p p s A$ ) used in a $\mathrm{P}$. aeruginosa multilocus sequence typing scheme developed by Curran et al. [126]. These genes were concatenated and pairwise genetic distances were calculated using only the seven housekeeping gene sequences and R package ape [127] on RStudio version 1.1.453 [128].

\section{Resource Competition}

The ability of the $54 P$. aeruginosa isolates to use 31 carbon sources was measured in triplicate using EcoPlates (Biolog, Hayward, CA, USA) and a protocol adapted from Schoustra et al. [120]. Cultures were grown overnight to stationary phase to a minimum O.D.595 of 0.8 . Cultures were diluted by adding 10 $\mathrm{L}$ of overnight culture to $10 \mathrm{~mL}$ of minimal salt media $\left(\mathrm{N}_{2} \mathrm{HPO}_{4} 6.8 \mathrm{~g}, \mathrm{KH}_{2} \mathrm{PO}_{4} 3\right.$ $\mathrm{g}, \mathrm{NaCl} 0.5 \mathrm{~g}, \mathrm{NH}_{4} \mathrm{Cl} 1 \mathrm{~g}, 1000 \mathrm{~mL} \mathrm{dH}{ }_{2}$ ). After a starvation period of two hours, plates were inoculated with $150 \mathrm{~L}$ of sample. The O.D.595 of all wells in the plate were measured immediately after inoculation $\left(T_{0}\right)$ and again after 48 hours of incubation at $28^{\circ} \mathrm{C}$. The absorbance measures from the 48-hour time point were used to calculate pairwise Bray-Curtis dissimilarity indices with $R$ package vegan [129]. 


\section{Statistical analysis}

To assess the differences in recovery from bathroom and kitchen sink drains, presence or absence of $P$. aeruginosa from each drain was analyzed using McNemar's test in the set of 58 houses, which were sampled using a standardized sampling technique.

Four generalized linear mixed models were performed with the SAS version 9.4 TS1M3 GLIMMIX procedure [130]. Models were run with LaPlace estimation and containment method of denominator degrees of freedom estimation. Self-on-self interactions were excluded from all analyses, as no inhibition was expected or observed in these controls. The results of the three replicate assays per pair were reduced to a dichotomous response variable, inhibition outcome by using the most common (2 out of 3 ) outcome when all three did not agree.

We examined the importance of spatial scale by running a generalized linear mixed model with inhibition as a binary response variable and spatial scale as a categorical predictor variable. House of isolation was not included in this model as a predictor variable because it is confounded with spatial scale, but was evaluated in all other models. This was done by including the house of the producer, the house of the indicator, as well as the interaction between the two as random effects. We also tested the effect of drain type by running a generalized linear mixed model with inhibition as a response variable and producer drain type, indicator drain type, and the interaction between the two terms included as fixed predictor variables. 
We explored the hump-shaped relationship between metabolic dissimilarity and inhibition by running a generalized linear mixed model with metabolic dissimilarity and the square of metabolic dissimilarity as predictor variables and call as the response variable. Similarly, we ran a generalized linear mixed model using genetic distance and the square of genetic distance as predictor variables and call on inhibition as the response variable.

\section{Results}

\section{$P$. aeruginosa is rarely found in multiple drains within a house}

The bathroom and kitchen sink drains of 70 houses were sampled in the Louisville KY Metropolitan area. 58 of these 70 houses were sampled using a standardized sampling protocol; this subset of houses was used for analysis of $P$. aeruginosa recovery. Of these 58 houses, 22 yielded $P$. aeruginosa from at least one drain with an overall recovery of roughly $37 \%$. $P$. aeruginosa was collected from the bathroom sink drain only in 11 houses (19\%), from the kitchen sink in only five houses (9\%), and from both the bathroom and kitchen sink drain in six houses (10\%). Despite slightly higher recovery from bathroom sink drains than from kitchen sink drains, this analysis identified no significant difference in recovery from the two drain types ( $p=0.21$, McNemar's Test).

\section{Inhibition varies across space}

We tested an isolate's ability to inhibit using an agar overlay method from a well-established protocol [124], which uses the DNA damaging agent 
mitomycin $\mathrm{C}$, to induce bacteriocin expression. Pairwise interactions were conducted, meaning that each isolate was examined as both a "producer" and as an "indicator." As a producer, an isolate was treated with mitomycin C and was tested for its ability to kill a non-induced strain, termed the indicator. Although the presence of pyocins was not directly confirmed during the inhibition assays, the presence of pyocin genes within the isolates used in these assays was confirmed comparison to the with BAGEL database [131](A.A.M., unpublished data). Additionally, zones of inhibition observed in the assays presented as diffuse or clear zones of inhibition, and did not present as plaques that would be expected if bacteriophage was responsible for killing. Previous studies have also repeatedly shown that an induction with mitomycin $\mathrm{C}$ is a reliable method to induce the expression of pyocin genes [52, 83]. Additionally, no cases selfinhibition were observed in the assays, suggesting that pyocins indeed were responsible for the zones of inhibition as each isolate should carry an immunity gene to its own toxin [132].

Self-on-self interactions, as expected, never resulted in inhibition (white squares, Fig. 4). Of the remaining 2862 pairwise interactions, overall, 944 (33\%) resulted in inhibition. The interactions in this study were observed across three spatial scales: within the same drain, between different drains in the same house, and across different houses. No inhibition was observed between isolates collected from the same drain (dark grey squares, Fig. 4). Inhibition was observed among isolates collected from different drains in the same house in three of nine houses (dark green squares). The majority of inhibition was 
observed among isolates collected from different houses (dark blue squares). A generalized linear mixed model assessing dependence of the outcome of the inhibition assay on spatial scale showed that as distance increased, there was a significantly higher probability of inhibition (Fig. 5, p<0.0001; Table 1).

We also examined patterns of pyocin inhibition and susceptibility among isolates collected across different houses through the inclusion of house as a predictor variable in generalized linear mixed models with metabolic and genetic distance. We found significant variability attributable to both the house of the producer and the house of the indicator. In other words, whether or not a producer is able to inhibit an indicator depends on the house of isolation for both interacting isolates (Fig. 4). Therefore, these results suggest that, in addition to scale, there is random stochasticity across space that contributes to diversity in pyocin phenotype. 


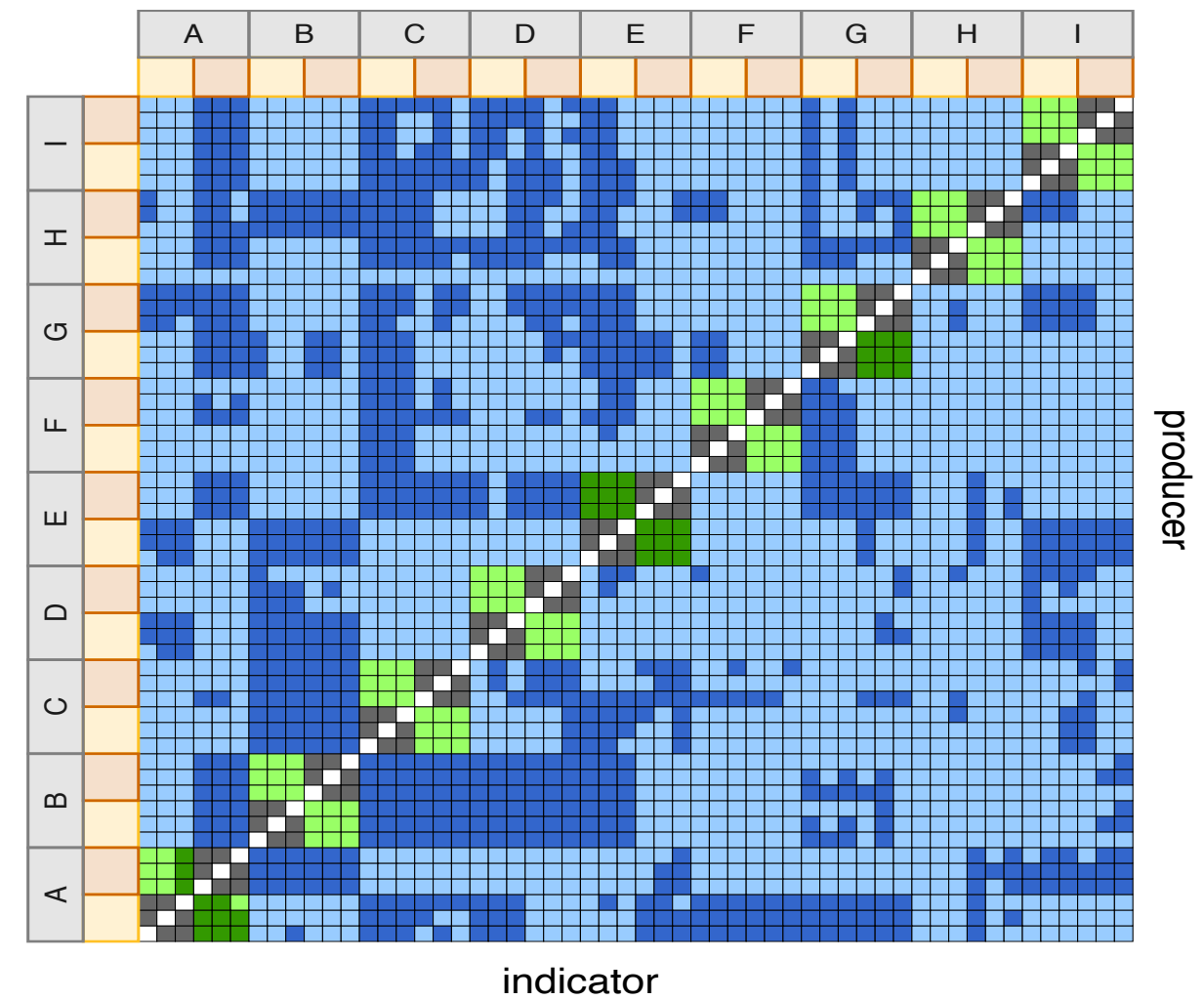

Figure 4. Pairwise inhibition assay outcomes. Light grey boxes with letters represent the nine houses from which bathroom and kitchen sink isolates were collected. Yellow and orange boxes represent isolates obtained from bathroom or kitchen sink drains, respectively. Pairwise interaction assay results were color coded based on a call on the outcome of inhibition, which was made if two out of three interactions resulted in inhibition. White squares represent no selfinhibition. Dark blue squares represent inhibition among isolates collected from different houses. Dark green squares represent inhibition among isolates collected from the same house and dark grey squares represent no inhibition observed among isolates collected from the same drain. Cases of non-inhibition across houses are indicated in light blue and cases of non-inhibition between drains of the same house are indicated in light green. 


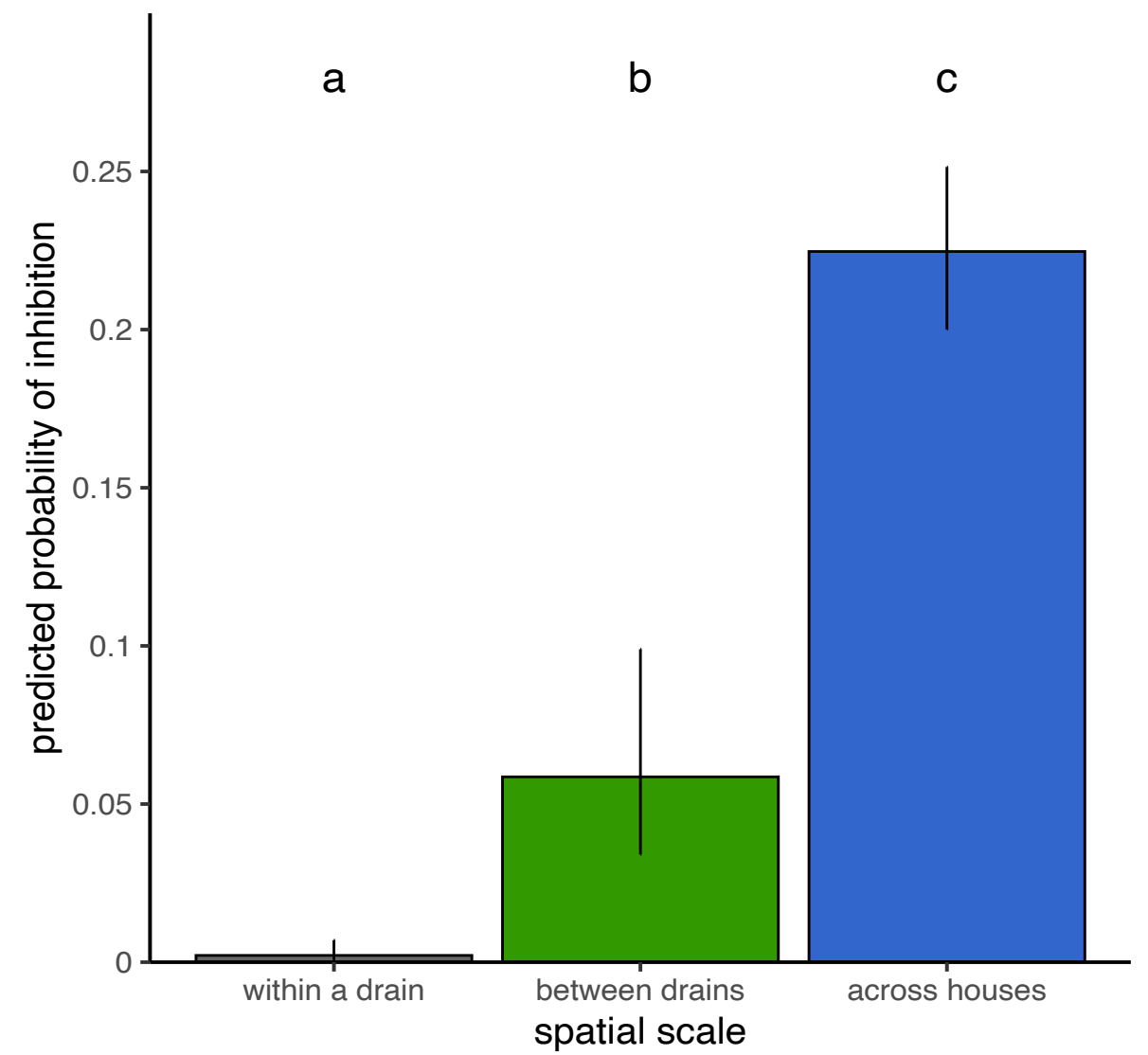

Figure 5. Predicted probability of inhibition when isolates are collected at different spatial scales. Least-squares means with $95 \%$ confidence intervals display the predicted probability of the producer isolate to inhibit the indicator isolate. Different letters indicate significant differences in means at alpha=0.05 after correcting for multiple comparisons using the Tukey-Kramer adjustment.

Table 1. Mean percentage of inhibition across scale. Scale Mean percentage of inhibition

Within a drain

Between drains

Across houses
0

$23.5 \%$

$34.9 \%$ 


\section{Inhibition varies with drain type}

Previous studies have shown that bathroom and kitchen sink drains often differ in their recovery of $P$. aeruginosa $[72,74]$. Based on these differences in recovery between drain types, we hypothesized that isolates collected from different drain types may differ with respect to their pyocin inhibition or susceptibility. To address this, pyocin inhibition was measured across two different household drain types: bathroom sink drains and kitchen sink drains. A generalized linear mixed model was run with producer drain type, indicator drain type, and the interaction between these two terms as fixed effects. We found that the inhibition observed was strongly affected by the particular combination of drain types from which the producer and indicator isolates were obtained (interaction effect, $p=0.05$ ). In particular, when indicators from kitchen sink drains were challenged with producers from bathroom sink drains, significantly less inhibition occurred in comparison to interactions between any other combination of isolation sources, and none of the other combinations resulted in differences in inhibition (Fig. 6). The detection of overall greater capacity to inhibit and greater resistance to being inhibited among kitchen sink isolates (producer main effect, $p=0.0248$, indicator main effect, $p=0.0026$ ) is likely driven by this single combination of drain types. 


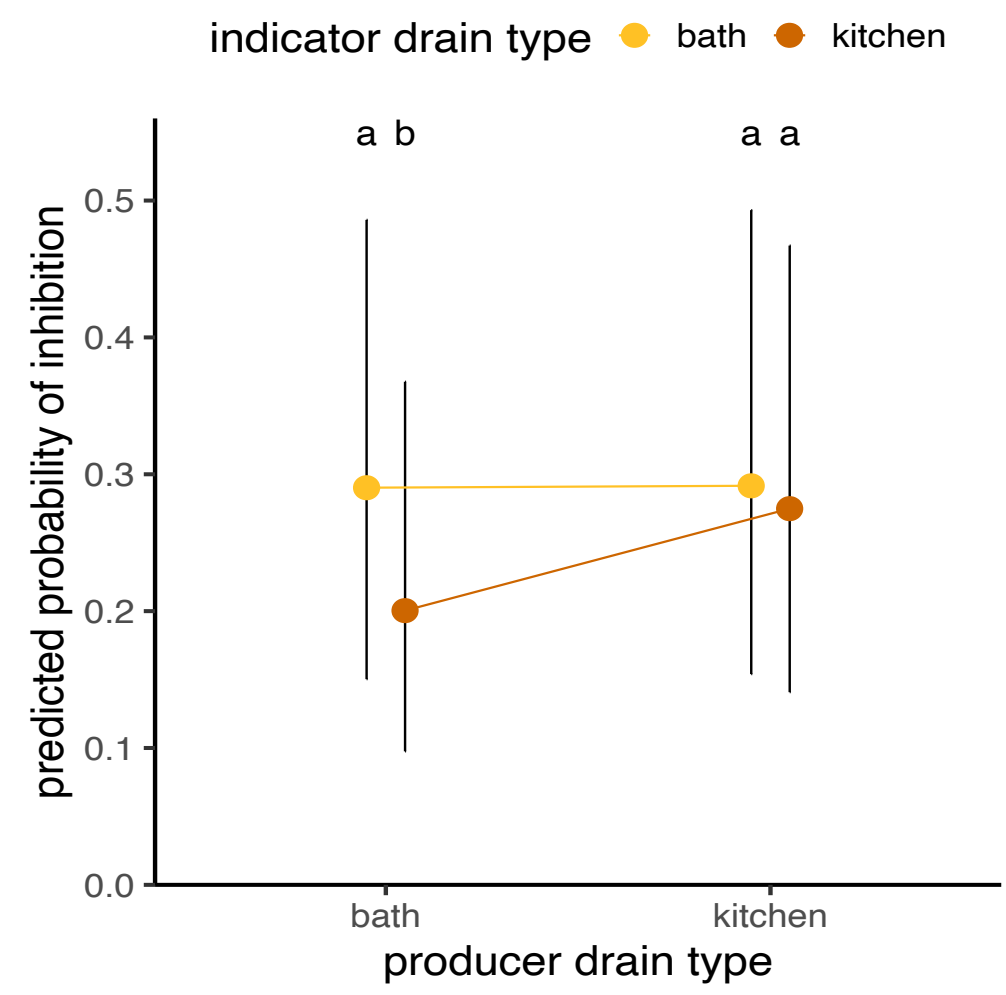

Figure 6. Predicted probability of inhibition within isolates collected from different drain types. Predicted probabilities of inhibition are least-squares means with 95\% confidence intervals. Different letters indicate significant differences in means at alpha $=0.05$ after correcting for multiple comparisons using the TukeyKramer adjustment.

\section{Metabolic dissimilarity does not predict inhibition}

To determine if metabolic dissimilarity is an important predictor of the outcome of inhibition, we measured resource use of 31 different carbon resources using EcoPlates (Biolog, Inc., Hayward, CA, USA) and calculated pairwise metabolic dissimilarities. We then ran a generalized linear mixed model with inhibition as the response variable and metabolic dissimilarity and the 
square of metabolic dissimilarity as predictor variables (Table 2). Neither metabolic dissimilarity nor its quadratic term was found to be significant in the model ( $p=0.4905$ and 0.7486 , respectively). Therefore, we found no evidence of a hump-shaped relationship between metabolic dissimilarity and inhibition. These results indicate that competition mediated by differential use of these common carbon sources may not play an important role in determining the outcomes of inhibitory interactions.

Table 2. Generalized linear mixed model testing the effect of metabolic dissimilarity and the square of metabolic dissimilarity as well as various random effects on the outcome of inhibition.

\begin{tabular}{lccc} 
Effect & Estimate & DF & Test Statistict \\
\hline Metabolic Dissimilarity & 2.5926 & 2515 & 0.48 \\
Metabolic Dissimilarity ${ }^{2}$ & 2.6765 & 2515 & 0.1 \\
Producer House & 0.2240 & 0.76 \\
Indicator House & 0.9343 & 1.47 \\
Draincomboordered & & \\
& 0.03819 & 0.1611 \\
Producer House*Indicator House & 2.4890 & \\
& & $3.89 * * *$ \\
+ Fixed effect is tested with an approximate F test. Random effects are tested using Wald Z tests. & \\
$* 0.01<\mathrm{p}<0.05$ & & \\
$* * 0.001<\mathrm{p}<0.01$ & & \\
$* * * \mathrm{p}<0.001$ & &
\end{tabular}

\section{Genetic distance has a hump-shaped relationship with inhibition}

To determine if genetic distance has a hump-shaped relationship with inhibition, we measured genetic distance using differences among isolates' 
sequences at seven housekeeping genes in the $P$. aeruginosa genome. We looked to see if inhibition occurs most frequently at an intermediate genetic distance by running a generalized linear mixed model with inhibition as the response variable and genetic distance and the square of genetic distance as the predictor variables (Table 3). This model identified a significant positive value for the parameter estimating the linear effect of genetic distance $(p<0.0001)$ and fit a negative parameter estimate for the effect of the square of genetic distance $(p=0.0006)$. These estimates model the predicted hump-shaped relationship for genetic distance and bacteriocin-mediated interactions in which these interactions are predicted to occur most frequently when two isolates are intermediately genetically related (Fig. 7).

Table 3. Generalized linear mixed model testing the effect of genetic distance and the square of genetic distance as well as various random effects on the outcome of inhibition.

\begin{tabular}{|c|c|c|c|}
\hline Effect & Estimate & DF & Test Statistic+ \\
\hline Genetic Distance & 308.18 & 1871 & $17.84 * * *$ \\
\hline Genetic Distance $^{2}$ & -17798 & 1871 & $11.97 * * *$ \\
\hline Producer House & 0.2110 & & . \\
\hline Indicator House & 0.9595 & & 1.40 \\
\hline Draincomboordered & 0.05152 & & . \\
\hline Producer House*Indicator House & 2.2006 & & $3.89^{* * *}$ \\
\hline $\begin{array}{l}+ \text { Fixed effect is tested with an approximate } \\
* 0.01<\mathrm{p}<0.05 \\
* * 0.001<\mathrm{p}<0.01 \\
* * * \mathrm{p}<0.001\end{array}$ & ndom effe & ed usir & \\
\hline
\end{tabular}




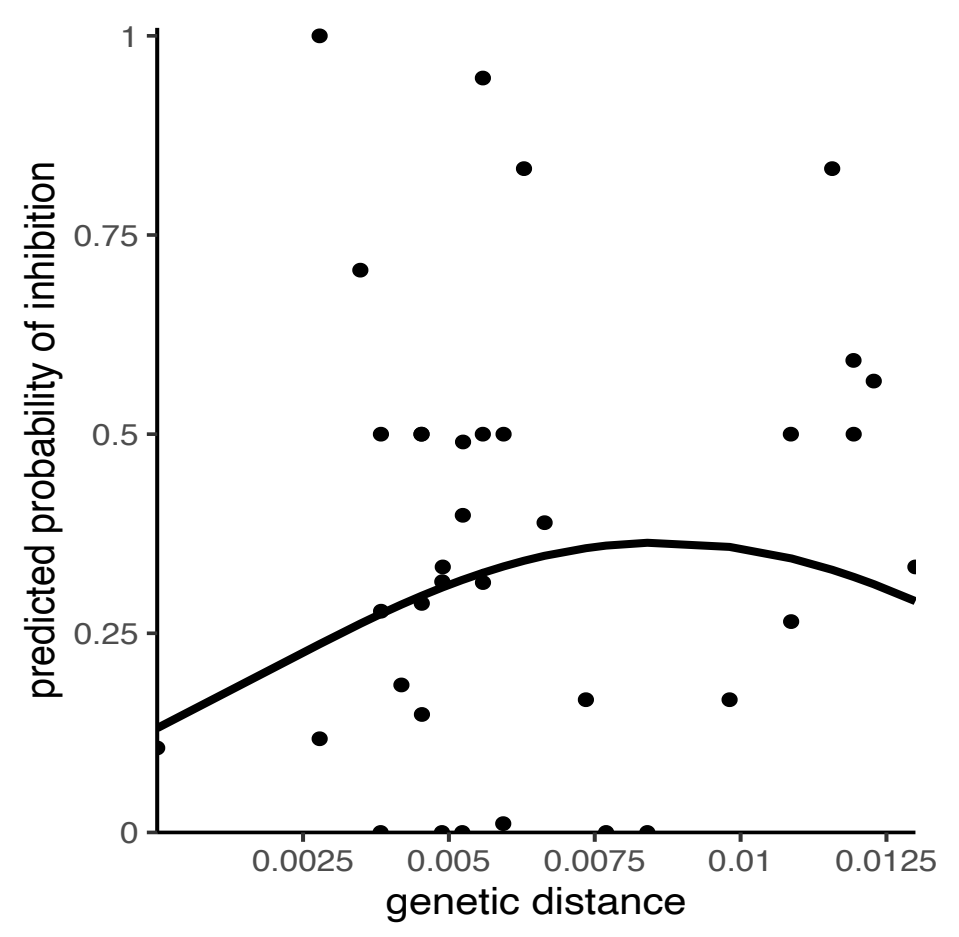

Figure 7. Predicted probability of inhibition with genetic distance. The line is plotted using estimates from the generalized linear mixed model run to examine the effect of genetic distance and the square of genetic distance on the outcome of inhibition. Points represent frequency of inhibition for each measure of genetic distance, calculated by averaging call on the outcome of inhibition among all interacting isolates of a particular genetic distance.

\section{Discussion}

\section{$P$. aeruginosa is not ubiquitous in household drains}

In this study, we found a greater percentage of drains containing $P$. aeruginosa than in previous sampling studies done by our group (37\% as opposed to 15 and $28 \%$ ) $[73,74]$. The sensitivity of detection of $P$. aeruginosa was expected to be higher than in similar studies, for two reasons. The culture- 
based sampling employed the more species-specific medium cetrimide rather than Pseudomonas Isolation Agar [122], and more isolates were collected per sample taken. However, despite our intensive sampling focused on the single type of site in the house where $P$. aeruginosa has previously been shown to most frequently inhabit, and despite higher recovery in this study from each drain type than in those previous studies, we found that the proportion of houses from which $P$. aeruginosa was recovered from both bath and kitchen sink drains was still relatively low (10\%). This suggests that, in addition to dispersal into the house, within-house forces such as dispersal limitation or selective differences between bathroom and kitchen sink drains limit the distribution of this species. This is notable in part because it runs counter to the traditional characterization of this species as a ubiquitous generalist $[62,133]$.

\section{Inhibition increases with scale and varies with house}

In our assays, we found that inhibition increases with the separation in the isolation sites of the producer and indicator (Fig. 2). This suggests that the selective pressure from pyocin producing isolates of $P$. aeruginosa may have eliminated diversity with respect to this phenotype at the within-drain level. Isolates within the same drain have either co-evolved as to not be susceptible to the particular pyocins being produced within a single drain, or pyocin sensitive isolates have been competitively excluded by producer isolates. In contrast, isolates taken from different houses that were less likely to have interacted, showed greater diversity in pyocin phenotypes, and were able to inhibit one 
another. The positive relationship among inhibition and increasing spatial scale is consistent with those of previous studies in Pseudomonas fluorescens and in species of the Xenhorhabdus genus [12, 57]. Although, this trend was not observed among soil pseudomonads by Kraemer et al. [14], the scale on which the isolates were collected in that study may have been too large to detect a relationship with inhibition. Unlike studies done in other Pseudomonas species and species in the Xenhorhabdus genus [12, 14, 57], we found a much higher frequency of inhibition among isolates overall, which is likely explained by the highly abundant production of pyocins in $P$. aeruginosa, and particularly in environmental isolates of $P$. aeruginosa $[51,55]$.

Previous studies have shown that spatial structure in microbial populations may lead to a decrease in local population diversity, but an increase in overall diversity across larger spatial scales $[12,14,57]$. In laboratory strains of Escherichia coli, it has been demonstrated that in unstructured environments such as a broth culture, bacteriocin production will lead to a decrease in diversity as one strain will competitively exclude the other. However, in a structured environment such as that of an agar plate, competitive interactions occur more locally, which allows for the coexistence of multiple bacteriocin phenotypes [34].

Similarly, Inglis et al. [54] also found that a pyocin producing strain of $P$. aeruginosa has increased fitness relative to a non-pyocin producer under conditions of local competition. This is because, when competition is localized, individuals that are genetically related to the bacteriocin producer are close by and are likely to benefit as bacteriocin production frees up resources. High rates 
of dispersal, however, will cause competition to occur more globally and bacteriocin production will provide less of a fitness benefit. Based on the results of our sampling study, it appears that $P$. aeruginosa dispersal among houses, and, to a lesser extent, within the houses, could potentially be limited. Moreover, even accounting for differences among drain type, metabolic similarity, and genetic distance, significant variability in pyocin phenotype was detected among $P$. aeruginosa isolated from different houses. This further supports our conclusion that dispersal limitations across different houses leads to the maintenance of diversity in inhibitory interactions. Further investigation into the relationship between highly patchy environments, like the built environment, and diversity in bacteriocin inhibition in this species and others is warranted.

\section{Local adaptation to drain type may influence inhibition}

Previous sampling studies have yielded varying results regarding the difference in $P$. aeruginosa recovery from bathroom and kitchen sink drains, with either greater recovery from bathroom drains $[72,74]$ or no differences detected $[71,73]$; our study showed a non-significant trend toward greater recovery in bathroom drains. In evaluating possible differences in the outcome of inhibition assays with respect to isolates' house drain types, we observed differences in the pyocin inhibition and sensitivity profiles. We found that inhibition assay outcomes depended on the drain types of interacting isolates. This suggests that local adaptation to drain type may be at play and responsible for differences in the competitive interactions among those isolates. 
While we have not explored the particular ecological differences between bathroom and kitchen sink drains, there may be both abiotic and biotic components of these drain types that could contribute to local adaptation of $P$. aeruginosa isolates. For example, there could be differences in available resources or in microbial community compositions, either of which could affect selection through competitive interactions among $P$. aeruginosa. Future studies in this area could work to clarify the differences in drain types with respect to both abiotic and biotic factors.

\section{Resource competition does not drive inhibition}

We looked for differences in resource use among isolates to test the prediction that resource dissimilarity may help predict inhibitory interactions [12, 14,120 ], but found no evidence of such a relationship. Schoustra et al. [120] observed the frequency of inhibition to peak at intermediate resource usage overlap among clinical and laboratory $P$. aeruginosa isolates. Differences between our results and that study could be due the fact that we used only environmental isolates, not clinical isolates and laboratory strains. Kraemer et al. [14] found metabolic dissimilarity to negatively correlate with frequency of inhibition, while Bruce et al. [12] similarly found that inhibition was significantly higher between isolates with greater niche overlap, suggesting that competition for shared resources may play an important role in the selection for and maintenance of bacteriocin production. This could occur if outcompeting other isolates with similar resource requirements through bacteriocin production 
liberated limited resources and provided the bacteriocin producing strain with a competitive advantage. The differences between the findings in our study and the outcomes of Bruce et al. [12] and Kraemer et al. [14] could be attributed to the fact that Kraemer et al. [14] were likely examining relationships among different Pseudomonas species rather than within one species, and Bruce et al. [12] calculated niche overlap as opposed to metabolic dissimilarity as we did. Although we detected no significant relationship between metabolic dissimilarity and pyocin inhibition profile, we note that there are many ways in which resource similarity could differ among isolates that would not be detectable in our assay, particularly in light of the known metabolic versatility of $P$. aeruginosa [62].

Additionally, the carbon resources in Biolog EcoPlates are biased toward plant-based carbon sources, which are likely different from the carbon sources available in sink drains. Future work addressing metabolic similarity could explore other resources over which competition might be occurring such as alternative carbon sources, nitrogen sources, and other bacterial nutritional requirements that might be more available to isolates in sink drains. It can also be noted here that Bara et al. [55] found that the ability to inhibit another isolate via pyocin production does not always predict overall competitive ability, so it is possible that pyocin inhibition does not play a critical role in competition and therefore is unrelated to resource use. As such, future investigation into the specific ecological functions of pyocins could further illuminate the maintenance of these antibiotics in microbial populations. 


\section{Inhibition is most favored at an intermediate genetic distance}

We examined the relationship between genetic distance and patterns of inhibition among the isolates in this study and found strong evidence to support a hump-shaped relationship. These results are consistent with the predicted humpshaped relationship that was observed by Schoustra et al. [120], though not with those of Hawlena et al. [57], Kraemer et al. [14] and Bruce et al. [12], which examined such relationships among more distantly related taxa and used different approaches to measuring genetic distance.

Because the measure of genetic distance that we used is based on sequence comparison of conserved housekeeping genes, it measures genetic similarity based on phylogenetic history, and is not mechanistically driven by selection on pyocin use. We know that bacteriocin production in $P$. aeruginosa, particularly in household isolates [55], is much more common than that of other Pseudomonas and bacterial species [51]. Thus, the hump-shaped relationship between this form of genetic distance and inhibition patterns could be caused by widespread use of pyocins and restricted movement in space, which shape the population genetic structure of this species. We note that other measures of genetic distance could reveal additional evolutionary dynamics affecting patterns of pyocin interactions. For example, a decline in killing at greater genetic distance can occur if more genetically distant bacteria lack the particular cell surface receptors required for bacteriocin binding $[95,105,132]$. Such patterns would be better detected using measures of genetic distance based on gene content or gene sequence of pyocin associated genes such as toxin, immunity, regulatory, 
and receptor synthesis genes. Use of such different genetic distance measures might not reveal the hump-shaped relationship that we detected with our measure.

\section{Conclusion}

In this study, we explored many potential driving forces of diversity in pyocin-mediated inhibition using isolates collected from spatially structured bathroom and kitchen sink drains across nine different houses. Differences in the outcome of inhibition among isolates from different drain types and among isolates differing in their genetic distance suggest roles for local adaptation and/or limited local dispersal, and a signature of phylogenetic history in maintaining pyocin diversity. However, we also found strong patterns indicating an important role for dispersal limitation at a landscape level in driving patterns of pyocin-mediated inhibition. When combined with competitive exclusion within a drain, dispersal limitation can explain an increase in inhibition with spatial scale and random house-to-house variation in patterns of inhibition. 
CHAPTER III

\section{GENETIC PATTERNS OF PYOCIN DIVERSITY IN HOUSEHOLD PSEUDOMONAS AERUGINOSA}

\section{Summary}

Bacteriocins are narrow-spectrum antibiotics, meaning that the killing capacities of these antimicrobials are typically restricted to the same species or closely related species. Pseudomonas aeruginosa, a Gram-negative opportunistic pathogen, is characterized by the diverse and abundant nature of putative bacteriocin genes found in this species, called pyocins in this system. Diversity in pyocin gene content has been reported in clinical isolates of $P$. aeruginosa, particularly in those isolated from individuals with Cystic Fibrosis (CF), but patterns of diversity in pyocin gene content, as well as the ecological and evolutionary underpinnings of these patterns, is not well-characterized in environmental isolates. Furthermore, it is unclear how pyocin genes contribute to outcomes of inhibition. We sequenced genomes of 46 isolates collected from bathroom and kitchen sink drains across eight houses and searched the genomes for 11 well-characterized pyocin genes. We previously examined pyocin inhibition among these isolates using pairwise inhibition assays. We found that isolates across houses differed primarily with respect to immunity 
genes while isolates collected from bathroom sink drains encoded significantly more pyocin genes than those collected from kitchen sink drains. We also found that isolates carrying immunity genes were less likely to be inhibited and that isolates carrying only R-type pyocin killing genes had the highest likelihood of inhibition. These findings suggest that current environmental conditions in different drain types and, to a lesser extent, spatial isolation across houses contribute to differences in pyocin gene content. Furthermore, while some patterns of inhibition can be related to pyocin genotypes in interacting isolates, there are likely more factors in this complex system contributing to these observed patterns including differential expression of pyocin genes and alternative mechanisms of resistance.

\section{Introduction}

Bacteriocins are highly-prevalent narrow-spectrum antibiotics, meaning that the killing capacities of these proteinaceous antimicrobials are typically restricted to the same species or closely related species [48]. The bacteriocins of Pseudomonas aeruginosa, called pyocins, are chromosomally encoded and can be distinguished from other bacteriocin systems due to the high abundance of pyocin genes in this species, as nearly all strains of $P$. aeruginosa carry genes for at least one pyocin. Additionally, these antimicrobials are highly diverse and composed of three types: S, R, and F. The S-type pyocins share homology to the system of bacteriocins in Escherichia coli in that these antimicrobials are composed of two genes: one gene encoding a protein responsible for killing activity and one gene encoding a protein that binds to an inactivates the killing 
protein, thus providing immunity for a producing cell as well as potential target cells $[80,86]$. S-type pyocins must bind to cell surface receptors and be translocated into a target cell for the killing activity to occur [103]. The receptors for many S-type pyocins are receptors for iron-binding molecules called siderophores [93-95, 102, 134]; in addition to the presence of a cognate immunity gene, it is thought that resistance to S-type pyocins may also come from receptor alteration such that the pyocins can no longer bind. While it is presumed that the immunity protein is needed for a producer cell to have protection against its own pyocin activity, previous studies have found many occurrences of "orphan" genes in which either killing or immunity genes are present singly $[55,88]$. Due to the presence of these so-called "orphan" genes, and in particular, those instances in which killing genes are present alone, it is unclear if pyocin immunity genes always provide immunity to a target cell and if immunity genes are essential for a cell to be resistant to an associated killing protein.

R-and F-type pyocins, collectively referred to as talocins, are ancestrally derived from bacteriophage; when produced, these pyocins are multi-subunit protein complexes that resemble headless phage tails [83]. Like the S-type pyocins, the talocins target specific receptors on the surface of a target cell; however, for the talocins, these receptors are lipopolysaccharides (LPS) [104, 105]. Unlike S-type pyocins, talocins act through pore formation, leading to membrane depolarization in a target cell. Talocins are not accompanied by immunity genes, and instead, resistance is mediated through receptor incompatibility due to differences in LPS composition. There are 5 R-subtypes 
(R1-R5) and 3 F-subtypes (F1-F3) that differ only with respect to tail fiber composition, which accounts for receptor specificity and, therefore, the killing spectra of these pyocins. The genes encoding R- and F-type pyocin structural proteins are located together in the $P$. aeruginosa genome between two genes: $\operatorname{trp} E$ (anthranilate synthase component I) and $\operatorname{trpG}$ (anthranilate synthase component II) in the genome. Within this region, there are genes, prtR and prt $N$, which encode regulatory proteins and are involved in the expression of pyocin genes [83]. PrtR is a protein that acts as a repressor for pyocin expression under normal conditions, and PrtN is a protein that serves as an activator of pyocin expression under stressful conditions such as those involving low nutrients or the presence of a mutagenic agent $[81,82]$. The S-type pyocins are located elsewhere in the genome, often near the tox $A$ gene (encoding exotoxin A) [89]; however, it is predicted that the expression of S-type pyocin genes is also regulated by the same system as that of $R$ and F-type pyocins [81]. Also located within the R/F gene cluster are a group of putative genes that are believed to encode lytic enzymes, which would enable cells producing pyocins to release these antibiotics in the presence of target cells [83].

Previous studies have found evidence that R-type pyocins may play a significant role in mediating the outcomes of inhibitory interactions in laboratory settings [135]. However, the vast majority of these studies focus on pyocinmediated interactions among clinical isolates and, because $P$ aeruginosa causes chronic lung infections in individuals with cystic fibrosis (CF) [60], the most commonly studied clinical isolates are derived from these infections. The 
contribution of R-type pyocins to the outcomes of inhibitory interactions in nonclinical isolates of $P$. aeruginosa has not been extensively investigated. We anticipate that the roles of R-type pyocins could differ from those previously reported based on phenotypic and genotypic differences in environmental and clinical isolates. Furthermore, it is also of interest to detect patterns of inhibition among isolates concurrently producing different combinations of pyocin killing genes, as this has not yet been investigated and should be of particular relevance because a large proportion of $P$. aeruginosa isolates have been found to carry multiple pyocin genes.

We sequenced 46 genomes from a collection of $P$. aeruginosa isolates derived from eight different spatially isolated households in the Louisville, KY metropolitan area and searched the genomes for pyocin genes. The spatial structure of the isolate collection allowed us to investigate the influences of historical processes such as dispersal limitations. Additionally, these isolates were collected from bathroom and kitchen sink drains, which provided a collection comprised of isolates likely experiencing different abiotic and biotic conditions, allowing us to explore the effects of contemporary conditions on pyocin diversity. The pyocin-mediated killing patterns were previously described [136]. The first aim of this study was to characterize overall diversity in pyocin gene content among isolates in our strain collection and to elucidate the mechanisms underlying this diversity. The second aim of this study was to uncover the relationship between pyocin genotype and the outcome of inhibitory interactions. We predicted that producer isolates carrying higher numbers of 
pyocin killing genes would have a higher likelihood of inhibition than isolates carrying fewer killing genes. We also hypothesized that indicator isolates carrying immunity genes would have a lower likelihood of being inhibited when compared to isolates that do not carry immunity genes.

We found that isolates from different houses differ primarily with respect to the total number of immunity genes found in each isolate, but do not significantly differ in the total number of all pyocin genes, suggesting a weak relationship between historical events and pyocin gene content. Isolates collected from bathroom sink drains encoded significantly more killing and immunity genes, indicating that the current conditions, either abiotic or biotic, may play an important role in shaping patterns of diversity in pyocin genetics. Finally, isolates with S-type immunity genes have a significantly lower probability of being inhibited by S-type killing proteins, and isolates producing only R-type pyocins exhibit the highest likelihood of inhibition than all other killing gene combinations. While pyocin genotype was found to be an important predictor in the outcome of inhibition, pyocin killing and immunity genes alone do not account for the variability in inhibitory interactions, and we hypothesize that other factors such as receptor specificity and gene expression further contribute to patterns of inhibition.

\section{Materials and Methods}

\section{Strain collection}

The bathroom and kitchen sink drains of 70 households in the Louisville, 
KY metropolitan area were sampled from June 2016-May 2017. The methods for sampling and $P$. aeruginosa identification were performed as described in a previous study [136]. Strains were maintained in LB unless otherwise noted. Pairwise inhibition assays were previously reported in [136].

\section{Pyocin inhibition assays}

Of the $105 P$. aeruginosa isolates, three isolates were randomly selected from each drain, resulting in a total number of 54 isolates used in the inhibition assay (nine houses $x$ two drains $x$ three isolates). Three biological replicates of a $54 \times 54$ pairwise inhibition assay were performed according to previously described methods [136].

\section{Genetic analyses}

Purified DNA was obtained from $P$. aeruginosa isolates grown overnight at $37^{\circ} \mathrm{C}$ in LB broth using the Wizard Genomic DNA Purification Kit (Promega, Madison, WI, USA). Paired-end Illumina sequencing was performed on 46 of the 54 isolates in our strain collection at the Roy J. Carver Biotechnology Center at the University of Illinois Urbana-Champaign on an Illumina MiSeq machine. Trimmomatic [137] was used to trim raw reads, and SPAdes [138] was used to assemble the genomes. Default settings were used for both trimming and assembly.

The website http://pseudomonas.com [139] was used to retrieve all putative pyocin gene sequences of interest in this study (Appendix, Tables 4 \& 
5). CLC Genomics Workbench (Qiagen, Germantown, MD, USA) was used to create a custom BLAST database of the genome assemblies in this study. A tblastx was performed to search for complete pyocin gene nucleotide sequences. Default settings for tblastx were used. The statistical significance threshold used was 10; the scores for a nucleotide match and penalty for a nucleotide mismatch were 1 and -2 , respectively. To confirm the accuracy of the BLAST results, publicly available genomes (Appendix, Tables $4 \& 5$ ) reported in the literature to harbor specific pyocin genes of interest were added to the custom BLAST database along with the genomes in our collection and served as reference genomes.

Genomes were screened for S-type pyocins S1, S2, S3, S5, and AP41 (Appendix, Table 4). To determine if an R or F-type pyocin was present in our genomes, the sequences of all annotated genes between $\operatorname{trp} E$ and $\operatorname{trp} G$ in the genome of PAO1 [62] (Appendix, Table 5), which is known to carry genes for both $R$ and $F$ type pyocins, were used as query sequences in BLAST searches of our genomes. R-type pyocin genes were considered present if an isolate was found to have nucleotide sequences annotated with the locus tags PA0616PA028, which are putative genes in PAO1 that encode for structural components of R-type pyocins. It should be noted that isolates carrying $\mathrm{R}$ pyocin genes differed at locus PA0621, which is logical as this gene is presumed to encode for tail fiber proteins, which vary across different R-type pyocin subtypes. F-type pyocin genes were considered present if an isolate was found to have nucleotide sequences annotated with the locus tags PA0632-PA040, which are putative 
genes in PAO1 that encode for structural components of F-type pyocins (Appendix, Fig. 8). Genes with the locus tags PA0643-PA0648 are believed to encode tail fiber proteins and, as such, sequences are variable in this region. Genes were considered present if the hits in our set of genomes mirrored those of the reference genomes, which have been reported in the literature to carry particular pyocin genes. For all genes considered present, the percent identity, which represents the percentage of identical residues between the query and hit sequence, was at least $94 \%$ and the sequence overlap, a percentage value for the overlap of the query sequence and hit sequence, was at least $80 \%$. If a gene was considered present, it was coded in the dataset as " 1 ," and if a gene was considered absent, it was coded as "0."

\section{Statistical analyses}

All analyses were performed in R Studio Version 1.3.959 [128]. R package emmeans [140] was used to calculate estimated marginal means from the generalized linear models.

Two generalized linear mixed models (GLMER) were used to assess the differences among houses with respect to the total number of pyocin genes encoded in each isolate. The total number of pyocin killing genes, immunity genes, and total number of genes (killing + immunity) were calculated for each isolate. The sum of pyocin genes was a categorical response variable, house was used as a categorical predictor variable, and drain type was included as a random effect. The model for the total number of immunity genes did not 
converge when drain type was included as a random effect so it was dropped from this analysis, and a generalized linear model (GLM) was used. The Poisson distribution was used in all of these analyses.

Three generalized linear mixed (GLMER) models were used to assess the differences among drain types (bath versus kitchen) with respect to the number of pyocin killing genes, immunity genes, or the total number of pyocin genes (killing + immunity). The sum of pyocin genes was a categorical response variable, drain type was a categorical predictor variable, and house was included as a random effect. The Poisson distribution was used in the analyses.

To assess whether the presence of an S-type immunity gene contributed to the outcome of inhibitory interactions among our isolates, we subset the data such that all inhibitory interactions included only cases in which the producer isolate carried a single S-type pyocin killing gene; this included isolates carrying an S1 killing gene and isolates carrying an S2 killing gene. None of the isolates in our study were found to encode a single S-type pyocin gene without also carrying talocin genes and, due to this, the producer isolates used in this dataset carried either S1 and R-type pyocin genes, S2 and F-type pyocin genes, or S2 with Rand F-type pyocin genes. A call was made on the outcome of inhibition based on the results of the triplicate assays performed. If at least two out of three interactions resulted in inhibition, then a call of inhibition was made and coded as "1." If one or no interactions resulted in inhibition, then a call of no inhibition was made and coded as "0." Self-on-self interactions were excluded from the analysis because, as expected, none of these interactions resulted in a case of inhibition. 
A generalized linear mixed model was run using call on the outcome of inhibition as a binary response variable with the presence or absence of an S1S2 immunity gene in the indicator isolate as a binary predictor variable, "1" meaning an S1S2 immunity gene was found to be present in the genome of the indicator and "0" meaning the gene was determined to be absent. House of the producer and house of the indicator were included as random effects in the model. The model would not converge when the interaction between these two random effects was included and, as such, the interaction was dropped from the analysis. Inclusion of drain type of the producer isolate or drain type of the indicator isolate did not significantly improve the fit of the model, and therefore, these terms were also dropped from the analysis. The binomial distribution was used in this analysis.

To investigate differences in inhibitory capacity among isolates carrying genes encoding different combinations of pyocins, we subset the data such that all inhibitory interactions included cases in which the indicator did not carry any S-type immunity genes (S1/S2, S3, S5, AP41) as we were only interested in the effect of killing gene combinations on the outcome of inhibition. First, to examine the relative contributions of each of the pyocin types $(S, R$, and $F)$ to the outcome of inhibition, we ran three generalized linear mixed models with call on the outcome of inhibition as a binary response variable and presence of at least one S-type pyocin gene, presence of an R-type pyocin gene, or presence of an Ftype pyocin gene as categorical predictor variables. House of the producer isolate and house of the indicator isolate were included as random effects. The 
binomial distribution was used in all three of these analyses.

Then, to assess the differences in inhibition capacity among isolates carrying combinations of pyocin killing genes, we created a variable that encompassed each of the seven pyocin killing gene combinations found in our isolate collection: R, S2-F, S1-R, S1-S5-R-F, S1-AP41-R, S2-R-F, and S3-R-F. T. A generalized linear model was run with call on the outcome of inhibition as a binary response variable and pyocin killing gene combination as a categorical predictor variable. Variables defining the house of the producer isolate and the house of the indicator isolate were included as random effects. The interaction between these two terms did now allow for convergence of the model so it was dropped from our analysis. Drain type of the producer and drain type of the indicator did not significantly contribute to the fit of the model, and therefore, these terms were dropped from the analysis. The binomial distribution was used in this analysis.

\section{Results}

We previously assembled a collection of $P$. aeruginosa isolates from spatially structured sink drains with three isolates from each bathroom drain, and three isolates from sink drains for each of the eight houses in the study. We used whole genome sequencing of these isolates to search for genes encoding with Stype pyocin and immunity proteins. The genomes of each isolate were also

probed for R- and F-type pyocins often found between the $\operatorname{trp} E$ and $\operatorname{trp} G$ genes in the $P$. aeruginosa genomes (Appendix, Fig. 8). Approximately half the isolates 
had seemingly intact R- and F-type pyocin loci, while the remaining $50 \%$ did not. All isolates were found to encode PrtR and PrtN, the repressor and activator, respectively, responsible for pyocin gene expression [81, 82]. With this summary of pyocin gene content, we sought to identify patterns of diversity based on these pyocin genotypes.

\section{Overall patterns of diversity in pyocin genotype}

We searched whole genome sequences of $46 P$. aeruginosa isolates in our study for complete nucleotide sequences of 11 currently described pyocin genes. Overall, the isolates in our collection were found to carry, on average, 2.67 pyocin genes with killing and immunity gene averages of 2.15 and 0.52 , respectively. We calculated the percentage of the isolates in our collection found to carry each gene (Fig. 9A). We then examined the complete pyocin genotype of each isolate with respect to the pyocin genes examined in this study including Stype pyocin killing and immunity genes as well as genes of the talocins, $R$ and $F$ (Fig. 9B). We found that all 46 isolates in this study carry at least one pyocin gene, with a large number $(76 \%$ or $35 / 46)$ carrying more than one gene. We found the R-type pyocin to be the most commonly found gene as it appeared in $63 \%(29 / 46)$ of our isolates, followed by the F-type pyocin, which was found in $56.5 \%(26 / 46)$ of our isolates. S2 pyocin, S1 pyocin, and S1/S2 immunity proteins were the next most commonly found pyocin genes with percentages of $43.5,32.6$, and 32.6 , respectively. In contrast, the rest of the pyocin killing and immunity genes (S3, S5, and AP41) were found at much smaller frequencies 
( $3 / 46$ or $6.5 \%$ for all). Overall, $82.6 \%(38 / 46)$ of the isolates carried at least one S-type pyocin, and all isolates (46/46) carried at least one talocin. We note that all strains carrying a gene encoding a S-type pyocin also carry a gene encoding the cognate immunity protein except for strains with genes bearing S2 pyocins.

We found seven unique gene combinations of pyocin killing and immunity genes (Fig. 9B). The highest percentage of strains carried genes encoding for the S2 and F-type pyocin (17/46 strains or $37 \%$ of isolates). This gene combination was followed by isolates encoding $\mathrm{S} 1$ pyocin, $\mathrm{S} 1 / \mathrm{S} 2$ immunity protein, and R-type pyocin (9/46 or 19.6\%) and isolates only encoding an R-type pyocin ( $8 / 46$ or $17.4 \%)$. The remaining pyocin genotypes were found in three of the 46 isolates in this study (6.5\%). Notably, while pyocins S1, AP41, S3, and S5 are always found along with their cognate immunity genes, the $\mathrm{S} 2$ pyocin never appears with its associated immunity protein, S1/S2 immunity protein. 

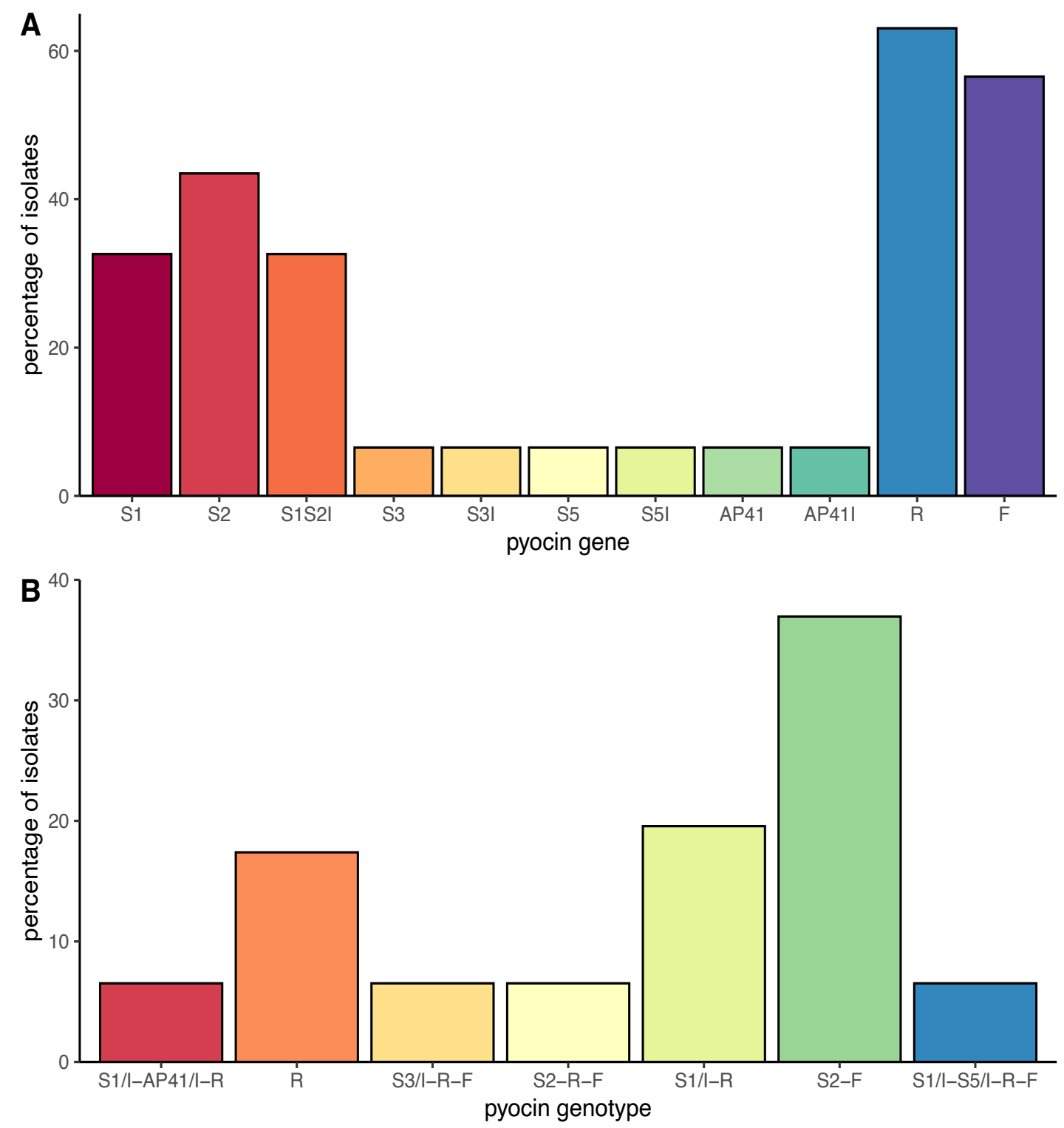

Figure 9. Diversity in pyocin gene (A) and genotype (B) among the isolates in our study. Percentages of isolates in our collection carrying each of the 11 pyocin genes $(A)$ and percentages of isolates in the study carrying each of the pyocin genotypes (B). S1S2I, S3I, S5I, and AP41I indicate immunity genes for the associated S-type pyocin gene (A) and S1/I, S3/I, AP41/I, and S5/I indicate that the associated immunity gene is present with the pyocin killing gene (B). 


\section{Spatial variability in pyocin genotypes}

To further understand whether the pyocin genotypes of our organisms differed across spatial scale, we compared the total number of pyocin genes or a subset of this, the killing genes, across the nine houses and two drain types. We found that isolates from different houses varied with respect to the number of immunity genes, but not in regard to the number of killing genes or total number of pyocin genes. We found isolates from houses $G, A$, and $H$ to encode the highest number of total pyocin genes with averages of 3.5 genes per isolate. These houses are followed by isolates from house $F$ ( 3 genes per isolate), house $\mathrm{E}$ (2.5 genes per isolate), houses $\mathrm{C}$ and $\mathrm{D}$ (2 genes per isolate), and house $\mathrm{B}$ with an average of 1 pyocin gene per isolate. Additionally, we found that all isolates within the same drain have identical pyocin genotypes for all the houses. Furthermore, in four homes (B, C, D, and F), all isolates in both bathroom and kitchen sink drains carry identical pyocin genotypes. However, isolates collected from houses $\mathrm{A}, \mathrm{G}$, and $\mathrm{H}$ display differences in pyocin genotype across drains. $\mathrm{A}$ general mixed linear model using "house" as a variable showed no significant differences among all houses with respect to total pyocin gene content $(p=0.076)$.

Isolates from houses $\mathrm{G}, \mathrm{A}, \mathrm{H}$ were found to carry the highest number of pyocin killing genes with a mean of $3,2,5$, and 2.5 killing genes per isolate, respectively, while houses C-F were found to carry an average of 2 killing genes per isolate (Fig. 10B). House B was found to carry the lowest number of pyocin killing genes per isolate with an average of 1 killing gene per isolate. Similar to the total number of pyocin genes, "house" was not significant with respect to the 
number of killing genes (Fig. 10B, $p=0.48$ )

Isolates from houses $\mathrm{B}, \mathrm{C}$, and $\mathrm{D}$ were not found to carry any known immunity genes, while isolates from house $A, F$, and $H$ were found to encode the highest number of pyocin immunity genes with a mean number of 1 gene per isolate. In contrast, isolates from house $E$ and $G$ were found to carry an average of 0.5 immunity genes per isolate (Fig. 10C). Unlike the total number of pyocin genes or just the killing genes, houses were significantly different in the number of pyocin immunity genes (Fig. 10C, $p=0.0018$ ).
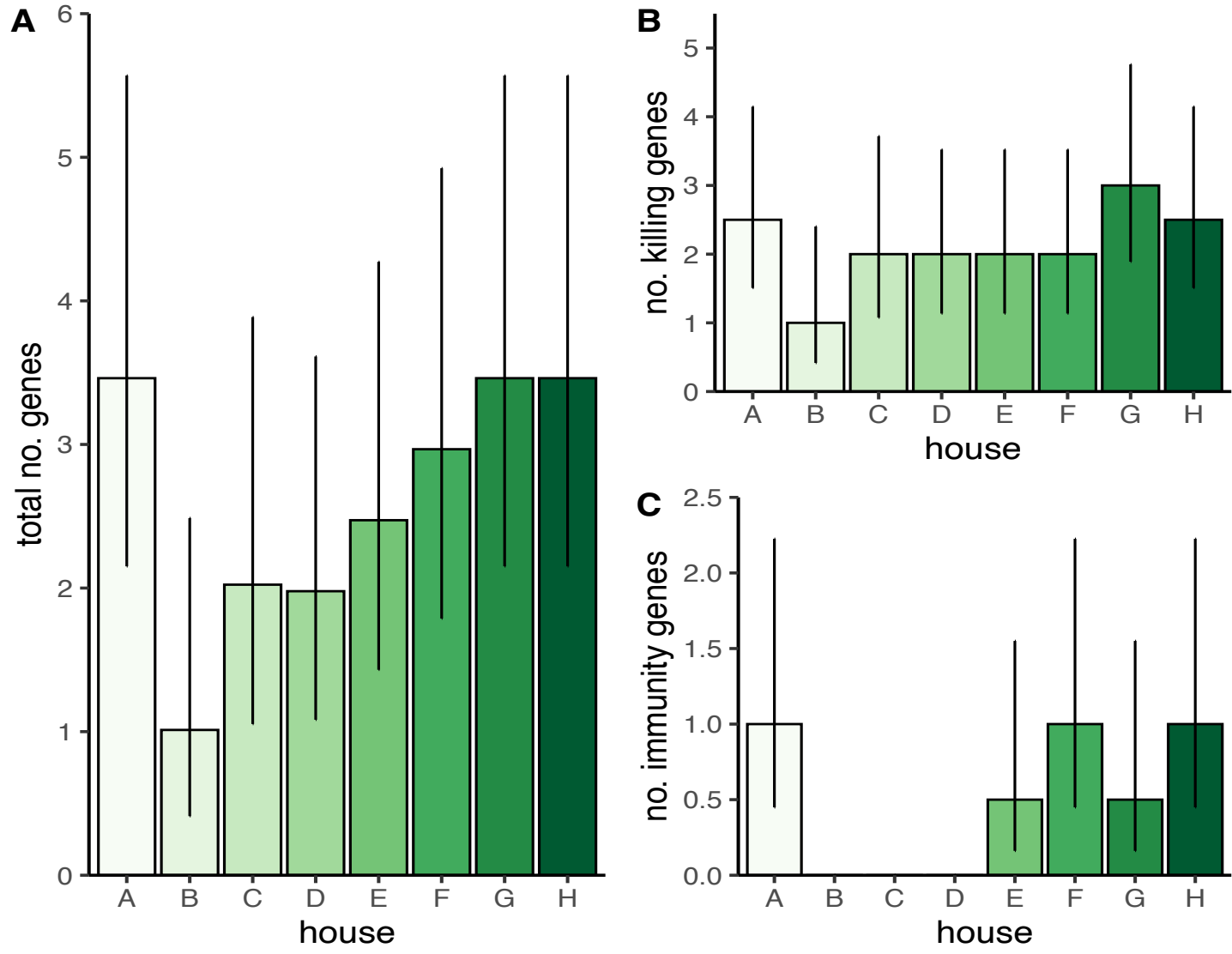

Figure 10. Mean number of total pyocin genes $(A)$, killing genes $(B)$, and immunity genes $(C)$ per isolate across the eight homes in this study. Mean number of genes are estimated marginal means with $95 \%$ confidence intervals. 


\section{Bathroom isolates encode more genes than kitchen isolates}

In previous studies, bathroom and kitchen sink drains were found to differ in the likelihood that each of these drain types were to yield $P$. aeruginosa [74]. Furthermore, in our previous study [17], we found slight differences in pyocin inhibition and susceptibility profiles between isolates collected from different drain types. We therefore hypothesized that isolates collected from different drain types would differ from one another in their pyocin gene content. We found that isolates collected from bathroom sink drains encode significantly more pyocin immunity genes and total number of pyocin genes compared to those collected from kitchen sink drains ( $p=0.0093$ and $p=0.02$, respectively) (Fig. 11A and $C$ ). Isolates from bathroom sink drains also carry more genes for pyocin killing genes than those from kitchen sink drains (Fig. 11B), but these differences are not significant $(p=0.181)$. Isolates from bathroom sink drains encode an average of roughly 2.5 killing genes, 0.6 immunity genes, and 3.2 total pyocin genes per isolate. Isolates from kitchen sink drains carry an average of 1.9 killing genes, 0.19 immunity genes, and roughly 2.1 total pyocin genes per isolate. These results suggest that both drain type and house of origin appear to contribute to pyocin genotype selection. Next, we sought to determine if the presence of genes or combination of genes correlates with these isolates ability to kill other $P$. aeruginosa isolates. 

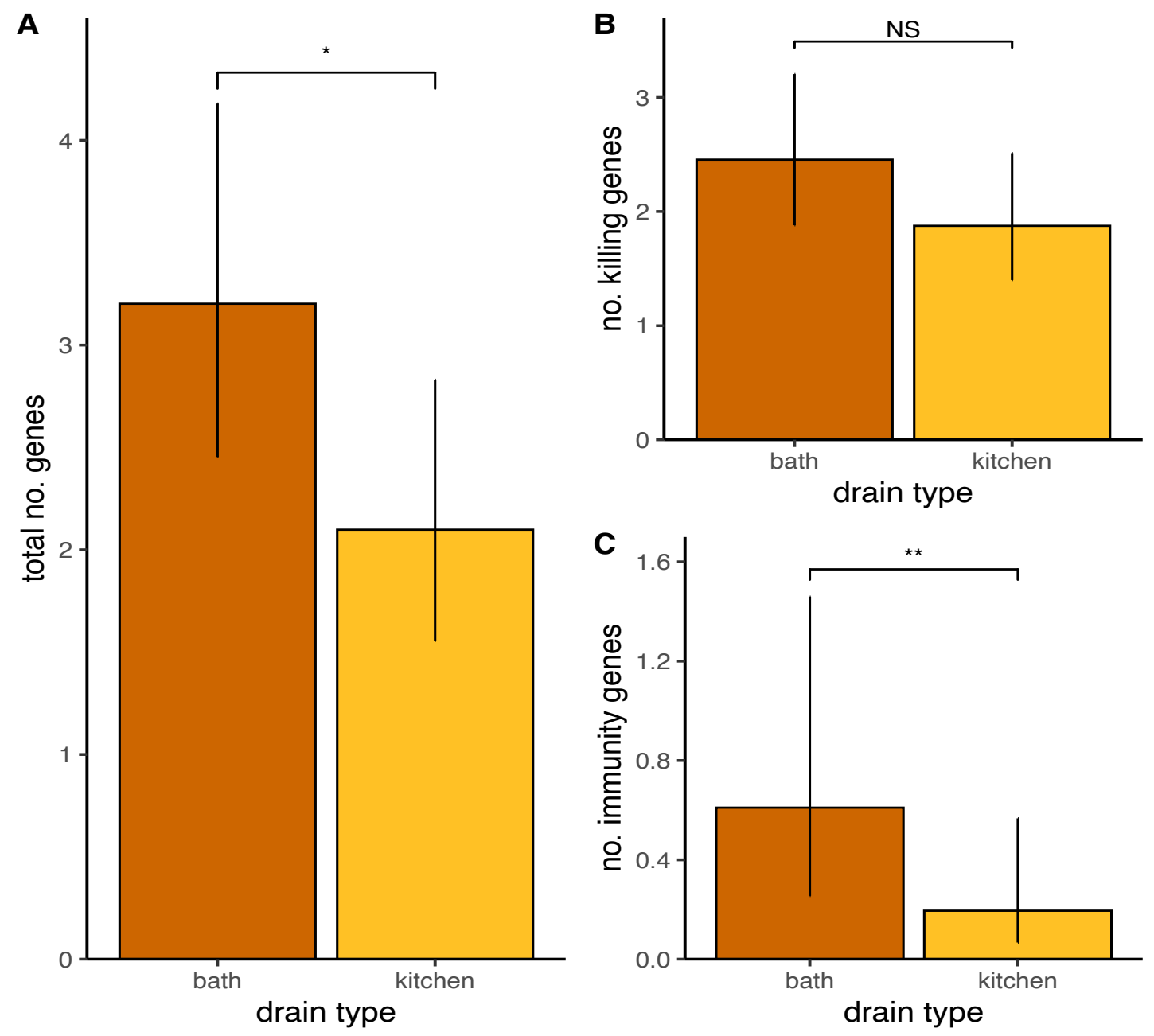

Figure 11. Mean number of total pyocin genes $(A)$, killing genes $(B)$, and immunity genes per isolate across bathroom and kitchen sink drains. Mean number of genes are estimated marginal means with $95 \%$ confidence intervals. ${ }^{*} 0.01<p<0.05 ;{ }^{* *} 0.001<p<0.01$.

Relationship between pyocin genotype and the ability to kill other $P$. aeruginosa isolates

We have previously reported on the interaction between these $P$. aeruginosa isolates and their ability to kill other isolates in our collection [17]. To 
assess whether one type of pyocin is more potent than others, we calculated the likelihood of inhibition for strains containing S-, R-, and F-type pyocins. As shown in Figure 12B, strains bearing genes encoding R-type pyocins are more likely to inhibit other strains. However, this experiment may be biased as strains often bear two or more pyocin genes. Because of this, all individual pyocin genotypes were then compared. To eliminate the role of immunity proteins in this analysis, all interactions in which indicator isolates carried genes encoding immunity proteins were excluded. Overall, pyocin killing gene combination significantly affected the outcome of inhibitory interactions $(p<0.001)$. We found that isolates carrying only an R-type pyocin exhibited the highest predicted probability of inhibition with a probability of 0.65 (Fig. 13). This was followed by the genotypes S1-R, S3-R-F, and S2-R-F with predicted probabilities of 0.59, 0.53 , and 0.47 , respectively. Pyocin killing gene genotypes with the lowest predicted probabilities of inhibition were S1-S5-R-F, S1-AP41-R, and S2-F (predicted probabilities of $0.4,0.4$, and 0.18 , respectively).

Finally, the roles of immunity proteins in $P$. aeruginosa interactions were examined. We assessed whether the presence of an S-immunity gene in a strain protected that isolate from inhibition by a producer carrying an S1 or S2 killing gene. The predicted probability of inhibition was significantly higher for isolates that were not found to carry the S1/S2 immunity gene when compared to those isolates that did carry the immunity gene (Fig. 14, $p=0.035)$. 

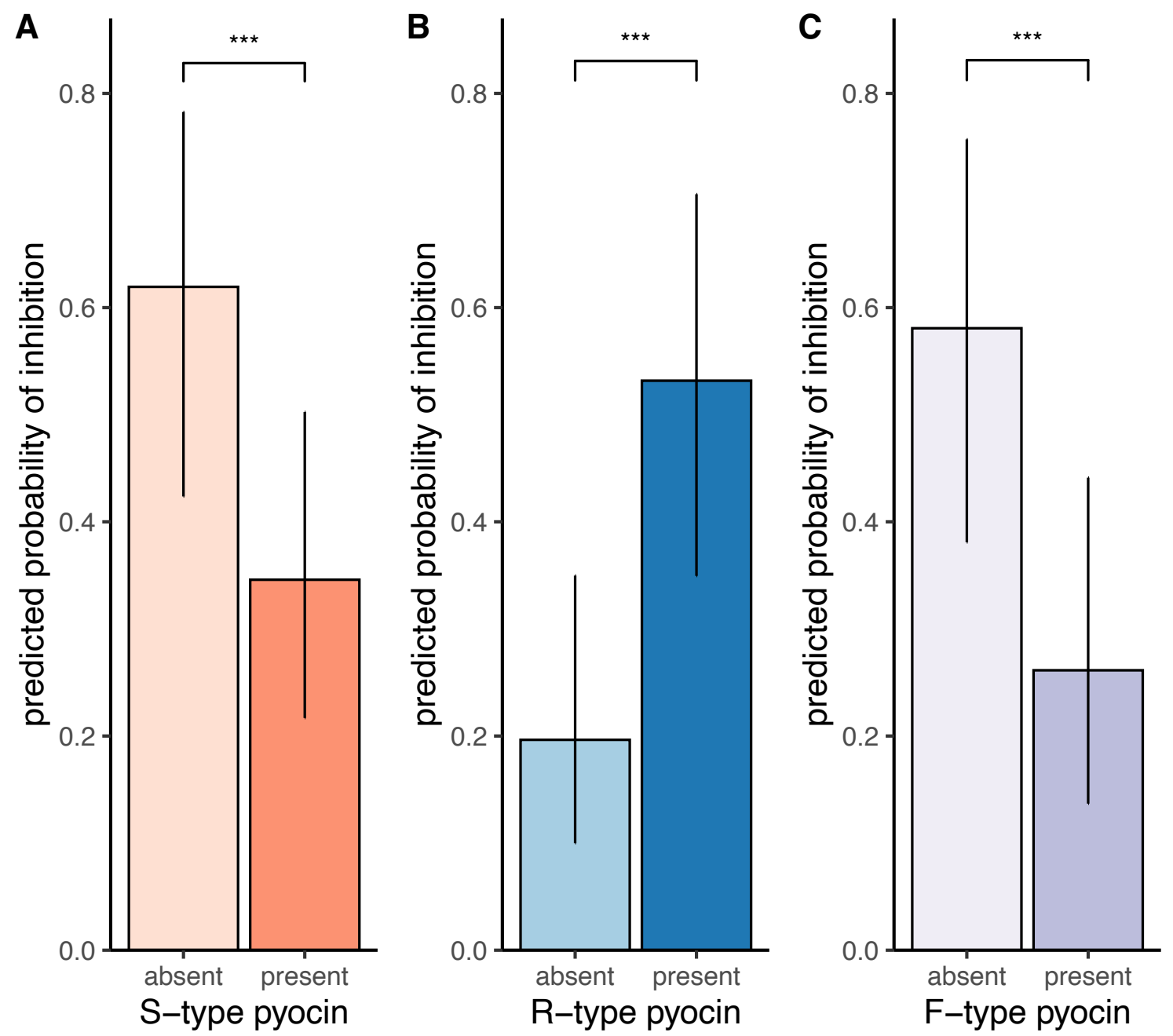

Figure 12. Predicted probability of inhibition when a producer isolate carries a gene for at least one S-type pyocin (A), an R-type pyocin (B), or an F-type pyocin (C). Error bars represent $95 \%$ confidence intervals. ${ }^{* *} p<0.001$. 


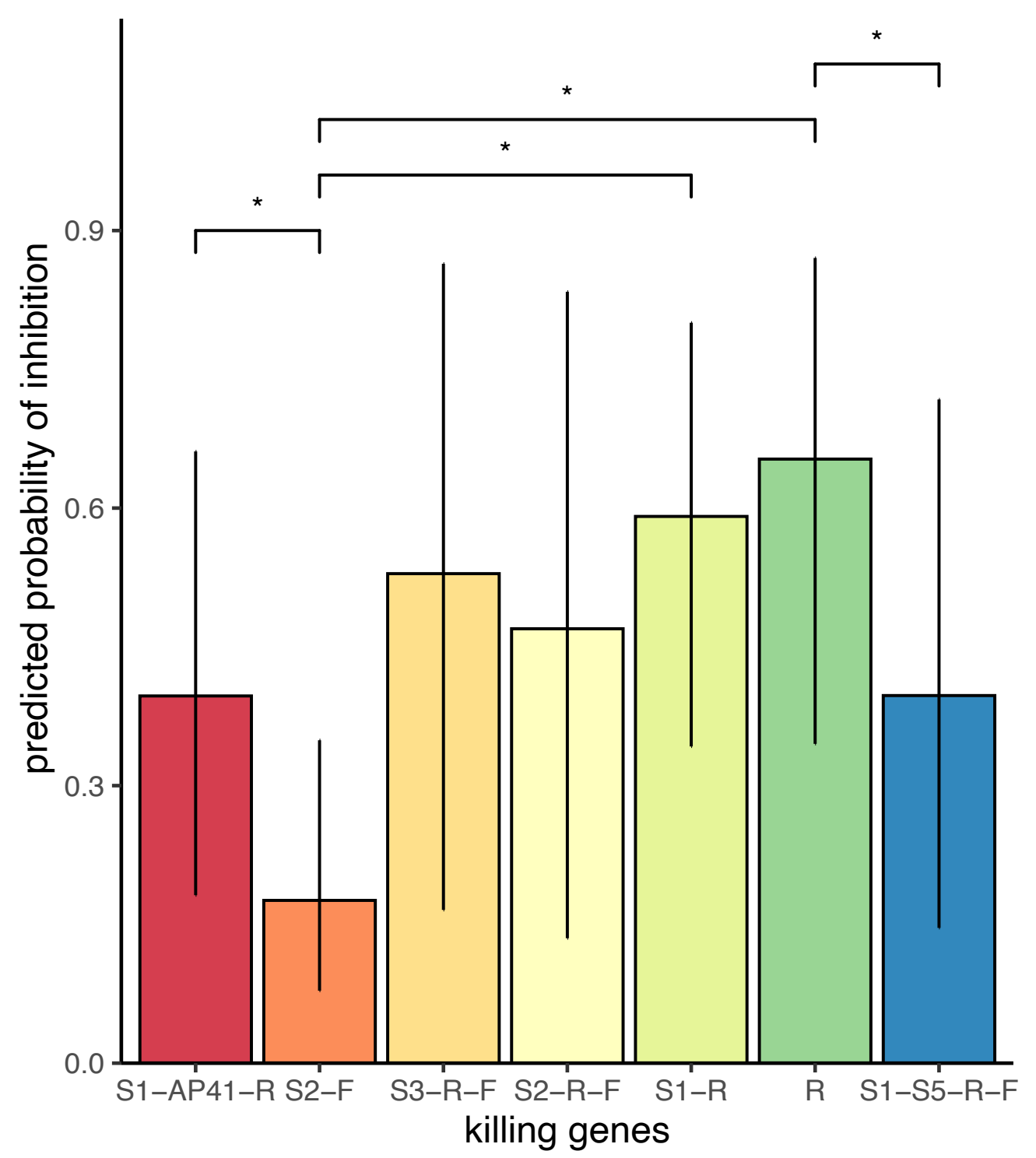

Figure 13. Predicted probability of inhibition among different combinations of killing genes in the producer isolate and when there are no immunity genes present in the indicator isolate. Predicted probabilities of inhibition are estimated marginal means with $95 \%$ confidence intervals. Tukey's test for multiple comparisons was performed at alpha $=0.05 .{ }^{*} 0.01<p<0.05$. 


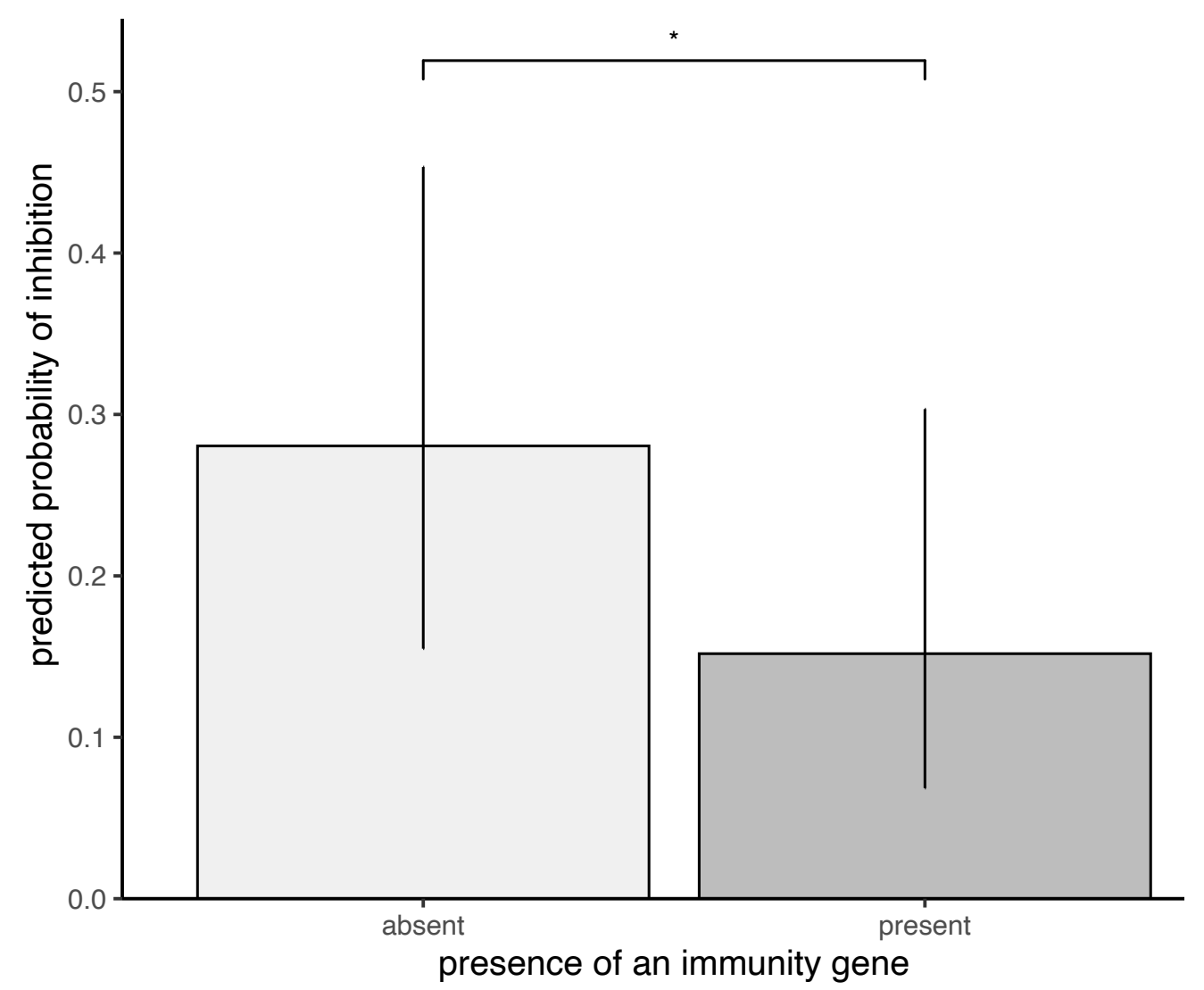

Figure 14. Predicted probability of inhibition when an immunity gene is present or absent in the indicator isolate. Predicted probabilities are estimated marginal means with $95 \%$ confidence intervals. ${ }^{*} 0.01<p<0.05$.

\section{Discussion}

\section{Pyocin genotype diversity in environmental isolates}

We found that all 46 isolates in our collection encode genes for at least one type of pyocin. These results are consistent with the findings of other studies, particularly those of Olubukola et al. [135], who similarly found that all 24 of the CF isolates in their collection encoded genes for least one type of pyocin, signifying the extremely high abundance of these narrow-spectrum antibiotics in clinical isolates of $P$. aeruginosa. However, the prevalence of particular pyocin 
types in our study varies slightly from previous findings. Similar to our results, Snopkova et al. [141] found some of the most commonly encoded pyocin genes to be that of $\mathrm{R}$ and $\mathrm{S} 2$, which were present in their strains at $67 \%$ and $67.4 \%$, respectively, and were present in our strains at $63 \%$ and $43.5 \%$. We found that all of our isolates carried genes for at least one talocin, while $81.4 \%$ carried genes for at least one S-type pyocin. Snopkova et al. [141] found S-type pyocins in a greater abundance at $93 \%$, and talocins were found at a lower abundance of $80 \%$.

Similarly, Ghoul et al. [88] found S-type pyocins present at a rate of $98 \%$ and Bakaal et al. [50] found these soluble pyocins present at a rate of 95\%. Bara et al. [55] observed that over $50 \%$ of the isolates in their study lacked genes for S-type pyocins. The pyocin genotypes observed in our isolate collection vary from those of other studies as we appeared to have far less unique pyocins in comparison to that of Bara \& Remold [55], who found the isolates in their study to encode 41 unique pyocin gene combinations across the 116 isolates used in their study, and Snopkova et al. [141], who observed 53 unique pyocin genotypes in the 135 isolates used in their study. We found only seven unique genotypes in the 46 isolates examined in our study.

The observation that our isolate collection differs from other studies in the prevalence of particular pyocin genes and overall diversity in pyocin genotype could exist because the origins of our strain collection are different from those of other studies. Studies done by Snopkova et al. [141], Ghoul et al. [88], and Bakaal et al. [50] involved the use of clinical strains derived from catheter 
infections, lung infections in individuals with $\mathrm{CF}$, or non-CF isolates derived from other human infections such as those in burns. The study done by Bara et al. [55], which included environmental and CF-associated isolates, determined that environmental isolates differed from those derived from individuals with CF in terms of both pyocin phenotype and genotype. As such, it is possible that the pyocin gene content differences between our study and others of could be the result of differences in the environment of isolation. Another potential source of variation could be in sampling bias. Our collection has isolates from nine houses. If more houses had been sampled, it is possible that more genotypes would have been detected.

Environmental and clinical isolates may differ in pyocin gene content due to the potential role that pyocins play in mediating the outcome of competitive interactions during initial infection. If the presumption that initially infecting strains are environmental in nature is correct, the strains that are most likely to outcompete and remain in the host environment may be able to do so due to a competitive advantage provided by an abundance and diversity of pyocin genes. Alternatively, isolates carrying fewer pyocin genes may have a competitive advantage as they do not incur the cost of carrying and producing these antimicrobials. It could also be that pyocin genes are pleiotropically linked to other virulence factors that are important for initial colonization and persistence in the host environment. Snopkova et al. [141] found a number of strong positive and negative co-associations between pyocin genes and virulence genes, suggesting a relationship between pyocin gene content and the ability to cause 
infection. For example, they found the presence of pyocin AP41 to have a strong positive association with overall antibiotic resistance; however, other studies have shown that the presence of the R/F pyocin gene cluster may increase susceptibility to fluoroquinolones due to induction of the lytic system [142]. If certain pyocin genes and virulence factors are pleiotropically linked, it could be that certain pyocin genes are passively selected for or against along with genes that play an important role in initial host colonization or persistence in the host environment. More work is needed in examining the functional role that pyocin production may play when isolates are initially colonizing the host environment and if these genes continue to play an important role in allowing an isolate to persist in the host environment or if these genes may only be passively selected for during host colonization and subsequent adaptation.

Lastly, we found very distinct patterns in the S-type pyocin gene pairs in our isolates as pyocins S1, S3, S5, and AP41 are always encoded in isolates along with their cognate immunity protein. However, in our isolate collection, pyocin $\mathrm{S} 2$ is never accompanied by an immunity protein. The presence of socalled "orphan" pyocin genes has been commonly identified across studies and encompasses both orphan immunity genes in which an immunity gene is found without its cognate killing gene and orphan killing genes in which killing genes are present without an immunity gene $[55,88]$. Our findings of only orphan killing genes in pyocin $\mathrm{S} 2$ is difficult to interpret, as these immunity genes are presumed to protect a producing cell so that a producer can be immune to its own pyocin killing protein. There could be novel genes encoding immunity to the $\mathrm{S} 2$ pyocin 
that have yet to be discovered. Towards this, in our inhibition assays, we never observed self-on-self inhibition, meaning that no isolate was able to inhibit itself via pyocin production, which suggests that resistance to pyocins may be more complex than previously thought and mediated not only through the presence of immunity proteins, but potentially also through other mechanisms, perhaps related to cell surface receptors or secondary immunity genes. More work is needed to elucidate the mechanisms underlying the ability of the pyocin killing gene to exist singly without an immunity gene, perhaps due to alternative mechanisms of immunity.

\section{Spatial isolation contributes to patterns of pyocin gene content}

We examined differences in pyocin genotypes from isolates collected from different homes and found that the genomes of these isolates were most likely to differ in the number of pyocin immunity genes. The diversity in the number of pyocin-encoding genes among isolates collected from different houses as well as the limited diversity within drains and, to an extent, within homes is reasonable based on our phenotypic observations of these isolates in laboratory inhibition assays. We found a significant effect of house of the outcome of inhibitory interactions as well as differences in both inhibition and susceptibility profile among isolates from different houses [17]. Additionally, we found that isolates from different houses were most likely to inhibit one another, followed by isolates from different drains in the same house, and isolates from the same drain never inhibited one another. Taken together, these pyocin phenotypic and genotypic 
observations confirm our conclusions from our previous study that historical processes such as dispersal limitations across houses and, in some cases, across drains within houses, contribute to the phenotypic patterns of pyocin diversity observed in our strain collection [17]. However, without more information on each of the houses in the sampling studying, we cannot rule out the potential for contemporary abiotic or biotic conditions to play a role in contributing to pyocin genotype or phenotype of the isolates in our study. Conditions such as inputs into the drains, amount of water flow, cleaning habits, and characteristics of the inhabitants of a home are contemporary processes that could impact the drain populations of $P$. aeruginosa. More information on the environment of isolation is needed to distinguish between the relative importance of historical processes and current conditions in shaping patterns of pyocin diversity.

\section{Current environmental conditions contribute to pyocin gene content}

We examined pyocin gene content from isolates collected from different drain types (bathroom and kitchen sink drains) and found that isolates derived from bathroom sink drains encoded significantly more pyocin killing and immunity genes when compared to those collected from kitchen sink drains. These results are interesting because, in our previous study, we observed that bathroom sink drain isolates were significantly less likely to inhibit kitchen sink drain isolates [17]. However, based on our findings in this study and others [55], the total number of pyocin genes does not appear to accurately predict the outcome of pyocin-mediated interactions in laboratory settings. We propose that this is due 
to the extreme complexity of pyocin genetics as it involves not only killing and immunity genes, but also an intricate regulatory system as well as receptor variability that most certainly could account for a particular isolates likelihood of being killing by a particular pyocin [80]. Furthermore, it could be that the number of pyocin genes is not an important predictor in the outcome of inhibition, and instead, the particular killing genes an isolate is carrying may indicate whether or not it is more likely to inhibit when compared to other isolates.

Additionally, these findings indicate that, even across homes, isolates collected from different sink drain types differ with respect to their pyocin genotype. These findings suggest that there are factors, either abiotic or biotic, contributing to differences in pyocin gene content in isolates collected from different sink drains. Analyses of bacterial community composition in bathroom and kitchen sink drains in our group have indicated that sink drain types differ from one another and kitchen sink drains appear to have overall higher bacterial diversity when compared to bathroom sink drains (A.A.M, unpublished data). It is possible that the biological differences in drain types could account for the differences observed in pyocin genotypes. If $P$. aeruginosa isolates face more diverse competitors within the kitchen sink drain environment, producing a higher number of pyocin genes may not provide a competitive benefit due to the costly nature of carrying and releasing these antimicrobials [80, 82]. Furthermore, as bacteriocins are primarily thought to mediate intraspecific interactions, pyocin production may not be beneficial if the bacterial community is highly diverse and composed of members of distant taxa. There could also be differences in abiotic 
factors between drain types such as resource availability and frequency of use. More work would be needed in characterizing specific abiotic and biotic differences in drain types to elucidate the mechanisms driving differences in pyocin gene content observed among isolates collected from bathroom and kitchen sink drains.

\section{Isolates carrying only R-type pyocins are most likely to inhibit}

While several previous studies have focused on pyocin genotype diversity and overall abundance of pyocin genes in $P$. aeruginosa populations, few studies have investigated the extent to which different pyocin killing genes and combinations of killing genes contribute to the outcome of inhibitory interactions. We investigated the differences in the probability of inhibition for seven different pyocin killing gene genotypes in interactions in which the indicator isolates carry no immunity genes to S-type pyocins. We found producer isolates carrying genes encoding for an R-type pyocin to have the highest probability of inhibition, while isolates carrying genes for S2 and F-type pyocins to have the lowest likelihood of inhibition in our study (Fig. 13).

Our finding that isolates carrying genes encoding for an R-type pyocin had the highest predicted probability of inhibition are reasonable in the context of a study done by Oluyombo et al. [135] in which R-type pyocins were found to play a significant role in the outcome of inhibitory interactions among CF isolates of $P$. aeruginosa; R-pyocin deletion mutants were observed to lose the capacity for inhibition when compared to their R-pyocin carrying counterparts. These 
observations were consistent across both planktonic cultures and growth in a biofilm. Furthermore, when an R-sensitive strain was grown in a biofilm and treated with purified R-type pyocin, a significant decrease in the number of viable cells was observed. Similar conclusions have been drawn in other studies in which R-type pyocins appear to significantly contribute to inhibitory interactions in clinical isolates of $P$. aeruginosa $[50,143]$. This could be due to the relative high potency of R-type pyocins when compared to other types of pyocins; it has been shown that a single molecule of an R-pyocin can kill a sensitive cell whereas 100-200 F-pyocin molecules and as many as 300 S2 pyocin molecules are needed to inhibit a competitor [114, 144, 145]. Furthermore, induction of R-type pyocin genes can result in the production of 200 pyocin molecules per cell [146]. Interestingly, however, when an R-type pyocin is present with other killing genes such as an S-type pyocin (S1, S5, AP41, S3) and an F-type pyocin, the predicted probability of killing decreases. These findings are somewhat counterintuitive as it might be logical that a higher number of pyocin killing genes would provide a producer with the ability to inhibit a higher number of isolates. One explanation of this observation could relate to differential gene expression of pyocin killing genes. Numerous studies have confirmed that all pyocin killing and immunity genes are regulated in the same RecA-mediated manner; however, it has not yet been investigated if pyocin genes will be differentially expressed when they are present in combination with one another compared to when they are present singly in a producing cell. It is possible that we observed the highest rate of inhibition in isolates that carry only an R-type pyocin gene because the 
presence of a single killing gene allows for more expression whereas, if multiple killing genes are present, expression levels of each gene may be lower to allow for concurrent expression.

Another explanation for differences observed between interactions in which $\mathrm{R}$ is present alone and found with other pyocin killing genes could be related to talocin subtypes as we did not sub-type the R or F pyocins in this study and it is well-known that different talocin subtypes (R1-R5; F1-F3) differ in their receptor specificity and, as a result, differ in their killing range. Furthermore, we do not know the specific components of LPS, the receptor for R-and F-type pyocins, for each of the isolates in this study. Consequently, the specifics of how particular pairs of producer and indicator isolates interact with one another regarding their talocins are unclear. We may lack sufficient information to understand the entirety of our data.

\section{Presence of an immunity gene provides protection}

We found that, overall, isolates carrying an S1S2 immunity gene have a significantly lower probability of being inhibited by isolates carrying S1 or S2 pyocin killing genes. These results are logical as they indicate that the presence of a gene encoding for an $\mathrm{S}$ immunity protein protects an isolate that is the target of the corresponding S killing protein. Despite this finding, however, there are two interesting observations of note in these results. The first is that, although isolates with an immunity gene are less likely to be inhibited, there is still a probability of 0.15 that an isolate with a gene for an S1/S2 immunity protein will 
be inhibited by an isolate carrying a gene for an S1 or S2 killing protein. It is possible that, in these cases, perhaps the S1/S2 immunity was not expressed or was not expressed at levels sufficient enough to provide protection for the indicator.

It should be noted that, in our inhibition assay, pyocin expression was induced using a DNA damaging agent, mitomycin C, only in producer isolates, so it is possible that the indicator isolate was not expressing the immunity gene or is only expressing it at low levels that are not sufficient to evade inhibition by the producer. Studies have shown that $\mathbf{S 6}$ pyocin immunity genes have higher levels of basal expression than the S6 killing protein [89]; however, it is unclear if this phenomenon is also observed in other S-type pyocin genes such as the S1/S2 immunity gene. Alternatively, isolates carrying a gene encoding for the S1/S2 immunity protein may still be susceptible to inhibition by the producer isolate if the killing results from mechanisms other than S2 pyocin production. While our inhibition assay method allowed us to rule out contact-dependent inhibition (CDI), we could not rule out inhibition through other mechanisms such as bacteriophage, other secreted antimicrobials, or even other pyocin types that were not characterized in this study. The second result of note is that not all isolates lacking an immunity gene are susceptible to a producer carrying a gene for the S2 killing protein. These isolates may not be susceptible due to other immunity mechanisms such as receptor incompatibility. More research is warranted to investigate basal level expression of pyocin killing and immunity genes as well as alternative mechanisms of pyocin resistance. Furthermore, it 
should be noted that isolates carrying S1 or S2 pyocin genes also carried genes for R-and/or F-type pyocins, which could impact the trends observed in our study, as an R- or F-type pyocin could be responsible for killing activity in addition to an S-type pyocin in these interactions. None of the isolates in our study were found to carry only one S-type killing gene. Given this limitation, we were unable to distinguish between inhibition due to talocins or S-type pyocins in our inhibition assays. Therefore, we are cautious with the conclusions in this portion of our study and more investigation is needed into the potential protection that an immunity protein may provide from an S-type pyocin.

\section{Conclusion}

This study aimed to characterize patterns of diversity in pyocin gene content among household isolates and investigate potential ecological, evolutionary, and genetic drivers of these patterns. We found that isolates from different houses differ primarily with respect to the total number of immunity genes found in each isolate, but do not significantly differ in the total number of all pyocin genes, suggesting a weak relationship between historical events such as dispersal limitations and pyocin gene content. Isolates collected from bathroom sink drains encoded significantly more killing and immunity genes, indicating that the current conditions, either abiotic or biotic, may play an important role in shaping patterns of diversity in pyocin genetics. Finally, isolates

with S-type immunity genes have a significantly lower probability of being inhibited by S-type killing proteins, and isolates producing only R-type pyocins 
exhibit the highest likelihood of inhibition than all other killing gene combinations. Overall, it appears that both dispersal limitations and local adaptation to current environmental conditions contribute in some capacity to pyocin genotype. Additionally, particular pyocin genotypes are more adept at killing than others, and S-type immunity genes protect isolates from being killing; however, it is likely that alternative mechanisms of resistance also play a role in the outcomes of inhibition. Furthermore, the massive complexity of the pyocin genetic system does not allow us to completely understand the genetic and mechanistic processes that are responsible for the outcomes of inhibitory interactions. 


\section{REFERENCES}

[1] Quinn, J.F. \& Harrison, S.P. 1988 Effects of habitat fragmentation and isolation on species richness: evidence from biogeographic patterns. Oecologia 75, 132-140. (doi:10.1007/BF00378826).

[2] Qian, H. 1998 Large-scale biogeographic patterns of vascular plant richness in North America: an analysis at the generic level. Journal of Biogeography 25, 829-836. (doi:https://doi.org/10.1046/j.1365-2699.1998.00247.x).

[3] Ward, D.M., Weller, R. \& Bateson, M.M. 1990 16S rRNA sequences reveal numerous uncultured microorganisms in a natural community. Nature 345, 63-65. (doi:10.1038/345063a0).

[4] Øvreås, L. 2000 Population and community level approaches for analysing microbial diversity in natural environments. Ecology Letters 3, 236-251. (doi:https://doi.org/10.1046/j.1461-0248.2000.00148.x).

[5] Martiny, J.B., Bohannan, B.J., Brown, J.H., Colwell, R.K., Fuhrman, J.A., Green, J.L., Horner-Devine, M.C., Kane, M., Krumins, J.A., Kuske, C.R., et al. 2006 Microbial biogeography: putting microorganisms on the map. Nat Rev Microbiol 4, 102-112. (doi:10.1038/nrmicro1341).

[6] Baas Becking, L.G.M. 1934 Geobiologie of Inleiding Tot de Milieukunde. The Hague, Netherlands, Stockkum \& Zoon.

[7] Whitaker, R.J., Grogan, D.W. \& Taylor, J.W. 2003 Geographic barriers isolate endemic populations of hyperthermophilic archaea. Science 301, 976-978. 
(doi:10.1126/science.1086909).

[8] Yannarell, A.C. \& Triplett, E.W. 2004 Within- and between-lake variability in the composition of bacterioplankton communities: investigations using multiple spatial scales. Appl Environ Microbiol 70, 214-223. (doi:10.1128/aem.70.1.214223.2004).

[9] Bokulich, N.A., Thorngate, J.H., Richardson, P.M. \& Mills, D.A. 2014 Microbial biogeography of wine grapes is conditioned by cultivar, vintage, and climate. Proceedings of the National Academy of Sciences 111, E139-E148. (doi:10.1073/pnas.1317377110). [10] Power, J.F., Carere, C.R., Lee, C.K., Wakerley, G.L.J., Evans, D.W., Button, M., White, D., Climo, M.D., Hinze, A.M., Morgan, X.C., et al. 2018 Microbial biogeography of 925 geothermal springs in New Zealand. Nature Communications 9, 2876. (doi:10.1038/s41467-018-05020-y). [11] Papke, R.T., Ramsing, N.B., Bateson, M.M. \& Ward, D.M. 2003 Geographical isolation in hot spring cyanobacteria. Environmental Microbiology 5, 650-659. (doi:https://doi.org/10.1046/j.1462-2920.2003.00460.x). [12] Bruce, J.B., West, S.A. \& Griffin, A.S. 2017 Bacteriocins and the assembly of natural Pseudomonas fluorescens populations. J Evol Biol 30, 352-360. (doi:10.1111/jeb.13010).

[13] Hawlena, H., Bashey, F. \& Lively, C.M. 2010 The evolution of spite: population structure and bacteriocin-mediated antagonism in two natural populations of Xenorhabdus bacteria. Evolution 64, 3198-3204. (doi:10.1111/j.1558-5646.2010.01070.x). 
[14] Kraemer, S.A., Soucy, J.R. \& Kassen, R. 2017 Antagonistic interactions of soil pseudomonads are structured in time. FEMS Microbiol Ecol 93. (doi:10.1093/femsec/fix046).

[15] Crump, B.C., Kling, G.W., Bahr, M. \& Hobbie, J.E. 2003 Bacterioplankton community shifts in an arctic lake correlate with seasonal changes in organic matter source. Appl Environ Microbio/ 69, 2253-2268.

(doi:10.1128/aem.69.4.2253-2268.2003).

[16] Rodriguez-Brito, B., Li, L., Wegley, L., Furlan, M., Angly, F., Breitbart, M., Buchanan, J., Desnues, C., Dinsdale, E., Edwards, R., et al. 2010 Viral and microbial community dynamics in four aquatic environments. ISME J 4, 739-751. (doi:10.1038/ismej.2010.1).

[17] Mojesky, A.A. \& Remold, S.K. 2020 Spatial structure maintains diversity of pyocin inhibition in household Pseudomonas aeruginosa. Proc Biol Sci 287, 20201706. (doi:10.1098/rspb.2020.1706).

[18] Reichenbach, T., Mobilia, M. \& Frey, E. 2007 Mobility promotes and jeopardizes biodiversity in rock-paper-scissors games. Nature 448, 1046-1049. (doi:10.1038/nature06095).

[19] Roberts, M.S. \& Cohan, F.M. 1995 Recombination and Migration Rates in Natural Populations of Bacillus subtilis and Bacillus mojavensis. Evolution 49, 1081-1094. (doi:https://doi.org/10.1111/j.1558-5646.1995.tb04435.x). [20] Ghoul, M. \& Mitri, S. 2016 The Ecology and Evolution of Microbial Competition. Trends Microbiol 24, 833-845. (doi:10.1016/j.tim.2016.06.011). [21] Aldén, L., Demoling, F. \& Bååth, E. 2001 Rapid Method of Determining 
Factors Limiting Bacterial Growth in Soil. Applied and Environmental Microbiology 67, 1830-1838. (doi:10.1128/aem.67.4.1830-1838.2001). [22] Nicholson, A. 1954 An outline of the dynamics of animal populations. Australian Journal of Zoology 2, 9-65. (doi:https://doi.org/10.1071/ZO9540009). [23] Vulić, M. \& Kolter, R. 2001 Evolutionary Cheating in Escherichia coli Stationary Phase Cultures. Genetics 158, 519-526. (doi:10.1093/genetics/158.2.519).

[24] Khan, A., Geetha, R., Akolkar, A., Pandya, A., Archana, G. \& Desai, A.J. 2006 Differential cross-utilization of heterologous siderophores by nodule bacteria of Cajanus cajan and its possible role in growth under iron-limited conditions. Applied Soil Ecology 34, 19-26. (doi:https://doi.org/10.1016/j.apsoil.2005.12.001). [25] Cordero, O.X., Ventouras, L.-A., DeLong, E.F. \& Polz, M.F. 2012 Public good dynamics drive evolution of iron acquisition strategies in natural bacterioplankton populations. Proceedings of the National Academy of Sciences 109, 20059-20064. (doi:10.1073/pnas.1213344109). [26] Rainey, P.B. \& Rainey, K. 2003 Evolution of cooperation and conflict in experimental bacterial populations. Nature 425, 72-74. (doi:10.1038/nature01906). [27] Griffin, A.S., West, S.A. \& Buckling, A. 2004 Cooperation and competition in pathogenic bacteria. Nature 430, 1024-1027. (doi:10.1038/nature02744). [28] West, S.A. \& Buckling, A. 2003 Cooperation, virulence and siderophore production in bacterial parasites. Proc Biol Sci 270, 37-44. 
(doi:10.1098/rspb.2002.2209).

[29] Harrison, F., Paul, J., Massey, R.C. \& Buckling, A. 2008 Interspecific competition and siderophore-mediated cooperation in Pseudomonas aeruginosa. ISME J 2, 49-55. (doi:10.1038/ismej.2007.96).

[30] Sandoz, K.M., Mitzimberg, S.M. \& Schuster, M. 2007 Social cheating in Pseudomonas aeruginosa quorum sensing. Proc Natl Acad Sci U S A 104, 15876-15881. (doi:10.1073/pnas.0705653104).

[31] Diggle, S.P., Griffin, A.S., Campbell, G.S. \& West, S.A. 2007 Cooperation and conflict in quorum-sensing bacterial populations. Nature 450, 411-414. (doi:10.1038/nature06279).

[32] Hood, R.D., Singh, P., Hsu, F., Güvener, T., Carl, M.A., Trinidad, R.R.S., Silverman, J.M., Ohlson, B.B., Hicks, K.G., Plemel, R.L., et al. 2010 A Type VI Secretion System of Pseudomonas aeruginosa Targets a Toxin to Bacteria. Cell Host \& Microbe 7, 25-37. (doi:https://doi.org/10.1016/j.chom.2009.12.007). [33] Yim, G., Wang, H.H. \& FRS, J.D. 2007 Antibiotics as signalling molecules. Philosophical Transactions of the Royal Society B: Biological Sciences $\mathbf{3 6 2}$, 1195-1200. (doi:doi:10.1098/rstb.2007.2044).

[34] Chao, L. \& Levin, B.R. 1981 Structured habitats and the evolution of anticompetitor toxins in bacteria. Proc Natl Acad Sci U S A 78, 6324-6328. (doi:10.1073/pnas.78.10.6324).

[35] Watve, M.G., Tickoo, R., Jog, M.M. \& Bhole, B.D. 2001 How many antibiotics are produced by the genus Streptomyces? Archives of Microbiology 176, 386-390. (doi:10.1007/s002030100345). 
[36] Hibbing, M.E., Fuqua, C., Parsek, M.R. \& Peterson, S.B. 2010 Bacterial competition: surviving and thriving in the microbial jungle. Nat Rev Microbio/ 8 , 15-25. (doi:10.1038/nrmicro2259).

[37] Hardin, G. 1960 The Competitive Exclusion Principle. Science 131, 12921297.

[38] Darwin, C. 1859 On the origin of species by means of natural selection, or preservation of favoured races in the struggle for life, London : John Murray, 1859.

[39] Foster, K.R., Wenseleers, T. \& Ratnieks, F.L.W. 2001 Spite: Hamilton's unproven theory. Annales Zoologici Fennici 38, 229-238.

[40] Hamilton, W.D. 1964 The genetical evolution of social behaviour. II. Journal of Theoretical Biology 7, 17-52. (doi:https://doi.org/10.1016/0022-5193(64)90039$6)$.

[41] Hamilton, W.D. 1970 Selfish and spiteful behaviour in an evolutionary model. Nature 228, 1218-1220. (doi:10.1038/2281218a0).

[42] Bourke, A.F.G. 1988 Worker Reproduction in the Higher Eusocial Hymenoptera. The Quarterly Review of Biology 63, 291-311. (doi:10.1086/415930).

[43] Smith, J.M. 1964 Group Selection and Kin Selection. Nature 201, 11451147. (doi:10.1038/2011145a0).

[44] Queller, D.C., Ponte, E., Bozzaro, S. \& Strassmann, J.E. 2003 Single-gene greenbeard effects in the social amoeba Dictyostelium discoideum. Science 299, 105-106. (doi:10.1126/science.1077742). 
[45] West, S.A. \& Gardner, A. 2010 Altruism, spite, and greenbeards. Science 327, 1341-1344. (doi:10.1126/science.1178332).

[46] Wilson, E.O. 1975 Sociobiology: the New Synthesis. Cambridge, MA, Harvard Press.

[47] Gardner, A. \& West, S.A. 2004 Spite and the scale of competition. J Evol Biol 17, 1195-1203. (doi:10.1111/j.1420-9101.2004.00775.x).

[48] Riley, M.A. \& Wertz, J.E. 2002 Bacteriocins: evolution, ecology, and application. Annu Rev Microbiol 56, 117-137.

(doi:10.1146/annurev.micro.56.012302.161024).

[49] Gardner, A., West, S.A. \& Buckling, A. 2004 Bacteriocins, spite and virulence. Proc Biol Sci 271, 1529-1535. (doi:10.1098/rspb.2004.2756). [50] Bakkal, S., Robinson, S.M., Ordonez, C.L., Waltz, D.A. \& Riley, M.A. 2010 Role of bacteriocins in mediating interactions of bacterial isolates taken from cystic fibrosis patients. Microbiology (Reading) 156, 2058-2067. (doi:10.1099/mic.0.036848-0).

[51] France, M.T. \& Remold, S.K. 2016 Interference Competition Among Household Strains of Pseudomonas. Microb Ecol 72, 821-830. (doi:10.1007/s00248-015-0652-1).

[52] Riley, M.A., Goldstone, C.M., Wertz, J.E. \& Gordon, D. 2003 A phylogenetic approach to assessing the targets of microbial warfare. J Evol Biol 16, 690-697. (doi:10.1046/j.1420-9101.2003.00575.x).

[53] Kerr, B., Riley, M.A., Feldman, M.W. \& Bohannan, B.J. 2002 Local dispersal promotes biodiversity in a real-life game of rock-paper-scissors. Nature 418,171 - 
174. (doi:10.1038/nature00823).

[54] Inglis, R.F., Roberts, P.G., Gardner, A. \& Buckling, A. 2011 Spite and the scale of competition in Pseudomonas aeruginosa. Am Nat 178, 276-285. (doi:10.1086/660827).

[55] Bara, J.J., Matson, Z. \& Remold, S.K. 2018 Life in the cystic fibrosis upper respiratory tract influences competitive ability of the opportunistic pathogen Pseudomonas aeruginosa. R Soc Open Sci 5, 180623. (doi:10.1098/rsos.180623).

[56] Bashey, F., Young, S.K., Hawlena, H. \& Lively, C.M. 2012 Spiteful interactions between sympatric natural isolates of Xenorhabdus bovienii benefit kin and reduce virulence. J Evol Biol 25, 431-437. (doi:10.1111/j.14209101.2011.02441.x).

[57] Hawlena, H., Bashey, F., Mendes-Soares, H. \& Lively, C.M. 2010 Spiteful Interactions in a natural population of the bacterium Xenorhabdus bovienii. Am Nat 175, 374-381. (doi:10.1086/650375).

[58] Hawlena, H.B., F.; Lively, C. M. 2012 Bacteriocin-mediated interactions within and between coexisting species. Ecology and Evolution 2. (doi:10.1002/ece3.354).

[59] Oliver, A., Canton, R., Campo, P., Baquero, F. \& Blazquez, J. 2000 High frequency of hypermutable Pseudomonas aeruginosa in cystic fibrosis lung infection. Science 288, 1251-1254. (doi:10.1126/science.288.5469.1251). [60] Davies, J.C. 2002 Pseudomonas aeruginosa in cystic fibrosis: pathogenesis and persistence. Paediatr Respir Rev 3, 128-134. (doi:10.1016/s1526- 
0550(02)00003-3).

[61] Neu, H.C. 1983 The role of Pseudomonas aeruginosa in infections. $J$ Antimicrob Chemother 11 Suppl B, 1-13. (doi:10.1093/jac/11.suppl_b.1). [62] Stover, C.K., Pham, X.Q., Erwin, A.L., Mizoguchi, S.D., Warrener, P., Hickey, M.J., Brinkman, F.S., Hufnagle, W.O., Kowalik, D.J., Lagrou, M., et al. 2000 Complete genome sequence of Pseudomonas aeruginosa PAO1, an opportunistic pathogen. Nature 406, 959-964. (doi:10.1038/35023079). [63] Blattner, F.R., Plunkett, G., 3rd, Bloch, C.A., Perna, N.T., Burland, V., Riley, M., Collado-Vides, J., Glasner, J.D., Rode, C.K., Mayhew, G.F., et al. 1997 The complete genome sequence of Escherichia coli K-12. Science 277, 1453-1462. (doi:10.1126/science.277.5331.1453).

[64] Stapleton, P.J., Izydorcyzk, C., Clark, S., Blanchard, A., Wang, P.W., Yau, Y., Waters, V. \& Guttman, D.S. 2020 Pseudomonas aeruginosa strain sharing in early infection among children with cystic fibrosis. Clin Infect Dis. (doi:10.1093/cid/ciaa788).

[65] Doring, G., Jansen, S., Noll, H., Grupp, H., Frank, F., Botzenhart, K., Magdorf, K. \& Wahn, U. 1996 Distribution and transmission of Pseudomonas aeruginosa and Burkholderia cepacia in a hospital ward. Pediatr Pulmonol 21, 90-100. (doi:10.1002/(SICl)1099-0496(199602)21:2<90::AID-PPUL5>3.0.CO;2T). [66] Denton, M., Kerr, K., Mooney, L., Keer, V., Rajgopal, A., Brownlee, K., Arundel, P. \& Conway, S. 2002 Transmission of colistin-resistant Pseudomonas aeruginosa between patients attending a pediatric cystic fibrosis center. Pediatr 
Pulmonol 34, 257-261. (doi:10.1002/ppul.10166).

[67] de Abreu, P.M., Farias, P.G., Paiva, G.S., Almeida, A.M. \& Morais, P.V.

2014 Persistence of microbial communities including Pseudomonas aeruginosa in a hospital environment: a potential health hazard. BMC Microbiol 14, 118. (doi:10.1186/1471-2180-14-118).

[68] Quick, J., Cumley, N., Wearn, C.M., Niebel, M., Constantinidou, C., Thomas, C.M., Pallen, M.J., Moiemen, N.S., Bamford, A., Oppenheim, B., et al. 2014 Seeking the source of Pseudomonas aeruginosa infections in a recently opened hospital: an observational study using whole-genome sequencing. BMJ Open 4, e006278. (doi:10.1136/bmjopen-2014-006278).

[69] Doring, G., Ulrich, M., Muller, W., Bitzer, J., Schmidt-Koenig, L., Munst, L., Grupp, H., Wolz, C., Stern, M. \& Botzenhart, K. 1991 Generation of Pseudomonas aeruginosa aerosols during handwashing from contaminated sink drains, transmission to hands of hospital personnel, and its prevention by use of a new heating device. Zentralbl Hyg Umweltmed 191, 494-505.

[70] Lalancette, C., Charron, D., Laferriere, C., Dolce, P., Deziel, E., Prevost, M. \& Bedard, E. 2017 Hospital Drains as Reservoirs of Pseudomonas aeruginosa: Multiple-Locus Variable-Number of Tandem Repeats Analysis Genotypes Recovered from Faucets, Sink Surfaces and Patients. Pathogens 6. (doi:10.3390/pathogens6030036).

[71] Regnath, T., Kreutzberger, M., Illing, S., Oehme, R. \& Liesenfeld, O. 2004 Prevalence of Pseudomonas aeruginosa in households of patients with cystic fibrosis. Int J Hyg Environ Health 207, 585-588. (doi:10.1078/1438-4639-00331). 
[72] Schelstraete, P., Van Daele, S., De Boeck, K., Proesmans, M., Lebecque, P., Leclercq-Foucart, J., Malfroot, A., Vaneechoutte, M. \& De Baets, F. 2008 Pseudomonas aeruginosa in the home environment of newly infected cystic fibrosis patients. Eur Respir J 31, 822-829. (doi:10.1183/09031936.00088907). [73] Purdy-Gibson, M.E., France, M., Hundley, T.C., Eid, N. \& Remold, S.K. 2015 Pseudomonas aeruginosa in CF and non-CF homes is found predominantly in drains. J Cyst Fibros 14, 341-346. (doi:10.1016/j.jcf.2014.10.008).

[74] Remold, S.K., Brown, C.K., Farris, J.E., Hundley, T.C., Perpich, J.A. \& Purdy, M.E. 2011 Differential habitat use and niche partitioning by Pseudomonas species in human homes. Microb Ecol 62, 505-517. (doi:10.1007/s00248-0119844-5).

[75] Rogues, A.M., Boulestreau, H., Lasheras, A., Boyer, A., Gruson, D., Merle, C., Castaing, Y., Bebear, C.M. \& Gachie, J.P. 2007 Contribution of tap water to patient colonisation with Pseudomonas aeruginosa in a medical intensive care unit. J Hosp Infect 67, 72-78. (doi:10.1016/j.jhin.2007.06.019).

[76] Reuter, S., Sigge, A., Wiedeck, H. \& Trautmann, M. 2002 Analysis of transmission pathways of Pseudomonas aeruginosa between patients and tap water outlets. Crit Care Med 30, 2222-2228. (doi:10.1097/00003246-20021000000008).

[77] Green, S.K., Schroth, M.N., Cho, J.J., Kominos, S.K. \& Vitanza-jack, V.B. 1974 Agricultural plants and soil as a reservoir for Pseudomonas aeruginosa. Appl Microbiol 28, 987-991.

[78] Parret, A.H. \& De Mot, R. 2002 Bacteria killing their own kind: novel 
bacteriocins of Pseudomonas and other gamma-proteobacteria. Trends Microbiol 10, 107-112. (doi:10.1016/s0966-842x(02)02307-7).

[79] Sano, Y., Matsui, H., Kobayashi, M. \& Kageyama, M. 1993 Molecular structures and functions of pyocins $\mathrm{S} 1$ and $\mathrm{S} 2$ in Pseudomonas aeruginosa. $J$ Bacteriol 175, 2907-2916. (doi:10.1128/jb.175.10.2907-2916.1993). [80] Michel-Briand, Y. \& Baysse, C. 2002 The pyocins of Pseudomonas aeruginosa. Biochimie 84, 499-510. (doi:10.1016/s0300-9084(02)01422-0). [81] Matsui, H., Sano, Y., Ishihara, H. \& Shinomiya, T. 1993 Regulation of pyocin genes in Pseudomonas aeruginosa by positive (prtN) and negative (prtR) regulatory genes. J Bacteriol 175, 1257-1263. (doi:10.1128/jb.175.5.12571263.1993).

[82] Penterman, J., Singh, P.K. \& Walker, G.C. 2014 Biological cost of pyocin production during the SOS response in Pseudomonas aeruginosa. $J$ Bacteriol 196, 3351-3359. (doi:10.1128/JB.01889-14).

[83] Nakayama, K., Takashima, K., Ishihara, H., Shinomiya, T., Kageyama, M., Kanaya, S., Ohnishi, M., Murata, T., Mori, H. \& Hayashi, T. 2000 The R-type pyocin of Pseudomonas aeruginosa is related to $\mathrm{P} 2$ phage, and the F-type is related to lambda phage. Mol Microbio/ 38, 213-231. (doi:10.1046/j.13652958.2000.02135.x).

[84] Parret, A. \& De Mot, R. 2000 Novel bacteriocins with predicted tRNase and pore-forming activities in Pseudomonas aeruginosa PAO1. Mol Microbiol 35, 472-473. (doi:10.1046/j.1365-2958.2000.01716.x).

[85] Turano, H., Gomes, F., Barros-Carvalho, G.A., Lopes, R., Cerdeira, L., 
Netto, L.E.S., Gales, A.C. \& Lincopan, N. 2017 Tn6350, a Novel Transposon Carrying Pyocin S8 Genes Encoding a Bacteriocin with Activity against Carbapenemase-Producing Pseudomonas aeruginosa. Antimicrob Agents Chemother 61. (doi:10.1128/AAC.00100-17).

[86] Braun, V., Pilsl, H. \& Groß, P. 1994 Colicins: structures, modes of action, transfer through membranes, and evolution. Archives of Microbiology 161, 199206. (doi:10.1007/BF00248693).

[87] Sano, Y. \& Kageyama, M. 1981 Purification and properties of an S-type pyocin, pyocin AP41. J Bacteriol 146, 733-739. (doi:10.1128/JB.146.2.733739.1981).

[88] Ghoul, M., West, S.A., Johansen, H.K., Molin, S., Harrison, O.B., Maiden, M.C., Jelsbak, L., Bruce, J.B. \& Griffin, A.S. 2015 Bacteriocin-mediated competition in cystic fibrosis lung infections. Proc Biol Sci 282. (doi:10.1098/rspb.2015.0972).

[89] Dingemans, J., Ghequire, M.G., Craggs, M., De Mot, R. \& Cornelis, P. 2016 Identification and functional analysis of a bacteriocin, pyocin S6, with ribonuclease activity from a Pseudomonas aeruginosa cystic fibrosis clinical isolate. Microbiologyopen 5, 413-423. (doi:10.1002/mbo3.339). [90] Duport, C., Baysse, C. \& Michel-Briand, Y. 1995 Molecular characterization of pyocin S3, a novel S-type pyocin from Pseudomonas aeruginosa. J Biol Chem 270, 8920-8927. (doi:10.1074/jbc.270.15.8920).

[91] Seo, Y. \& Galloway, D.R. 1990 Purification of the pyocin S2 complex from Pseudomonas aeruginosa PAO1: Analysis of DNase activity. Biochemical and 
Biophysical Research Communications 172, 455-461.

(doi:https://doi.org/10.1016/0006-291X(90)90694-I).

[92] Ohkawa, I., Maruo, B. \& Kageyama, M. 1975 Preferential Inhibition of Lipid Synthesis by the Bacteriocin Pyocin S2. The Journal of Biochemistry 78, 213223. (doi:10.1093/oxfordjournals.jbchem.a130886).

[93] Elfarash, A., Dingemans, J., Ye, L., Hassan, A.A., Craggs, M., Reimmann, C., Thomas, M.S. \& Cornelis, P. 2014 Pore-forming pyocin S5 utilizes the FptA ferripyochelin receptor to kill Pseudomonas aeruginosa. Microbiology (Reading) 160, 261-269. (doi:10.1099/mic.0.070672-0).

[94] Elfarash, A., Wei, Q. \& Cornelis, P. 2012 The soluble pyocins S2 and S4 from Pseudomonas aeruginosa bind to the same FpvAl receptor. Microbiologyopen 1, 268-275. (doi:10.1002/mbo3.27).

[95] Baysse, C., Meyer, J.M., Plesiat, P., Geoffroy, V., Michel-Briand, Y. \& Cornelis, P. 1999 Uptake of pyocin S3 occurs through the outer membrane ferripyoverdine type II receptor of Pseudomonas aeruginosa. J Bacteriol 181, 3849-3851. (doi:10.1128/JB.181.12.3849-3851.1999).

[96] Ohkawa, I., Shiga, S. \& Kageyama, M. 1980 Effect of Iron Concentration in the Growth Medium on the Sensitivity of Pseudomonas aeruginosa to Pyocin S2. The Journal of Biochemistry 87, 323-331.

(doi:10.1093/oxfordjournals.jbchem.a132740).

[97] Schalk, I.J., Hennard, C., Dugave, C., Poole, K., Abdallah, M.A. \& Pattus, F. 2001 Iron-free pyoverdin binds to its outer membrane receptor FpvA in Pseudomonas aeruginosa: a new mechanism for membrane iron transport. 
Molecular Microbiology 39, 351-361. (doi:https://doi.org/10.1046/j.13652958.2001.02207.x).

[98] Dennis, J.J., Lafontaine, E.R. \& Sokol, P.A. 1996 Identification and characterization of the tolQRA genes of Pseudomonas aeruginosa. Journal of Bacteriology 178, 7059-7068. (doi:10.1128/jb.178.24.7059-7068.1996).

[99] S Ito, S.K., M. Egami, F. 1970 Isolation and characterization of pyocins from several strains of Pseudomonas aeruginosa. The Journal of General and Applied Microbiology 16.

[100] Ferrara, S., Falcone, M., Macchi, R., Bragonzi, A., Girelli, D., Cariani, L., Cigana, C. \& Bertoni, G. 2017 The PAPI-1 pathogenicity island-encoded small RNA PesA influences Pseudomonas aeruginosa virulence and modulates pyocin S3 production. PLoS One 12, e0180386. (doi:10.1371/journal.pone.0180386). [101] Sano, Y. \& Kageyama, M. 1993 A novel transposon-like structure carries the genes for pyocin AP41, a Pseudomonas aeruginosa bacteriocin with a DNase domain homology to E2 group colicins. Mol Gen Genet 237, 161-170. (doi:10.1007/BF00282797). [102] Smith, A.W., Hirst, P.H., Hughes, K., Gensberg, K. \& Govan, J.R. 1992 The pyocin Sa receptor of Pseudomonas aeruginosa is associated with ferripyoverdin uptake. J Bacteriol 174, 4847-4849. (doi:10.1128/jb.174.14.4847-4849.1992). [103] Govan, J.R. 1974 Studies on the pyocins of Pseudomonas aeruginosa: morphology and mode of action of contractile pyocins. J Gen Microbiol 80, 1-15. (doi:10.1099/00221287-80-1-1).

[104] Ikeda, K. 1973 [Receptor of pyocin R (author's transI)]. Tanpakushitsu 
Kakusan Koso 18, 603-610.

[105] Kohler, T., Donner, V. \& van Delden, C. 2010 Lipopolysaccharide as shield and receptor for R-pyocin-mediated killing in Pseudomonas aeruginosa. $J$ Bacteriol 192, 1921-1928. (doi:10.1128/JB.01459-09).

[106] Kageyama, M., Ikeda, K. \& Egami, F. 1964 Studies of a Pyocin. lii. Biological Properties of the Pyocin. J Biochem 55, 59-64. (doi:10.1093/oxfordjournals.jbchem.a127841). [107] Ikeda, K., Kageyama, M. \& Egami, F. 1964 Studies of a Pyocin. Ii. Mode of Production of the Pyocin. J Biochem 55, 54-58.

(doi:10.1093/oxfordjournals.jbchem.a127840). [108] Kageyama, M. 1964 Studies of a Pyocin. I. Physical and Chemical Properties. J Biochem 55, 49-53. (doi:10.1093/oxfordjournals.jbchem.a127839). [109] Ishii, S.I., Nishi, Y. \& Egami, F. 1965 The fine structure of a pyocin. J Mol Biol 13, 428-431. (doi:10.1016/s0022-2836(65)80107-3).

[110] Takeda, A. \& Kageyama, M. 1975 Subunit Arrangement in the Extended Sheath of Pyocin R. The Journal of Biochemistry 77, 679-684. (doi:10.1093/oxfordjournals.jbchem.a130770).

[111] Yui-Furihata, C. 1972 Structure of Pyocin R: II. Subunits of Sheath*. The Journal of Biochemistry 72, 1-10. (doi:10.1093/oxfordjournals.jbchem.a129873). [112] Shinomiya, T., Osumi, M. \& Kageyama, M. 1975 Defective pyocin particles produced by some mutant strains of Pseudomonas aeruginosa. Journal of Bacteriology 124, 1508-1521.

[113] Ohsumi, M., Shinomiya, T. \& Kageyama, M. 1980 Comparative study on R- 
type pyocins of Pseudomonas aeruginosa. J Biochem 87, 1119-1125.

[114] Uratani, Y. \& Hoshino, T. 1984 Pyocin R1 inhibits active transport in Pseudomonas aeruginosa and depolarizes membrane potential. Journal of Bacteriology 157, 632-636.

[115] Kageyama, M. 1974 Genetic mapping of pyocin R1 factor in Pseudomonas aeruginosa. J. Gen. Appl. Microbiol. 20.

[116] Takeya, K., Minamishima, Y., Amako, K. \& Ohnishi, Y. 1967 A small rodshaped pyocin. Virology 31, 166-168. (doi:10.1016/0042-6822(67)90021-9). [117] Kuroda, K. \& Kageyama, M. 1981 Comparative study of F-type pyocins of Pseudomonas aeruginosa. J Biochem 89, 1721-1736.

(doi:10.1093/oxfordjournals.jbchem.a133372).

[118] Kuroda, K. \& Kageyama, M. 1979 Biochemical properties of a new flexuous bacteriocin, pyocin F1, produced by Pseudomonas aeruginosa. J Biochem 85, 719. (doi:10.1093/oxfordjournals.jbchem.a132332).

[119] Pérez-Gutiérrez, R.-A., López-Ramírez, V., Islas, Á., Alcaraz, L.D., Hernández-González, I., Olivera, B.C.L., Santillán, M., Eguiarte, L.E., Souza, V., Travisano, M., et al. 2013 Antagonism influences assembly of a Bacillus guild in a local community and is depicted as a food-chain network. The ISME Journal 7, 487-497. (doi:10.1038/ismej.2012.119).

[120] Schoustra, S.E., Dench, J., Dali, R., Aaron, S.D. \& Kassen, R. 2012 Antagonistic interactions peak at intermediate genetic distance in clinical and laboratory strains of Pseudomonas aeruginosa. BMC Microbiol 12, 40. (doi:10.1186/1471-2180-12-40). 
[121] Freilich, S., Zarecki, R., Eilam, O., Segal, E.S., Henry, C.S., Kupiec, M., Gophna, U., Sharan, R. \& Ruppin, E. 2011 Competitive and cooperative metabolic interactions in bacterial communities. Nature Communications 2, 589. (doi:10.1038/ncomms1597).

[122] Atlas, R. 2010 Handbook of microbiological media 4th edition ed.

Washington, DC, CRC Press.

[123] Spilker, T., Coenye, T., Vandamme, P. \& LiPuma, J.J. 2004 PCR-based assay for differentiation of Pseudomonas aeruginosa from other Pseudomonas species recovered from cystic fibrosis patients. J Clin Microbiol 42, 2074-2079. (doi:10.1128/jcm.42.5.2074-2079.2004).

[124] Fyfe, J.A., Harris, G. \& Govan, J.R. 1984 Revised pyocin typing method for Pseudomonas aeruginosa. J Clin Microbiol 20, 47-50. (doi:10.1128/JCM.20.1.4750.1984).

[125] Hunt, M., Mather, A.E., Sanchez-Buso, L., Page, A.J., Parkhill, J., Keane, J.A. \& Harris, S.R. 2017 ARIBA: rapid antimicrobial resistance genotyping directly from sequencing reads. Microb Genom 3, e000131. (doi:10.1099/mgen.0.000131).

[126] Curran, B., Jonas, D., Grundmann, H., Pitt, T. \& Dowson, C.G. 2004 Development of a multilocus sequence typing scheme for the opportunistic pathogen Pseudomonas aeruginosa. J Clin Microbiol 42, 5644-5649. (doi:10.1128/JCM.42.12.5644-5649.2004).

[127] Paradis, E. \& Schliep, K. 2019 ape 5.0: an environment for modern phylogenetics and evolutionary analyses in R. Bioinformatics 35, 526-528. 
(doi:10.1093/bioinformatics/bty633).

[128] R Core Team. 2018 R: a language and environment for statistical computing. Vienna, Austria, R Foundation for Statistical Computing. [129] Oksanen, J. et al. 2019 vegan: Community Ecology Package. R package version 2.0-2 ed.

[130] Inc., S.I. 2017 Base SAS 9.4 procedures guide. Cary, NC, SAS Institute. [131] van Heel, A.J., de Jong, A., Montalban-Lopez, M., Kok, J. \& Kuipers, O.P. 2013 BAGEL3: Automated identification of genes encoding bacteriocins and (non-)bactericidal posttranslationally modified peptides. Nucleic Acids Res 41, W448-453. (doi:10.1093/nar/gkt391). [132] Riley, M.A. \& Wertz, J.E. 2002 Bacteriocin diversity: ecological and evolutionary perspectives. Biochimie 84, 357-364. (doi:10.1016/s03009084(02)01421-9).

[133] Goldberg, J.B. 2000 Pseudomonas: global bacteria. Trends Microbiol 8, 5557. (doi:10.1016/s0966-842x(99)01671-6).

[134] Denayer, S., Matthijs, S. \& Cornelis, P. 2007 Pyocin S2 (Sa) kills Pseudomonas aeruginosa strains via the FpvA type I ferripyoverdine receptor. $J$ Bacteriol 189, 7663-7668. (doi:10.1128/JB.00992-07). [135] Oluyombo, O., Penfold, C.N. \& Diggle, S.P. 2019 Competition in Biofilms between Cystic Fibrosis Isolates of Pseudomonas aeruginosa Is Shaped by RPyocins. mBio 10. (doi:10.1128/mBio.01828-18).

[136] Mojesky, A.A. \& Remold, S.K. 2020 Spatial structure maintains diversity of pyocin inhibition in household Pseudomonas aeruginosa. Proceedings of the 
Royal Society B: Biological Sciences 287, 20201706.

(doi:doi:10.1098/rspb.2020.1706).

[137] Bolger, A.M., Lohse, M. \& Usadel, B. 2014 Trimmomatic: a flexible trimmer for Illumina sequence data. Bioinformatics 30, 2114-2120.

(doi:10.1093/bioinformatics/btu170).

[138] Bankevich, A., Nurk, S., Antipov, D., Gurevich, A.A., Dvorkin, M., Kulikov, A.S., Lesin, V.M., Nikolenko, S.I., Pham, S., Prjibelski, A.D., et al. 2012 SPAdes: a new genome assembly algorithm and its applications to single-cell sequencing. J Comput Biol 19, 455-477. (doi:10.1089/cmb.2012.0021). [139] Winsor, G.L., Griffiths, E.J., Lo, R., Dhillon, B.K., Shay, J.A. \& Brinkman, F.S. 2016 Enhanced annotations and features for comparing thousands of Pseudomonas genomes in the Pseudomonas genome database. Nucleic Acids Res 44, D646-653. (doi:10.1093/nar/gkv1227).

[140] Lenth, R.V. 2021 emmeans: Estimated Marginal Means, aka LeastSquares Means.

[141] Snopkova, K., Dufkova, K., Klimesova, P., Vanerkova, M., Ruzicka, F. \& Hola, V. 2020 Prevalence of bacteriocins and their co-association with virulence factors within Pseudomonas aeruginosa catheter isolates. Int J Med Microbiol 310, 151454. (doi:10.1016/j.jmm.2020.151454).

[142] Brazas, M.D. \& Hancock, R.E.W. 2005 Ciprofloxacin Induction of a Susceptibility Determinant in Pseudomonas aeruginosa. Antimicrobial Agents and Chemotherapy 49, 3222-3227. (doi:10.1128/aac.49.8.3222-3227.2005). [143] Heo, Y.J., Chung, I.Y., Choi, K.B. \& Cho, Y.H. 2007 R-type pyocin is 
required for competitive growth advantage between Pseudomonas aeruginosa strains. J Microbiol Biotechnol 17, 180-185.

[144] lijima, M. 1978 Mode of action of pyocin R1. J Biochem 83, 395-402. (doi:10.1093/oxfordjournals.jbchem.a131926).

[145] Strauch, E., Kaspar, H., Schaudinn, C., Dersch, P., Madela, K., Gewinner, C., Hertwig, S., Wecke, J. \& Appel, B. 2001 Characterization of Enterocoliticin, a Phage Tail-Like Bacteriocin, and Its Effect on Pathogenic Yersinia enterocolitica Strains. Applied and Environmental Microbiology 67, 5634-5642. (doi:10.1128/aem.67.12.5634-5642.2001).

[146] Williams, S.R., Gebhart, D., Martin, D.W. \& Scholl, D. 2008 Retargeting Rtype pyocins to generate novel bactericidal protein complexes. Applied and environmental microbiology 74, 3868-3876. (doi:10.1128/AEM.00141-0). 


\section{APPENDIX}

Table 4. S-type pyocin genes screened in all genomes and reference genomes used to retrieve gene sequences.

\begin{tabular}{|c|c|c|c|}
\hline pyocin & gene function & $\begin{array}{l}\text { gene name/locus } \\
\text { tag }\end{array}$ & genome \\
\hline S2 & killing protein & pys2 (PA1150) & $\begin{array}{l}\text { Pseudomonas aeruginosa PAO1 } \\
\text { (Reference)* }\end{array}$ \\
\hline $\begin{array}{l}\text { S1 and } \\
\text { S2 }\end{array}$ & $\begin{array}{l}\text { immunity } \\
\text { protein }\end{array}$ & imm2 (PA1151) & $\begin{array}{l}\text { Pseudomonas aeruginosa PAO1 } \\
\text { (Reference) }\end{array}$ \\
\hline S1 & killing protein & A4W92_RS05830 & $\begin{array}{l}\text { Pseudomonas aeruginosa ATCC } \\
278534 \dagger\end{array}$ \\
\hline S3 & killing protein & $\begin{array}{l}\text { pyoS3A } \\
\text { (PA14_49520) }\end{array}$ & $\begin{array}{l}\text { Pseudomonas aeruginosa UCBPP- } \\
\text { PA14 }\end{array}$ \\
\hline S3 & $\begin{array}{l}\text { immunity } \\
\text { protein }\end{array}$ & pyoS3I (PA14_49510) & Pseudomonas aeruginosa UCBPP-PA14 \\
\hline S5 & killing protein & pyoS5 (PA0985) & $\begin{array}{l}\text { Pseudomonas aeruginosa } \\
\text { PAO1 (Reference) }\end{array}$ \\
\hline S5 & $\begin{array}{l}\text { immunity } \\
\text { protein }\end{array}$ & PA0984 & $\begin{array}{l}\text { Pseudomonas aeruginosa PAO1 } \\
\text { (Reference) }\end{array}$ \\
\hline AP41 & killing protein & PADK1_RS07240 & $\begin{array}{l}\text { Pseudomonas aeruginosa } \\
\text { DK1 substr. NH57388A§ }\end{array}$ \\
\hline AP41 & $\begin{array}{l}\text { immunity } \\
\text { protein }\end{array}$ & PADK1_RS07235 & $\begin{array}{l}\text { Pseudomonas aeruginosa } \\
\text { DK1 substr. NH57388A }\end{array}$ \\
\hline
\end{tabular}

${ }^{*}$ RefSeq Assembly Accesstion GCF_000006765.1 †RefSeq Assembly Accession GCF_001618925.1 $\ddagger$ RefSeq Assembly Accession GCF_000014625.1 §RefSeq Assembly Accession GCF_900069025.1 
Table 5. R- and F-type pyocin genes screened in all isolate genomes.

\begin{tabular}{|c|c|c|c|}
\hline pyocin & gene function & $\underset{\text { tag }}{\text { gene name/locus }}$ & genome \\
\hline- & $\begin{array}{l}\text { anthranilate } \\
\text { synthetase I }\end{array}$ & $\operatorname{trpE}(\mathrm{PA0609)}$ & $\begin{array}{l}\text { Pseudomonas aeruginosa PAO1 } \\
\text { (Reference) }\end{array}$ \\
\hline $\begin{array}{l}\mathrm{R} \text { and } \\
\mathrm{F}\end{array}$ & $\begin{array}{l}\text { Transcriptional } \\
\text { repressor }\end{array}$ & prtR (PA0610) & $\begin{array}{l}\text { Pseudomonas aeruginosa PAO1 } \\
\text { (Reference) }\end{array}$ \\
\hline $\begin{array}{l}\mathrm{R} \text { and } \\
\mathrm{F}\end{array}$ & $\begin{array}{l}\text { Transcriptional } \\
\text { activator }\end{array}$ & prtN (PA0610) & $\begin{array}{l}\text { Pseudomonas aeruginosa PAO1 } \\
\text { (Reference) }\end{array}$ \\
\hline- & Repressor & ptrB (PA0612) & $\begin{array}{l}\text { Pseudomonas aeruginosa PAO1 } \\
\text { (Reference) }\end{array}$ \\
\hline- & Hypothetical protein & PA0613 & $\begin{array}{l}\text { Pseudomonas aeruginosa PAO1 } \\
\text { (Reference) }\end{array}$ \\
\hline $\begin{array}{l}\mathrm{R} \text { and } \\
\mathrm{F}\end{array}$ & Holin & PA0614 & $\begin{array}{l}\text { Pseudomonas aeruginosa PAO1 } \\
\text { (Reference) }\end{array}$ \\
\hline- & Hypothetical protein & PA0615 & $\begin{array}{l}\text { Pseudomonas aeruginosa PAO1 } \\
\text { (Reference) }\end{array}$ \\
\hline $\mathrm{R}$ & Tail spike & PA0616 & $\begin{array}{l}\text { Pseudomonas aeruginosa PAO1 } \\
\text { (Reference) }\end{array}$ \\
\hline $\mathrm{R}$ & Tail baseplate & PA0617 & $\begin{array}{l}\text { Pseudomonas aeruginosa PAO1 } \\
\text { (Reference) }\end{array}$ \\
\hline $\mathrm{R}$ & Tail baseplate & PA0618 & $\begin{array}{l}\text { Pseudomonas aeruginosa PAO1 } \\
\text { (Reference) }\end{array}$ \\
\hline $\mathrm{R}$ & Tail formation & PA0619 & $\begin{array}{l}\text { Pseudomonas aeruginosa PAO1 } \\
\text { (Reference) }\end{array}$ \\
\hline $\mathrm{R}$ & Tail fiber & PA0620 & $\begin{array}{l}\text { Pseudomonas aeruginosa PAO1 } \\
\text { (Reference) }\end{array}$ \\
\hline $\mathrm{R}$ & Tail fiber & PA0621 & $\begin{array}{l}\text { Pseudomonas aeruginosa PAO1 } \\
\text { (Reference) }\end{array}$ \\
\hline $\mathrm{R}$ & Tail sheath & PA0622 & $\begin{array}{l}\text { Pseudomonas aeruginosa PAO1 } \\
\text { (Reference) }\end{array}$ \\
\hline $\mathrm{R}$ & Tail tube & PA0623 & $\begin{array}{l}\text { Pseudomonas aeruginosa PAO1 } \\
\text { (Reference) }\end{array}$ \\
\hline $\mathrm{R}$ & Hypothetical protein & PA0624 & $\begin{array}{l}\text { Pseudomonas aeruginosa PAO1 } \\
\text { (Reference) }\end{array}$ \\
\hline $\mathrm{R}$ & Tail formation & PA0625 & $\begin{array}{l}\text { Pseudomonas aeruginosa PAO1 } \\
\text { (Reference) }\end{array}$ \\
\hline $\mathrm{R}$ & Tail formation & PA0626 & $\begin{array}{l}\text { Pseudomonas aeruginosa PAO1 } \\
\text { (Reference) }\end{array}$ \\
\hline $\mathrm{R}$ & Tail formation & PA0627 & $\begin{array}{l}\text { Pseudomonas aeruginosa PAO1 } \\
\text { (Reference) }\end{array}$ \\
\hline $\mathrm{R}$ & Tail formation & PA0628 & $\begin{array}{l}\text { Pseudomonas aeruginosa PAO1 } \\
\text { (Reference) }\end{array}$ \\
\hline $\begin{array}{l}\mathrm{R} \text { and } \\
\mathrm{F}\end{array}$ & Lytic enzyme & PA0629 & $\begin{array}{l}\text { Pseudomonas aeruginosa PAO1 } \\
\text { (Reference) }\end{array}$ \\
\hline $\mathrm{F}$ & Tail protein & PA0630 & $\begin{array}{l}\text { Pseudomonas aeruginosa PAO1 } \\
\text { (Reference) }\end{array}$ \\
\hline $\mathrm{F}$ & Tail formation & PA0631 & $\begin{array}{l}\text { Pseudomonas aeruginosa PAO1 } \\
\text { (Reference) }\end{array}$ \\
\hline $\mathrm{F}$ & Tail formation & PA0632 & $\begin{array}{l}\text { Pseudomonas aeruginosa PAO1 } \\
\text { (Reference) }\end{array}$ \\
\hline $\mathrm{F}$ & Tail protein & PA0633 & $\begin{array}{l}\text { Pseudomonas aeruginosa PAO1 } \\
\text { (Reference) }\end{array}$ \\
\hline
\end{tabular}




\begin{tabular}{|c|c|c|c|}
\hline $\mathrm{F}$ & Tail protein & PA0636 & $\begin{array}{l}\text { Pseudomonas aeruginosa PAO1 } \\
\text { (Reference) }\end{array}$ \\
\hline $\mathrm{F}$ & Hypothetical protein & PA0637 & $\begin{array}{l}\text { Pseudomonas aeruginosa PAO1 } \\
\text { (Reference) }\end{array}$ \\
\hline $\mathrm{F}$ & Tail protein & PA0638 & $\begin{array}{l}\text { Pseudomonas aeruginosa PAO1 } \\
\text { (Reference) }\end{array}$ \\
\hline $\mathrm{F}$ & Tail protein & PA0639 & $\begin{array}{l}\text { Pseudomonas aeruginosa PAO1 } \\
\text { (Reference) }\end{array}$ \\
\hline $\mathrm{F}$ & Hypothetical protein & PA0640 & $\begin{array}{l}\text { Pseudomonas aeruginosa PAO1 } \\
\text { (Reference) }\end{array}$ \\
\hline $\mathrm{F}$ & Hypothetical protein & PA0641 & $\begin{array}{l}\text { Pseudomonas aeruginosa PAO1 } \\
\text { (Reference) }\end{array}$ \\
\hline $\mathrm{F}$ & Hypothetical protein & PA0642 & $\begin{array}{l}\text { Pseudomonas aeruginosa PAO1 } \\
\text { (Reference) }\end{array}$ \\
\hline $\mathrm{F}$ & Hypothetical protein & PA0643 & $\begin{array}{l}\text { Pseudomonas aeruginosa PAO1 } \\
\text { (Reference) }\end{array}$ \\
\hline $\mathrm{F}$ & Hypothetical protein & PA0644 & $\begin{array}{l}\text { Pseudomonas aeruginosa PAO1 } \\
\text { (Reference) }\end{array}$ \\
\hline $\mathrm{F}$ & Hypothetical protein & PA0645 & $\begin{array}{l}\text { Pseudomonas aeruginosa PAO1 } \\
\text { (Reference) }\end{array}$ \\
\hline $\mathrm{F}$ & Hypothetical protein & PA0646 & $\begin{array}{l}\text { Pseudomonas aeruginosa PAO1 } \\
\text { (Reference) }\end{array}$ \\
\hline $\mathrm{F}$ & Hypothetical protein & PA0647 & $\begin{array}{l}\text { Pseudomonas aeruginosa PAO1 } \\
\text { (Reference) }\end{array}$ \\
\hline $\mathrm{F}$ & Hypothetical protein & PA0648 & $\begin{array}{l}\text { Pseudomonas aeruginosa PAO1 } \\
\text { (Reference) }\end{array}$ \\
\hline- & $\begin{array}{l}\text { anthranilate } \\
\text { synthetase II }\end{array}$ & $\operatorname{trpG}(\mathrm{PA0649})$ & $\begin{array}{l}\text { Pseudomonas aeruginosa PAO1 } \\
\text { (Reference) }\end{array}$ \\
\hline
\end{tabular}




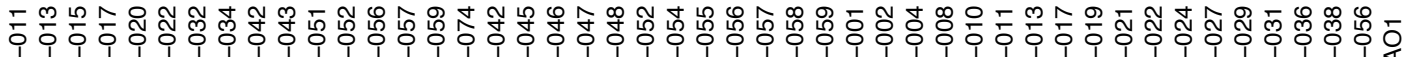

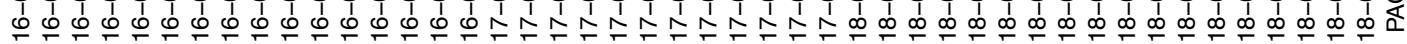

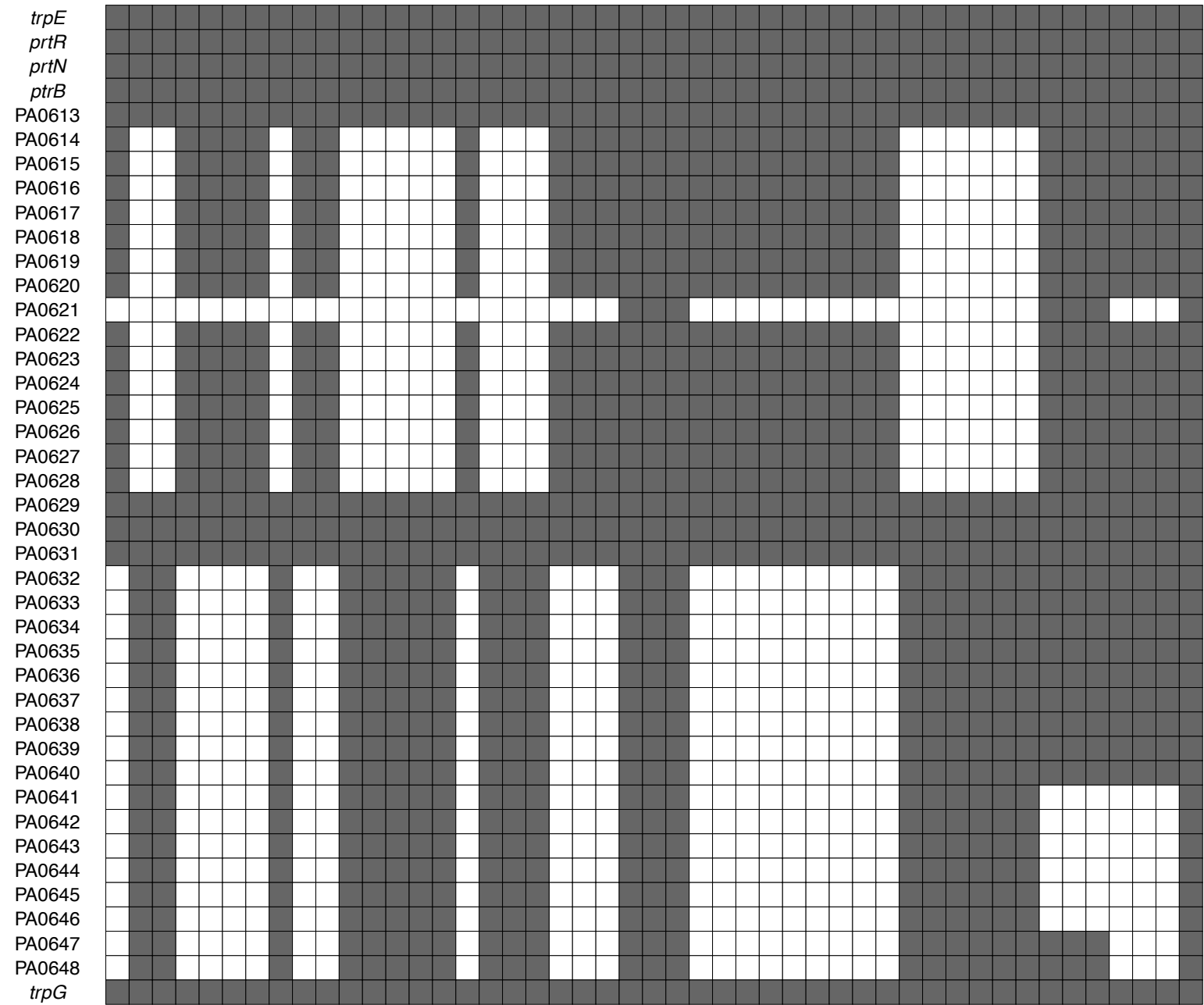

Figure 8. Presence/absence of all genes in the R/F pyocin gene cluster for each isolate. Grey squares indicate that the gene is present in that particular isolate, and white squares indicate that the gene is absent in that particular isolate. 


\section{CURRICULUM VITAE}

\section{Aubrey Mojesky}

(859) 516-1108•aubrey.mojesky@gmail.com•Louisville, KY

\section{EDUCATION}

Ph.D. Biology

University of Louisville

GPA: 3.96

August 2016-2021

Louisville, KY

B.S. Biology

May 2014

Centre College

Danville, KY

\section{EXPERIENCE}

Graduate Teaching Assistant

University of Louisville, Department of Biology

August 2016-December 2020

Louisville, KY

- Instructed 14 microbiology teaching lab sections over the course of 8 semesters

- Instructed 6 general biology teaching lab sections over the course of 2 semester

- Prepared bacterial cultures, media, and reagents for microbiology teaching labs

- Created educational material including quizzes, exams, labs, and assignments

\section{Laboratory Technologist I}

James Graham Brown Cancer Center

October 2014-July 2016

Louisville, KY

- Contributed to drug discovery research by exploring inhibitors for PFKFB4,

- a kinase/phosphatase metabolic enzyme associated with many different types of cancer

- Trained and mentored high school and undergraduate students

- Performed molecular cloning as well as recombinant protein expression and purification to obtain the PFKFB4, which was used for kinetic assays and crystallography

- Examined novel PFKFB4 inhibitors using mammalian cell culture, western blot, and functional assays 
Summer Laboratory Technician

University of Louisville, Department of Biology

Summer Research Assistant

University of Kentucky, Department of Biology
June 2014-September 2014

Louisville, KY

June 2014-August 2014

Lexington, $\mathrm{KY}$

\section{PRESENTATIONS}

"Phylogenetic history and dispersal limitations contribute to patterns July 2019 of bacteriocin inhibition in household Pseudomonas aeruginosa."

Poster Presentation, Gordon Research Conference on Microbial

Population Biology, Andover, $\mathrm{NH}$

"Bacteriocin-mediated interactions in the bacterium Pseudomonas

aeruginosa." Oral Presentation, Graduate Student Regional Research

April 2019 Conference (GSRRC), Louisville, KY

"Bacteriocin-mediated interactions increase with spatial scale in

October 2018 household Pseudomonas aeruginosa isolates" Oral Presentation, University of Louisville Graduate Network of Arts and Sciences (GNAS) Brown Bag Lunch Series, Louisville, KY

"Bacteriocin-mediated interactions increase with spatial scale in June 2018 household Pseudomonas aeruginosa isolates" Poster presentation, American Society of Microbiology Microbe, Atlanta, GA

"Bacteriocin-mediated interactions increase with spatial scale in June 2018 household Pseudomonas aeruginosa isolates" Oral Presentation (invited), session "Why can't we all just get along?: characterizing microbial interactions and dynamics" American Society of Microbiology Microbe, Atlanta, GA

"The impacts of spatial scale on pyocin interactions in household isolates of Pseudomonas aeruginosa." Poster Presentation, Gordon July 2017 Research Conference on Microbial Population Biology, Andover, NH

"Distribution of Pseudomonas aeruginosa in household bathroom March 2017 and kitchen sink drains." Oral Presentation, Midwestern Ecology and Evolution Conference, Urbana- Champaign, II

"The impacts of spatial isolation and phylogenetic distance on October 2016 pyocin inhibition in Pseudomonas aeruginosa." Oral Presentation, Kentucky Academy of Science, Louisville, KY 


\section{PUBLICATIONS}

Mojesky Aubrey A. and Remold Susanna K. 2020. Spatial structure maintains diversity of pyocin inhibition in household Pseudomonas aeruginosa. Proc. R. B. 287: 20201706. http://doi.org/10.1098/rspb.2020.1706

\section{FUNDING}

Biology Graduate Student Association, Travel Grant, \$175

July 2018

Graduate Student Council, Travel Grant, $\$ 200$

August 2018

Gordon Research Conference, "GRC Award"

(full registration reimbursement), $\$ 800$

July 2019

Mentored Undergraduate Research Award Grant, \$1000

September 2020

ADDITIONAL EXPERIENCE

Volunteer

Instructor for Area Health Education Center (AHEC), Louisville, KY

2016-2017

Instructor for Mystery at the Museum, Kentucky Science Center, Louisville, KY

May 2018

Judge for Valley High School Science Fair,

February $2020 \& 2021$ Louisville, KY

Judge for Louisville Regional Science and Engineering

March 2020 \& 2021

Fair, Louisville, KY

Judge for University of Louisville Undergraduate Research

Showcase, Louisville, KY

April 2020

Mentor for Louisville Regional Science and Engineering Fair

2020-2021

Louisville, KY

Other

Participant in Marine Biological Laboratory Workshop on

July 2018

Molecular Evolution, Woods Hole, MA

Recipient of Doctoral Dissertation Completion Fellowship, University of Louisville, Louisville, KY 